UNIVERSIDADE DE SÃO PAULO

ESCOLA DE ENFERMAGEM

DARLANE MARINHO DE SOUZA

DIAGNÓSTICO SITUACIONAL DA ATENÇÃO ÀS GESTANTES EM RELAÇÃO À SÍFILIS EM UMA UNIDADE BÁSICA DE SAÚDE NO MUNICÍPIO DE SÃO PAULO

SÃO PAULO 


\title{
DIAGNÓSTICO SITUACIONAL DA ATENÇÃO ÀS GESTANTES EM RELAÇÃO À SÍFILIS EM UMA UNIDADE BÁSICA DE SAÚDE NO MUNICÍPIO DE SÃO PAULO
}

\begin{abstract}
Versão corrigida da Dissertação apresentada ao Programa de Pós Graduação Mestrado Profissional em Enfermagem na Atenção Primária em Saúde no Sistema Único de Saúde, da Escola de Enfermagem da Universidade de São Paulo para obtenção do Título de Mestra em Ciências da Saúde.
\end{abstract}

Área de Concentração: Cuidado em Atenção Primária em Saúde.

Orientadora: Prof. ${ }^{a}$ Dra ${ }^{\mathrm{a}}$. Anna Luiza de Fátima Pinho Lins Gryschek

\section{VERSÃO CORRIGIDA}

A versão original encontra-se disponível na Biblioteca da Escola de Enfermagem da Universidade de São Paulo e na Biblioteca Digital de Teses e Dissertações da Universidade de São Paulo.

\section{São Paulo}


AUTORIZO A REPRODUÇÃO E DIVULGAÇÃO TOTAL OU PARCIAL DESTE TRABALHO, POR QUALQUER MEIO CONVENCIONAL OU ELETRÔNICO, PARA FINS DE ESTUDO E PESQUISA, DESDE QUE CITADA A FONTE.

Assinatura:

Data:

\section{Catalogação na Publicação (CIP) Biblioteca "Wanda de Aguiar Horta" Escola de Enfermagem da Universidade de São Paulo}

Souza, Darlane Marinho de

Diagnóstico situacional da atenção às gestantes em relação à sífilis em uma unidade básica de saúde no município de São Paulo / Darlane Marinho de Souza. São Paulo, 2018.

$108 \mathrm{p}$.

Dissertação (Mestrado) - Escola de Enfermagem da Universidade de São Paulo.

Orientadora: Prof. Dr. $^{\text {a }}$ Anna Luiza de Fátima Pinho Lins Gryschek

Área de concentração: Cuidado em Atenção Primária em Saúde

1. Sífilis. 2. Políticas públicas. 3. Enfermagem. I. Título.

Ficha catalográfica elaborada por Fabiana Gulin Longhi Palácio (CRB-8: 7257) 
Nome: Darlane Marinho de Souza

Título: Diagnóstico situacional da atenção às gestantes em relação à sífilis em uma Unidade Básica de Saúde no município de São Paulo.

Dissertação apresentada ao Programa de Pós-Graduação Mestrado Profissional em Enfermagem na Atenção Primária em Saúde no Sistema Único de Saúde, da Escola de Enfermagem da Universidade de São Paulo para obtenção do Título de Mestra em Ciências da Saúde.

Área de Concentração: Cuidado em Atenção Primária em Saúde.

Aprovado em: 1

BANCA EXAMINADORA

Prof. Dr. Instituição:

Julgamento: Assinatura:

Prof. Dr. Instituição:

Julgamento: Assinatura:

Prof. Dr. Instituição:

Julgamento: Assinatura: 


\section{Dedicatória}

A minha grandiosa família, meus amores e fortaleza a quem dedico todas as minhas conquistas.

Ao meu amor e esposo Marcelo Belchior da Silva, companheiro em todos momentos, com compreensão da delicada jornada para elaboração deste trabalho. 


\section{Agradecimentos}

Ao Grandioso Deus pela Benção concedida, fortalecendome a cada passo.

Agradeço a toda minha família, pelo grande amor que me sustenta e impulsiona a novos caminhos e pela compreensão da minha ausência.

À orientadora, Prof. ${ }^{a}$ Dra. Anna Luiza de Fátima Pinho Lins Gryschek, por toda sua benevolência a estender suas mãos, quando eu não avistava mais saída. Por toda sua competência e respeito com que conduziu este processo do alvorecer da ideia até a sua sintese.

Às queridas amigas Nair F. Menezes e Aracelle Santana que acompanharam e me ajudaram nesta trajetória.

À Tatiana Issida Fujinami, Gerente da Vnidade Básica de Saúde Vila Izolina Mazzei, por toda compreensão e flexibilidade para concretização deste trabalho.

A Regina Célia Dias Vieira da Silva - Psicóloga da Unidade Básica de Saúde Vila Izolina Mazzei, por todo carinho e preocupação com a concretização deste trabalho.

Aos profissionais de Enfermagem da Instituição de Saúde Associação Paulista para Desenvolvimento da Medicina SPDM - Coordenadoria Regional de saúde, Vila Maria Vila Guilherme, pela inestimável contribuição deste trabalho.

A todos que contribuíram, acompanharam e torceram por minha vitória. 
Feliz aquele que transfere o que sabe e aprende o que ensina. (Cora Coralina) 
Souza DM. "Diagnóstico situacional da atenção às gestantes em relação à sífilis, em uma Unidade Básica de Saúde no Município de São Paulo". Dissertação. Mestrado Profissional na Atenção Primária em Saúde no Sistema Único de Saúde, da Escola de Enfermagem da Universidade de São Paulo.

\section{RESUMO}

Introdução: A sífilis é uma doença infecciosa sistêmica, que desafia a humanidade há séculos. Seu agente etiológico é o Treponema pallidum, uma bactéria de alta patogenicidade, transmitida por via sexual e vertical. A sífilis no período gestacional, se não tratada, acarreta aumento da taxa de morbimortalidade materna, neonatal e infantil, indicando uma lacuna na atenção às gestantes no pré-natal. Objetivo: Analisar a atenção dos profissionais de saúde ao pré-natal das gestantes com sífilis, de uma Unidade Básica de Saúde do município de São Paulo. Método: Trata-se de um estudo descritivo, de corte transversal, com abordagem quantitativa, utilizando dados do Sistema SISPrenatal criado pelo DATASUS, do Sistema de Informação de Agravos de Notificação do Ministério da Saúde e do Sistema de Controle dos Exames Sorológicos da Secretaria Municipal de Saúde. O estudo consolidou dados de atendimentos às gestantes com sífilis que realizaram pré-natal no ano de $2015 \mathrm{e}$ 2016 em uma Unidade Básica de Saúde, do município de São Paulo, respeitando os aspectos éticos implicados da Resolução 466/2012. A análise crítica dos dados, referenciou-se às Políticas Públicas de Saúde, que norteiam as práticas assistenciais, através da adoção de protocolos para assistência ao pré-natal, principalmente no que se refere ao diagnóstico e tratamento da sífilis na gestação. Resultados: $O$ estudo identificou 14 gestantes com diagnóstico de sífilis. A caracterização das gestantes contemplou: faixa etária de 15 a 33 anos; Etnias $43 \%$ brancas, $43 \%$ pardas, $14 \%$ não informado; Nível de escolaridade, $43 \%$ de 4 a 7 anos de estudo, $50 \%$ de 8 a 11 anos e $7 \%$ com 12 anos ou mais. Pré-natal iniciado no primeiro trimestre em $86 \%$ das gestantes e $14 \%$ no segundo trimestre gestacional. A realização de seis ou mais consultas abrangeu $78 \%$ das gestantes. O tratamento para sífilis, atingiu $100 \%$ das gestantes e $07 \%$ dos parceiros. Referente a consulta de puerpério foi realizada por $57 \%$ das gestantes. A pesquisa identificou 01 caso de natimorto. Conclusão: Os dados apresentados evidenciaram que apesar da existência de protocolos voltados para a assistência às gestantes com sífilis, ainda ocorrem lacunas no processo do cuidar no pré-natal. Recomenda-se melhor adesão aos protocolos, principalmente no que se refere à captação precoce da gestante, possibilitando diagnóstico e tratamento da sífilis em tempo oportuno; Tratamento com a terapêutica adequada, na dosagem preconizada; Monitoramento sorológico mensal; Tratamento do parceiro e visita domiciliária à puérpera. Todas essas medidas poderão diminuir a ocorrência de sífilis congênita, reduzindo a morbimortalidade materna, neonatal e infantil. A presente pesquisa, trouxe como contribuição para a prática, a criação de um instrumento de monitoramento da gestante com sífilis, que será anexado ao prontuário da gestante com sífilis.

Descritores de saúde: Sífilis, Políticas Públicas, Enfermagem. 
Souza DM. "Situational diagnosis of attention to pregnant women in relation to syphilis, in a Basic Health Unit in the Municipality of São Paulo". Dissertation. Master Professional in Primary Health Care in the Unified Health System of the School of Nursing of the University of São Paulo.

\section{ABSTRACT}

Introduction: Syphilis is a systemic infectious disease that has defied humanity for centuries. It's etiologic agent is the Treponema pallidum, a bacteria of high pathogenicity, transmitted by sexual and vertical route. Syphilis in the gestational period, if not treated, leads to an increase in the rate of maternal, neonatal and infant morbidity and mortality, indicating a gap in attention to pregnant women in prenatal care. Objective: To analyze the attention of health professionals to prenatal care of pregnant women with syphilis, from a Basic Health Unit in the city of São Paulo. Method: This is a descriptive cross-sectional study, using a quantitative approach, using data from the SISPrenatal System created by DATASUS, the Information System for Notifiable Diseases of the Ministry of Health and the System of Control of Serological Tests of the Municipal Health Secretariat of São Paulo. The study consolidated data of care for pregnant women with syphilis who underwent prenatal care in 2015 and 2016 at a Basic Health Unit in the city of São Paulo, respecting the ethical aspects implied in Resolution 466/2012. The critical analysis of the data, referred to the Public Health Policies, which guide the therapeutic practices with technical norms for prenatal care regarding the diagnosis and treatment of syphilis in pregnancy. Results: The study identified 14 pregnant women diagnosed with syphilis. The characterization of pregnant women included: age range of 15 to 33 years; Ethnic groups $43 \%$ white, $43 \%$ gray, $14 \%$ not informed; level of education, $43 \%$ from 4 to 7 years of study, $50 \%$ from 8 to 11 years and $7 \%$ from 12 years or more of study. Prenatal care started in the first trimester, reaching $86 \%$ of pregnant women and $14 \%$ in the second trimester of pregnancy. Six or more consultations covered $78 \%$ of pregnant women. Treatment for syphilis reached $100 \%$ of pregnant women and $7 \%$ of partners. Referring to the puerperium consultation was performed by $57 \%$ of pregnant women. The research identified one case of stillbirth. Conclusion: The data presented evidenced that despite the existence of protocols aimed at assisting pregnant women with syphilis, there are still gaps in the prenatal care process. It is recommended better adherence to the protocols, especially with regard to the early collection of the pregnant woman, allowing the diagnosis and treatment of syphilis in a timely manner; Treatment with appropriate therapy, at the recommended dosage; Monthly serological monitoring; Treatment of the partner and home visit to the puerperium. All of these measures may reduce the occurrence of congenital syphilis, reducing maternal, neonatal and infant morbidity and mortality. The present research, brought as a contribution to the practice, the creation of a monitoring tool for the pregnant woman with syphilis, which will be attached to the pregnant woman's chart with syphilis.

Health descriptors: Syphilis, Public Policies, Nursing. 


\section{LISTA DE ILUSTRAÇÕES}

Figura 1- Mapa das Regiões, Subprefeituras e Distritos - Município de São Paulo2014. .51

Figura 2 - Mapa Zona Norte; Subprefeituras e Distritos - Município de São Paulo2014. .51 


\section{LISTA DE GRÁFICOS}

Gráfico 1 - Caracterização das gestantes com sífilis na Unidade Vila Izolina Mazzei, correlação entre a etnia e o nível de escolaridade em anos de estudo. São Paulo 2018

Gráfico 2 - Distribuição das gestantes, de acordo com a semana gestacional, no início do pré-natal na UBS Vila Izolina Mazzei nos anos de 2015 e 2016. São Paulo 2018 .63

Gráfico 3 - Número de consultas de pré-natal, em gestantes com sífilis, realizadas na UBS Vila Izolina Mazzei. São Paulo 2018.

Gráfico 4 - Idade Gestacional na primeira investigação da sífilis, relacionada à Idade gestacional no diagnóstico da sífilis. São Paulo 2018. .65

Gráfico 5 - Período em dias entre o diagnóstico da sífilis e o exame de controle da titulação e cura. Gestantes com sífilis acompanhadas na UBS Vila Izolina Mazzei. São Paulo 2018.

Gráfico 6 - Número de exames sorológicos posteriores ao diagnóstico da sífilis para controle da doença. São Paulo 2018.

Gráfico 7 - Período da semana gestacional no exame diagnóstico da sífilis e no início do tratamento da sífilis das gestantes acompanhas na UBS Vila Izolina Mazzei. São Paulo 2018.

Gráfico 8 - Período em dias entre o diagnóstico e o tratamento da sífilis, em gestantes acompanhas na UBS Vila Izolina Mazzei. São Paulo 2018. 68 


\section{LISTA DE TABELAS}

Tabela 1 - Caracterização das Gestantes; Pré natal e puerpério realizados nos anos 2015 e 2016 na Unidade Básica de Saúde Vila Izolina Mazzei. São Paulo 2018 ...58

Tabela 2 - Caracterização das gestantes com diagnóstico de sífilis, que iniciaram o pré-natal nos anos 2015 e 2016 na Unidade Básica de Saúde Vila Izolina Mazzei. São Paulo 2018. 60

Tabela 3 - Antecedentes obstétricos das gestantes com diagnóstico de sífilis da UBS Izolina Mazzei, que iniciaram pré-natal no ano 2015 e 2016. São Paulo 2018. 62

Tabela 4 - Puerpério e tratamento das gestantes com diagnóstico de sífilis e suas parcerias. UBS Vila Izolina Mazzei 2015 e 2016. São Paulo 2018 


\section{LISTA DE SIGLAS}

ACS Agentes Comunitários de Saúde

AMA Assistência Médica Ambulatorial

SPDM Associação Paulista para o Desenvolvimento da Medicina

CCD Coordenadoria de Controle de Doenças

CAPS IJ Centro de Atenção Psicossocial Infanto-juvenil

CECCO Centro de Convivência e Cooperativa

CEO Clínica de Especialidades Odontológica

CER III Centro Especializado em Reabilitação III

$\mathrm{Cl} \quad$ Coeficiente de Incidência.

CIPD Conferência Internacional de População e Desenvolvimento

CRS Coordenadorias Regionais de Saúde

DS Distrito de Saúde

ESF Estratégia Saúde da Família

FTA-AB Fluorescent Treponemal antidody absortion

EIA Imunoensaio enzimático treponêmico

IST Infecções Sexualmente Transmissíveis

LCR Líquido cefalorraquidiano

MS Ministério da Saúde

MHA-TP Microhemagglutination assay for antibody to Treponema pallidum)

NOB Normas Operacionais Básicas

NOAS Normas Operacionais de Assistência à Saúde

OMS Organização Mundial da Saúde

ODM Objetivos de Desenvolvimento do Milênio

ONU Organização das Nações Unidas

PNAB Política Nacional de Atenção Básica

PAS Programa Agentes de Saúde

PACS Programa Agentes Comunitários de Saúde 
PAISM Programa de Atenção Integral à Saúde da Mulher

PHPN Programa de Humanização do Pré Natal e Nascimento

PNAISM Política Nacional de Atenção Integral à Saúde da Mulher

PMI Programa Materno Infantil

PSF Programa Saúde da Família

TPI Prova de imobilização dos treponemas

RPR Rapid Plasma Reagen

RC Rede Cegonha

RAS Redes de atenção à saúde

PCR Reação em cadeia da polimerase

RN Recém Nascido

SC Sífilis Congênita

SUS Sistema Único de Saúde

TD Taxa de detecção

T. Pallidum Treponema pallidum

TPHA Treponema pallidum Hemagglutination

UBS Unidades Básicas de Saúde

VDRL Venereal Diseases Research Laboratory

VMVG Vila Maria / Vila Guilherme 


\section{SUMÁRIO}

APRESENTAÇÃO

1 INTRODUÇÃO

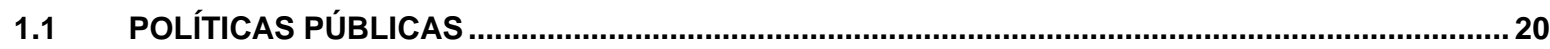

1.2 ASPECTOS HISTÓRICOS DAS POLÍTICAS PÚBLICAS EM SAÚDE MATERNA E INFANTIL NO

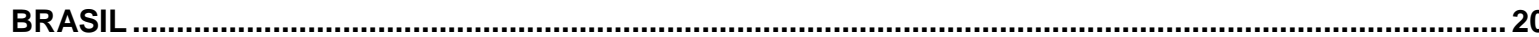

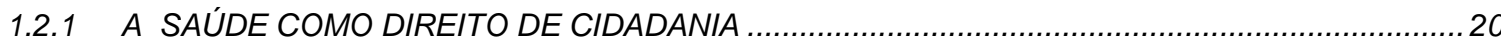

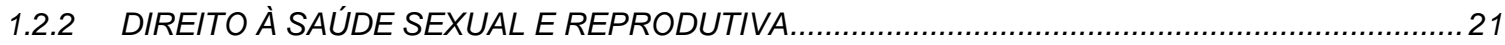

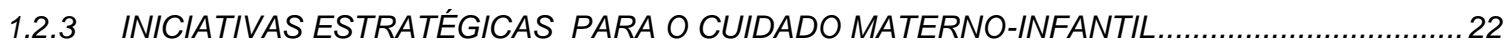

1.2.4 OBJETIVO DESENVOLVIMENTO DO MILÊNIO E A SAÚDE MATERNA E INFANTIL..................23

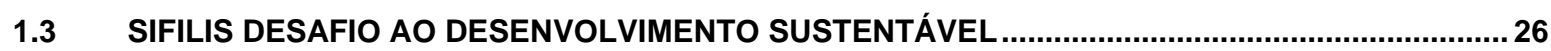

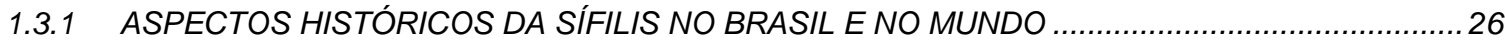

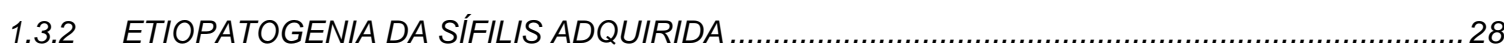

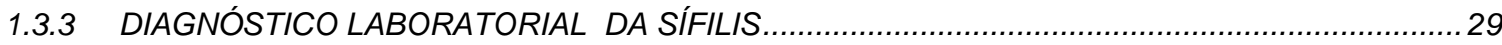

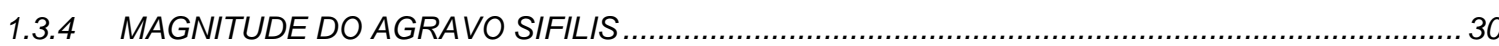

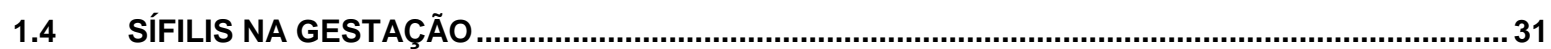

1.5 POLÍTICAS DE ATENÇÃO À GESTAÇÃO

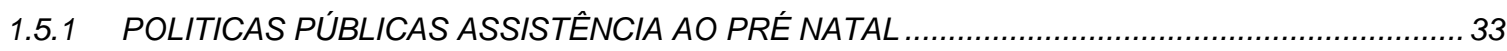

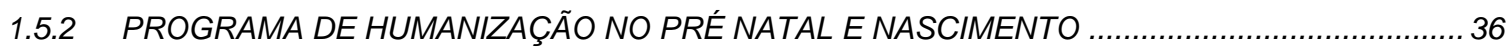

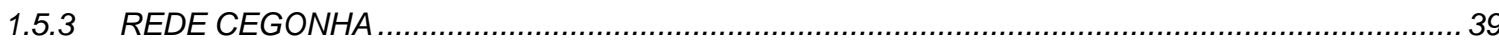

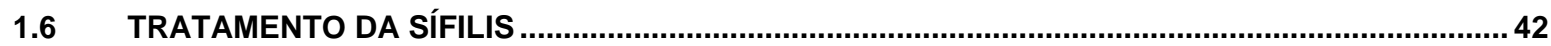

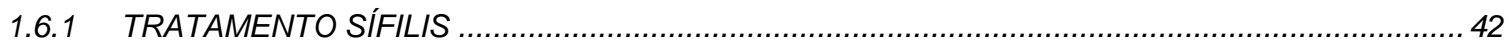

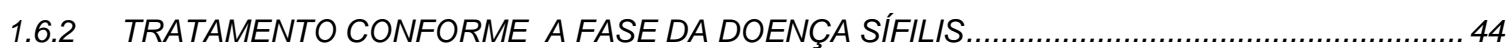

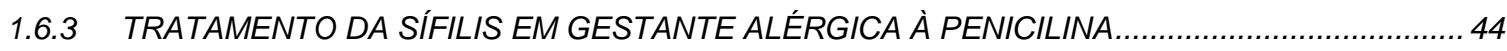

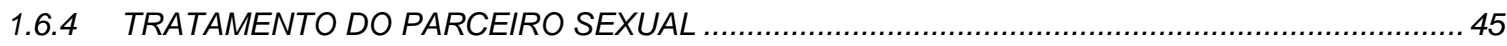

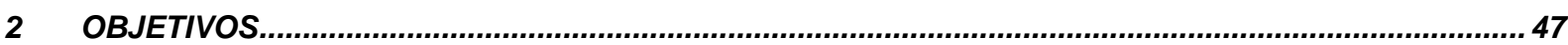

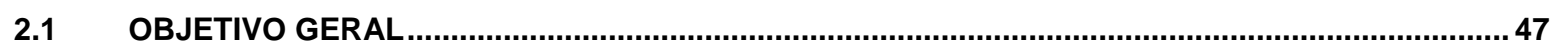

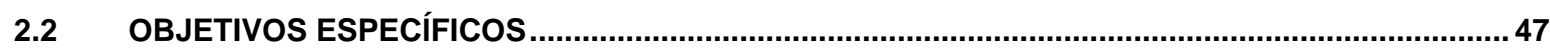

3 METODOLOGIA

$3.1 \quad$ TIPO DE ESTUDO

3.2 LOCAL DO ESTUDO

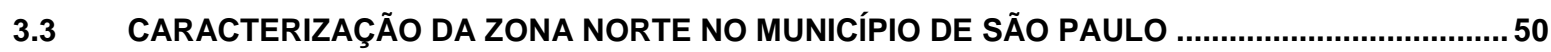

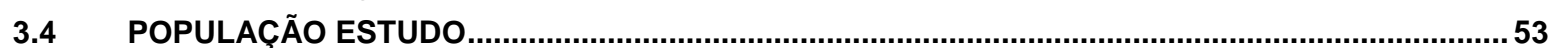

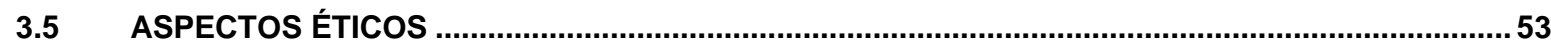

$3.6 \quad$ COLETA DE DADOS

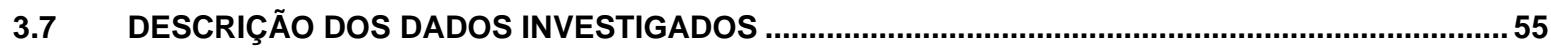

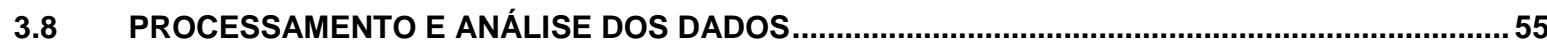

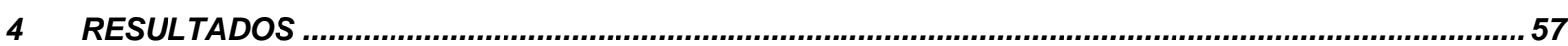

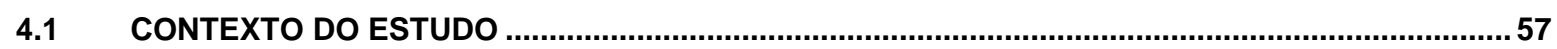

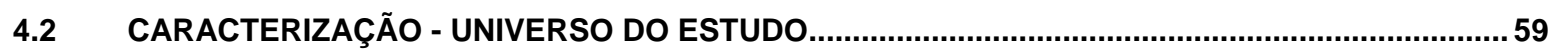

$5 \quad$ DISCUSSÃO.

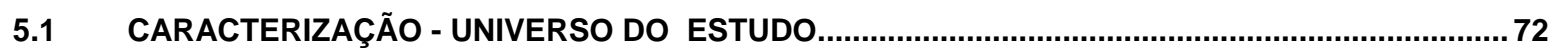

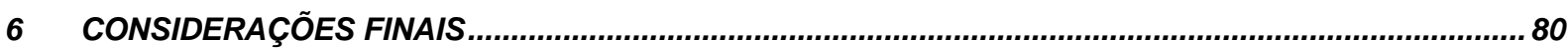

7 CONCLUSÃO

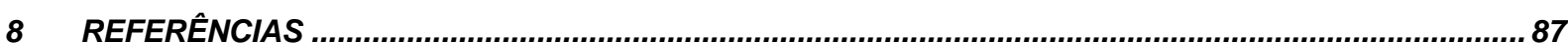

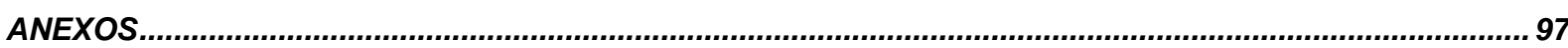

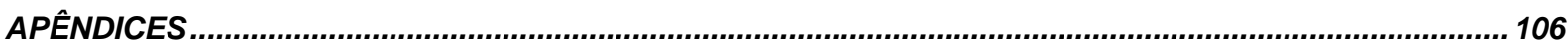


Apresentação 


\section{APRESENTAÇÃO}

A necessidade de contribuir de forma efetiva para a expansão das ações de vigilância epidemiológica das infecções sexualmente transmissíveis (IST) tem acompanhado meu percurso de vida. Inicia-se desde os tempos de juventude, quando presenciava relatos do meu grupo de amizades no que se referia à ocorrência de casos de IST, principalmente a sífilis entre os casais. Esta constatação despertava em mim indagações iniciais sobre quais ações efetivas poderiam ter alcançado e direcionado estes jovens, para a prevenção desse agravo.

Esta indagação de certa forma conduziu-me a atuar profissionalmente por um período de quatro anos pela Fundação Faculdade de Medicina - FFM no Projeto Ações Preventivas nas Escolas (APE), com ações educativas preventivas em saúde, contemplando as temáticas saúde sexual e reprodutiva e prevenção às IST/Aids, apresentadas ao público participante do Programa Escola da Família, pertencente à Diretoria de Ensino Leste III na Zona Leste de São Paulo. Contudo, essas ações educativas, muitas vezes atingiam um público já surpreendido pela gestação não planejada, identificando muitas vezes a sorologia positiva para sífilis gestacional dentre outras morbidades gestacional. Estas iniquidades sociais despertou em mim uma inquietude no sentido de compreender quais ações em saúde são desenvolvidas para a prevenção e cuidados das IST/Aids, com ênfase à sífilis gestacional.

$\mathrm{Na}$ busca por contribuir para a intensificação e expansão das ações educativas em diferentes setores, tenho desenvolvido minha trajetória profissional com foco na Atenção Primária em Saúde, acreditando ser o alicerce para transformação social. No entanto, atuo como Enfermeira de Unidade Básica de Saúde - UBS de modelo Tradicional, pertencente ao Distrito da Vila Maria / Vila Guilherme sob a Coordenação de Saúde Norte do Município de São Paulo, administrada pela Organização Social de Saúde - OSS / SPDM (Associação Paulista para o Desenvolvimento da Medicina). Desta feita, atuando numa UBS, sob a égide do Sistema Único de Saúde (SUS) e inserida como aluna no Mestrado Profissional em Enfermagem na Atenção Primária em Saúde no Sistema Único de Saúde, 
concede-me oportunidade e possibilidade de contribuir para as mudanças e melhorias sociais. 
1.Introdução 


\section{INTRODUÇÃO}

A sífilis é uma doença infecciosa sistêmica que desafia a humanidade há séculos. Seu agente etiológico o Treponema pallidum, uma bactéria de alta patogenicidade ao ser humano, é transmitida por via sanguínea e por secreções contaminadas, ocasionando danos neurológicos, físicos e sociais (Avelleira, Bottino 2006), (Souza, 1996), (Magalhães et al., 2011), (Santos, 2009), (Pinto et al., 2014). Embora seja uma doença anosa, seus dados epidemiológicos seguem em constante crescimento e desde a inclusão da sífilis na lista nacional de doenças compulsória, estabelecida pela Portaria o 2.472 de 31/ 08 / 2010, foram notificados 227.663 casos de sífilis adquiridas no Brasil, a contar de 2010 até junho 2016. No ano de 2015 foram contabilizados 65.878 casos, com taxa de detecção de 42,7 casos por 100 mil habitantes. Destes, 55,6\% compreendem a população com faixa etária de 20 a 39 anos de idade, período que envolve a fase reprodutiva, ampliando a possibilidade de ocorrer a sífilis gestacional (Brasil, 2016a), (São Paulo - Estado, 2013). A ocorrência de falhas ao diagnostico e tratamento inadequado da sífilis gestacional, resulta na disseminação hematogênica do agente etiológico Treponema pallidum para o concepto por transmissão vertical e evolui para a sífilis congênita, caracterizada por prematuridade, óbito fetal e óbito neonatal (Brasil, 2016a), (São Paulo - Estado, 2013), (Santos 2009 apud Miller, 2003). Apesar da descoberta secular do método diagnóstico laboratorial sorológico para a sífilis e da descoberta do tratamento eficaz desde 1928, a sífilis permanece como um problema de saúde pública contribuindo para o aumento das taxas de morbimortalidade materna, peri e neonatal (Brasil, 2016a), (Domingues 2013 apud Brasil, 2010), (Magalhães et al., 2011), (Souza, 1996). A busca por melhorias aos indicadores de mortalidade materno-infantil é um fato histórico, registra-se pela luta dos movimentos populares que alcançam a formação de leis e políticas públicas que permeiam a década de 70 , 80 e 90 e estendem-se até os anos 2000 com a criação e execução de programas e estratégias de saúde pública, direcionada à atenção materno-infantil (Neto ETS et al., 2008). Contudo, a permanência das elevadas taxas de mortalidade maternoinfantil desperta indagação sobre quais fatores impedem o êxito da prática das Políticas Públicas implantada. 


\subsection{POLÍTICAS PÚBLICAS}

\subsection{ASPECTOS HISTÓRICOS DAS POLÍTICAS PÚBLICAS EM SAÚDE MATERNA E INFANTIL NO BRASIL}

\subsubsection{A SAÚDE COMO DIREITO DE CIDADANIA}

No final da década de 70 inicia-se no Brasil a articulação de movimentos populacionais na luta por melhorias às condições de vida. Destaca-se neste período, a Reforma Sanitária, movimento de luta por direito à saúde como direito de cidadania à toda população. Este cenário foi oportuno para o surgimento de grupos feministas, que despertaram um novo modelo político, evidenciando as desigualdades sociais e de gênero. Os grupos feministas lutavam em defesa dos direitos reprodutivos, como direitos básicos de cidadania, sendo adversos às políticas contraceptivas coercitivas sem amparo à liberdade individual, lutavam por maior autonomia e justiça social na trajetória de vida dos cidadãos (Neto ETS et al., 2008), (Coelho, 2000). A ideologia das lutas feministas, ganharam voz na Conferência Mundial de Bucareste 1974, quando países do Terceiro Mundo, dentre eles o Brasil, defenderam a regulação da fecundidade como direito social, instituindo ao poder público o compromisso de prover ações educativas sobre saúde sexual e reprodutiva; fato que não ocorrera anteriormente, devido ao desinteresse político para sua concretização (Coelho, 2000), (Corrêa, 2006). Apesar das dificuldades enfrentadas, as lutas dos movimentos sociais, foram essenciais para o início das transformações das Políticas Públicas de saúde materno-infantil (Neto ETS et al., 2008).

A partir de 1975, houve a criação do Programa Nacional de Saúde Materno Infantil - (PMI), programa direcionado ao atendimento das classes sociais mais pobres, todavia, esse Programa detinha uma orientação distorcida de planejamento familiar, levando a população à responsabilização por seus problemas de saúde, desvinculando a responsabilidade do Poder Público (Coelho, 2000).

Na década de 80, em meio à crise brasileira na área da educação, habitação e saúde, os movimentos sociais passam a contestar o regime político vigente, reivindicando políticas sociais que assegurassem os direitos da cidadania. As 
mobilizações feministas em luta por um cuidado integral a saúde sexual e reprodutiva, tiveram fundamental importância na criação de políticas e programas voltados à Saúde da Mulher (Coelho, 2000). Com diferentes representantes sociais, a mobilização feminista alcançou apoio do Ministério da Saúde na criação do Programa de Atenção Integral à Saúde da Mulher - PAISM, 1983, um enfoque na política pública voltada à saúde da mulher, centrado na Integralidade e na equidade das ações, atendendo aos aspectos da saúde sexual e reprodutiva em todas as fases do seu ciclo vital (Brasil, 2005b), (Coelho, 2000). A implantação do PAISM em 1983, valida a responsabilidade do Poder Público em prover o cuidado integral à saúde da população (Coelho, 2000), (Brasil, 2004), (Figueiredo, 2014). Esta responsabilidade é ressaltada no ano 1986 na Oitava Conferência Nacional de Saúde, realizada com a participação dos setores sociais e da tecno-burocracia, na qual estabeleceram o ideário de um Sistema Único de Saúde Público, integral, universal, descentralizado e dependente da participação social. Esses princípios, incorporam-se como direito de cidadania na Constituição Brasileira de 1988, que reconhece a saúde como direito de todos e dever do Estado, criando definitivamente o Sistema Único de Saúde - (SUS) (Coelho, 2000), (Figueiredo, 2014), (Neto ETS et al., 2008).

\subsubsection{DIREITO A SAÚDE SEXUAL E REPRODUTIVA}

Realizada em 1994 no Cairo, a Conferência Internacional de População e Desenvolvimento (CIPD), foi um marco histórico do reconhecimento dos direitos sexuais e reprodutivos (Brasil, 2005b), (Brasil, 2010), (Ferreira et al., 2014), (Patriota, 2006). Foi a partir desta Conferência, que os direitos sexuais e reprodutivos foram reconhecidos como parte integrante dos direitos humanos estabelecido desde a Declaração Universal da Organização das Nações Unidas (ONU) 1948, sendo indivisíveis, interdependentes e inter-relacionado (Brasil, 2010).

Os direitos sexuais e reprodutivos englobam os direitos de que todos os indivíduos possam decidir ser ou não sexualmente ativos; possam ter vida sexual com segurança e satisfação; ter acesso aos métodos contraceptivos vigentes; acesso à orientação profissional sobre sexualidade e reprodução; acesso a assistência a infertilidade; possam ser capazes de decidir livre e 
corresponsavelmente sobre a quantidade, espaçamento e oportunidade de conceber ou não, sem que haja coerção ou violência e livre de discriminação (idade, etnia, gênero, nacionalidade, religião, orientação sexual, condição social e demais critérios) (Brasil, 2005b), (Brasil, 2010), (Corrêa, 2006), (Casarin, et al., 2010), (Patriota, 2006). Indubitavelmente, a Conferência do Cairo foi uma conquista histórica e deu visibilidade aos movimentos sociais que reivindicavam os direitos sexuais e reprodutivos. Com o objetivo de proteger e implementar políticas e ações que contemplem tais direitos, foram traçadas metas estratégicas consensuadas entre as 179 nações signatárias para a expansão do acesso universal aos serviços e ações de saúde sexual e reprodutiva. As metas estipuladas nesta conferência, destacam a lgualdade de gênero; o empoderamento e a autonomia da mulher; a redução da mortalidade infantil, a redução da mortalidade materna e a erradicação da pobreza; Medidas contribuintes para melhora da qualidade de vida populacional e ao avanço socioeconômico dos países (Brasil, 2005b), (Brasil, 2010), (Corrêa, 2006), (Patriota, 2006), (Silva, 2007).

\subsubsection{INICIATIVAS ESTRATÉGICAS PARA O CUIDADO MATERNO-INFANTIL}

A Constituição brasileira de 1988, instituiu o Sistema Único de Saúde estruturado na integralidade, na universalidade do acesso, no atendimento assistencial igualitário e na equidade da distribuição dos recursos. Estabelece a descentralização em cada nível do governo e garante a participação social como controle exercido pela sociedade (Coelho, 2000), (Figueiredo, 2014), (Neto ETS et al., 2008), (Ávila, 2011). As leis orgânicas de saúde nº 8.080 e 8.142 do ano de 1990, deliberou a operacionalização do SUS por mediação de ações de promoção, proteção, prevenção e recuperação da saúde, solidificada na participação e no controle social (Carvalho e Santos, 2006 apud Neto ETS et al., 2008), (Ávila, 2011), (Brasil, 2004). Neste contexto, para cumprir com a operacionalização desta política de saúde, fez-se necessário a projeção e execução de programas e estratégias direcionadas ao cuidado da população. Nesta perspectiva, a atuação dos Agentes Comunitários de Saúde (ACS) do Estado do Ceará ganharam grande visibilidade. Criado no ano 1987, em decorrência da seca no Estado do Ceará, os ACS promoviam ações de vigilância em saúde materno-infantil, realizando a busca ativa 
das gestantes ao pré-natal e à maternidade, além de incentivar o aleitamento materno, a vacinação e higienização das crianças. Medidas que ajudaram a reduzir as altas taxas de mortalidade infantil, decorrente das doenças infectocontagiosas e da desnutrição no estado do Ceará (Ávila, 2011), (Neto ETS et al., 2008). Neste contexto, o governo do Estado Ceará decidiu institucionalizar os Agentes Comunitários de Saúde, criando o Programa Agentes de Saúde (PAS), instituído pelo Decreto 19.945, de janeiro 1989 e posteriormente regulamentado pela Portaria 232/92 e Decreto 23.079/94. As experiências e resultados alcançados com o PAS, impulsionou o Ministério da Saúde para a criação do Programa Agentes Comunitários de Saúde (PACS) em 1991, ampliando o cuidado à toda família (Ávila, 2011), (Neto ETS et al., 2008). O PACS, norteou a criação do Programa Saúde da Família (PSF) em 1994, com enfoque nas relações da comunidade, família e indivíduo, eixos estruturantes para a organização da atenção à saúde em conformidade com os princípios do SUS, viabilizando a consolidação do processo de municipalização e reorganização das ações e serviços na Atenção Básica, conforme as Normas Operacionais Básicas (NOB) e posteriormente as Normas Operacionais de Assistência à Saúde (NOAS), instituídas pelo Ministério da Saúde (Ávila, 2011), (Brasil, 2004), (Neto ETS et al., 2008).

A formulação de programas e estratégias de cuidado para a saúde maternoinfantil, ultrapassam os anos 1990 e chegam aos anos 2000 fortalecendo as Políticas Públicas de proteção à saúde, com marcos normativos e manuais técnicos do Ministério da Saúde (Neto ETS et al., 2008).

\subsubsection{OBJETIVO DESENVOLVIMENTO DO MILÊNIO E A SAÚDE MATERNA E INFANTIL}

No ano 2000, a Organização das Nações Unidas (ONU), reuniu líderes Mundiais de 189 países, "Cúpula do Milênio da ONU", para rever os meios de viabilizar melhorias para o desenvolvimento social. Deste encontro, firmaram os Objetivos de Desenvolvimento do Milênio (ODM), aprazados até o ano de 2015. Entre os objetivos destaca-se o quarto objetivo, que visa reduzir a mortalidade na infância e o quinto objetivo de melhorar a saúde materna, na realidade, objetivos muito similares às metas determinadas na CIPD, Cairo 1994 (Shetty, 2005). 
Os índices de mortalidade materna e neonatal, configuram-se como grave problema de saúde pública que violam os direitos humanos de mulheres e crianças (Brasil, 2004a). No ano de 2010, os países desenvolvidos, apresentaram taxa de mortalidade materna de aproximadamente 16/100.000, já os países em desenvolvimento, apresentaram taxa de 240/100.000 no mesmo período (Rodrigues et al., 2016). O Objetivo do Milênio de melhorar a saúde materna, visava reduzir em três quartos a razão da mortalidade materna até 2015. A razão da Mortalidade materna estimada pelo Ministério da Saúde em 1990, foi de 141 por 100 mil nascidos vivos, entretanto, deveria atingir 36 óbitos por 100 mil nascidos vivos até o ano 2015 (Rodrigues et al., 2016). De 1990 a 2011, o Brasil apresentou redução de 55\%, passando de 141 para 64 óbitos por 100 mil nascidos vivos. O país avançou, mas não atingiu a meta proposta, permanecendo como um grande desafio da saúde pública a ser resolvido (Rodrigues et al., 2016), (Brasil, 2014).

O objetivo de Desenvolvimento do Milênio (ODM), de reduzir a mortalidade na infância, refere-se à redução da taxa de mortalidade na infância (menores de 5 anos) e da taxa de mortalidade infantil (menores de 1 ano) (Brasil, 2014). A meta de redução da mortalidade na infância, visa reduzir a taxa de mortalidade a dois terços, entre 1990 à 2015. A taxa de mortalidade global na infância passou de 90 para 43 mortes por 1.000 nascidos vivos, atingindo o objetivo proposto (United Nations, 2015). A taxa de mortalidade infantil no Brasil, de 1990 a 2011, caiu de 47,1 para 15,3 óbitos por mil nascidos vivos, superando a meta de 15,7 óbitos estimada para 2015 (Carlo e Travers, 2016), (ODM, 2015), (Brasil, 2014).

A redução da mortalidade materna e na infância é atribuída à criação das políticas públicas implantadas para enfrentamento desse problema. No ano 2004, o Ministério da Saúde em parceria com os diversos movimentos populacionais, formularam o documento "Política Nacional de Atenção Integral à Saúde da Mulher: princípios e diretrizes" (Brasil, 2004), (Neto ETS et al., 2008). O documento objetivava melhorias à saúde das mulheres, sustentado nos direitos legalmente constituídos, com ênfase aos direitos sexuais e reprodutivos inerentes aos Direitos Humanos (Brasil, 2004a). Neste mesmo ano, o Ministério da Saúde lançou o Pacto Nacional pela redução da Mortalidade Materna e Neonatal, um movimento político governamental, que consistia na execução compartilhada entre as diferentes esferas de governo, com estratégias de melhoria das ações e serviços de saúde (Brasil, 2004a). No ano de 2006, houve a implantação do Pacto pela Saúde, que visava a 
consolidação do Sistema Único de Saúde, publicado na Portaria /GM no 399, de 22 de fevereiro de 2006, que traz entre os seus componentes, o Pacto pela Vida, que visa a redução da taxa de mortalidade infantil, neonatal e materna. O Pacto pela Saúde trouxe novos rumos à organização e operacionalização do SUS, firmando entre os gestores do SUS, uma linha de cuidado responsável pelo fortalecimento da Atenção Básica (Brasil, 2006).

A Política Nacional de Atenção Básica (PNAB), publicada na Portaria nํㅜ 2488 de 21 de outubro de 2011, estabelece diretrizes e normas para a organização da Atenção Básica, da Estratégia Saúde da Família e do Programa Agentes Comunitários de Saúde (PACS) (Brasil, 2012). A Atenção Básica de Saúde, representa um conjunto de ações de promoção da saúde, prevenção de agravos, diagnósticos e recuperação da saúde, além de atuar na redução de danos no âmbito individual e coletivo, influenciando na autonomia das pessoas, nos determinantes e nos condicionantes de saúde da coletividade (Brasil, 2012). A Atenção Básica, representa a porta de entrada do usuário à toda Rede de Atenção à Saúde (RAS) e fundamenta-se pelos princípios do Sistema Único de Saúde - SUS (Brasil, 2012).

A cobertura da Atenção Básica, com destaque nas ações da Estratégia Saúde da Família (ESF), atendendo à população adscrita, contribui grandemente para a redução da mortalidade infantil (United Nations, 2015), (Brasil, 2004a), (Carlo e Travers, 2016).

No ano de 2015, ocorreu a Conferência das Nações Unidas sobre Desenvolvimento Sustentável - Agenda 2030. Acordada por 193 líderes Mundiais, a Conferência estabeleceu a ampliação dos oito Objetivos do Desenvolvimento do Milênio (ODM), para 17 objetivos, que conduzirão ao Desenvolvimento Sustentável dos países (ONU 2015). Dentre os objetivos repactuados nesta conferência, encontram-se: a igualdade de gênero, a autonomização das mulheres, a redução da mortalidade infantil e materna e a prevenção das Infecções Sexualmente Transmissíveis, reafirmando, mais uma vez, os direitos sexuais e reprodutivos e de cidadania, já descritos na Constituição Brasileira de 1988. 


\subsection{SIFILIS DESAFIO AO DESENVOLVIMENTO SUSTENTÁVEL}

\subsubsection{ASPECTOS HISTÓRICOS DA SÍFILIS NO BRASIL E NO MUNDO}

A sífilis é uma doença tão antiga como a própria humanidade. Em meados do século $\mathrm{XV}$, surge na Europa uma epidemia por afecção de pústulas dolorosas que acomete o organismo. A sífilis, chamada popularmente nesta época por "Mal das Bulbas", "Mal Serpentinas", logo é considerada pelo senso comum como pestilência de um desígnio Divino (Avelleira, Bottino, 2006), (Souza, 1996), (Magalhães et al., 2011). A sífilis avança por diversos continentes e torna-se motivo de preocupação mundial, sendo denominada diferentemente em vários países: "Mal napolitano" para os franceses que a contraíram em Nápoles; "Mal francês" para os italianos e Espanhóis; "Mal Alemão" para os polacos; "Mal polaco" para os Russos; "Mal Britânico" no Taiti; "Mal dos Portugueses" para o Brasil, entre outras denominações mundiais (Avelleira, Bottino, 2006), (Souza, 1996).

Desde então, a sífilis torna-se objeto de estudo nas áreas médicas e no ano de 1498, inicia-se os primeiros registros da transmissão da sífilis por via sexual, associando-a às relações sexuais com profissionais do sexo. Contudo, a população acreditava que a transmissão da sífilis se dava por vias aéreas e gotículas, entre outras possibilidades incertas, desconsiderando a via de transmissão sexual. Os médicos Jean Fernel e Girolamo Fracastoro, insistiam na importância do contágio sexual, também conhecido como contato venéreo (Souza, 1996).

No ano de 1501 em Portugal, houve a construção do Hospital Real de Todos os Santos direcionado aos cuidados dos pacientes acometidos por sífilis. Os cuidados se constituíam de unguentos de mercúrio e cuidados humanitários, permitindo aos estudiosos acompanhar a evolução da doença (Souza, 1996). No que se refere aos sinais e sintomas da doença, inicialmente muitos médicos descreviam: pústulas genitais que se disseminam por todo o corpo; mialgias, artralgias e osteoalgia com exacerbação noturna. Com o avançar das pesquisas, Fracastoro, um grande estudioso da sífilis, no ano de 1546, apresenta um quadro clínico descrevendo o processo gradual da doença (Magalhães et al., 2011), (Souza, 1996). 
No século XVIII, a sífilis já é uma doença reconhecida, sendo descrita como uma patologia com grande virulência, com muitos relatos de casos que apresentavam úlceras em todo o corpo, com maior acometimento no pescoço e no couro cabeludo causando alopecia total. Este período induz a moda da época, com o uso de perucas para disfarçar a alopecia; o uso de guarnição de farfalhudas rendas, para disfarçar as úlceras nos pescoços; o uso de luvas para encobrir as lesões palmares e uso de pinturas ou pó para disfarçar as lesões em face. Assim, influenciando a caracterização social daquela época (Souza, 1996).

Ao final do século XIX a II Conferência Internacional em Bruxelas sobre sífilis, contribuiu para uma nova influência social, defendendo a castidade antes do casamento e a monogamia na prevenção da doença. Esta medida obteve apoio das igrejas na época, que promoveram campanhas sustentando esta ideologia, contribuindo para a aceitação social da via de transmissão sexual da doença (Souza, 1996).

A partir do século XX, no ano de 1905 na Alemanha, os médicos bacteriologistas alemães Fritz Richard Schaudinn e Paul Erich Hoffmann, fazem a descoberta do agente etiológico da sífilis, o Treponema pallidum, uma bactéria gram negativa do grupo das espiroquetas de alta patogenicidade, acometendo praticamente todos os órgãos e sistemas. O Treponema pallidum não resiste muito tempo fora do seu ambiente e não é cultivável, sendo destruído pelo calor e falta de umidade (Avelleira, Bottino, 2006), (Magalhães et al., 2011), (Santos, 2009), (São Paulo - Estado, 2015). No ano de 1906, ocorre a descoberta do diagnóstico laboratorial sorológico para a sífilis, pelo médico e bacteriologista alemão August Von Wassermann (Souza, 1996). No ano de 1908 o médico alemão Paul Erlich descobriu a Arsefenamina, uma terapêutica que melhorava o aspecto das lesões dérmicas, contudo não eliminava o Treponema pallidum. Somente no ano de 1928, com a descoberta da penicilina pelo médico bacteriologista inglês Alexander Fleming, se conseguiu um tratamento eficaz contra o Treponema pallidum, sendo produzida e comercializada em grandes quantidades a partir do ano de 1943 (Magalhães et al., 2011), (Souza, 1996).

A sífilis foi extremamente prevalente na Europa e no resto do mundo por quase quatrocentos e cinquenta anos, privando milhares de pessoas da saúde e da vida, criando estigmas e modificando as condutas sociais no seu processo de 
adaptação. O advento da Penicilina, promoveu cura e liberdade social (Souza, 1996).

\subsubsection{ETIOPATOGENIA DA SÍFILIS ADQUIRIDA}

A sífilis é uma doença infecciosa sistêmica, causada pelo Treponema pallidum, uma bactéria exclusiva do ser humano, que acomete praticamente todos os órgãos e sistemas (São Paulo - Estado, 2015). A via de transmissão é sanguínea e por secreções contaminadas, ocorre por relação sexual desprotegida, por contato com lesões muco cutâneas com alta carga do Treponema pallidum e por via vertical (Avelleira, Bottino, 2006), (Magalhães et al., 2011), (Santos, 2009), (Pinto et al., 2014).

A história natural da sífilis adquirida caracteriza-se por distintas manifestações clínicas, histológicas e imunológicas, classificando-se em fase recente (com menos de um ano de evolução) e fase tardia (com mais de um ano de evolução). A fase recente compõe-se pela fase primária, secundária e latente recente; $A$ fase tardia compõe-se pela fase terciária e latente tardia (Avelleira, Bottino, 2006), (Santos, 2009). A fase primária da sífilis adquirida ocorre entre 7 a 90 dias após o contágio, caracteriza-se pela presença de cancro duro, geralmente único e indolor com poucas manifestações inflamatórias. Observa-se frequentes reações de adenopatia inguinal bilateral. Estes sinais localizam-se na maioria das vezes na região genital masculina e feminina, acometendo comumente as partes genitais externas, mas podendo ocorrer em seu interior dificultando sua identificação, principalmente nas mulheres. As localizações extragenitais ocorrem em região de boca, língua, região anal, região mamária e quirodáctilos. O cancro regride espontaneamente entre quatro a cinco semanas sem deixar cicatriz, ficando em estado de latência por um período de quatro a oito semanas (Avelleira, Bottino, 2006), (Brasil, 2005), (Brasil, 2006a).

A fase secundária surge posterior ao período de latência da fase primária e ocorre a disseminação do Treponema pallidum por todo o corpo, apresentando alta contagiosidade, acometendo o sistema tegumentar e os órgãos internos, sendo acompanhado de poliadenomegalia generalizada, apresentando sinais e sintomas peculiares a depender do local de acometimento. Nesta fase, a doença evolui no 
primeiro e no segundo ano por surtos de duração efêmera, que regridem espontaneamente por períodos de latência cada vez mais duradouros (Avelleira, Bottino, 2006), (Magalhães et al., 2011), (Santos, 2009).

Estudos sobre a evolução natural da doença, mostraram que após um enorme período de latência, um terço dos pacientes obtém a cura clínica e sorológica; outro terço evolui assintomático, porém apresenta provas sorológicas treponêmicas reagentes. Por fim, em outro grupo de pacientes a doença recrudesce (sífilis terciária) (Avelleira, Bottino, 2006).

A fase terciária ou tardia é a fase final de evolução do quadro clínico da doença. Apresenta-se como uma doença inflamatória lentamente progressiva, com alta potencialidade de acometimento de múltiplos órgãos. As manifestações mais comuns envolvem acometimento do sistema tegumentar com lesões de granulomas destrutivos (goma), sistema cardiovascular (aneurisma aórtico) e sistema nervoso com possível evolução ao quadro de neurossífilis (5 a 12 anos após a infecção primária). Também pode haver acometimento dos ossos (Artropatia de Charcot), músculos e fígado. A peculiaridade da fase terciária contempla ausência quase total de Treponemas pallidum nas lesões e baixa titulação (Avelleira, Bottino, 2006), (Brasil, 2006a), (Santos, 2009 apud Smeltzer, Bare, 2002).

\subsubsection{DIAGNÓSTICO LABORATORIAL DA SÍFILIS}

A Portaria no 2.012, de 19 de outubro de 2016, aprova o Manual Técnico para o Diagnóstico da sífilis (Brasil, 2016). O diagnóstico Laboratorial da sífilis e a escolha dos exames laboratoriais mais adequados, devem considerar a fase evolutiva da doença. Nos estágios iniciais da sífilis primária, o diagnóstico ocorre por prova direta, ou seja, técnica laboratorial que identifica a presença do Treponema pallidum. As técnicas de prova direta, contempla o exame em campo escuro; a pesquisa direta com material corado e a técnica de imunofluorência direta (Avelleira, Bottino, 2006). A partir da $2^{\circ}$ ou $3^{\circ}$ semana após surgimento do cancro, quando os anticorpos começam a ser detectados, o diagnóstico passa a ser por método sorológico (Avelleira, Bottino, 2006).

A contaminação por treponema pallidum, desencadeia dois tipos de anticorpos reagínicas, os específicos e inespecíficos. Os anticorpos inespecíficos 
IgM e IgG, fundamentam os testes não treponêmicos, o VDRL (Venereal Disease Research Laboratory) e o RPR (Rapid Plasma Reagen), técnica simples e de baixo custo, que reagem contra a Cardiolipina, um componente da parede do Treponema pallidum e de outras treponematoses. Considerando que o antígeno pode reagir positivamente em outras treponematose além do Treponema pallidum, o teste não treponêmico, deverá ser utilizado para triagem em grupos populacionais e para monitorização do tratamento (Avelleira, Bottino 2006), (Brasil, 2005), (Brasil, 2015).

Os anticorpos específicos, agem contra o Treponema pallidum, fundamentando os testes treponêmicos (qualitativos), utilizados para confirmação da reatividade do teste não treponêmico. Os testes treponêmicos contemplam: TPI (prova de imobilização dos treponemas); a FTA-AB (Fluorescent Treponemal antidody absorption); TPHA (Treponema pallidum Hemagglutination); MHA-TP (Microhemagglutination assay for antibody to T.pallidum); PCR (reação em cadeia da polimerase); EIA (imunoensaio enzimático treponêmico) e Western-blot (Avelleira, Bottino, 2006), (Brasil, 2015).

O diagnóstico laboratorial da doença se dá pelo resultado reagente do teste treponêmico e do teste não treponêmico com qualquer titulação, aos indivíduos com evidência clínica da fase primária ou secundária ou aos indivíduos assintomáticos (Brasil, 2016a).

\subsubsection{MAGNITUDE DO AGRAVO SIFILIS}

Os dados de vigilância epidemiológica da sífilis adquirida apresentaram um grande avanço após a inclusão deste agravo na lista nacional das doenças de notificação compulsória, estabelecida pela Portaria nำ2.472, de 31/ 08 / 2010 (Brasil, 2016a), (São Paulo - Estado, 2013). Desde o ano 2010 até junho 2016, foram notificados 227.663 casos de sífilis adquirida no Brasil. No ano de 2015 foram contabilizados 65.878 casos, com taxa de detecção de 42,7 casos por 100 mil habitantes. Destes, 55,6\% compreendem a população com faixa etária de 20 a 39 anos, idade que envolve a fase reprodutiva (Brasil, 2016a). Da totalidade notificada no ano de 2015, 37.056 (56,2\%) casos, foram registrados na região Sudeste, destes 25.909 (39,3\%) casos foram notificados no Estado de São Paulo (Brasil, 2016a). Estes dados notificados evidenciam a manutenção, em nosso meio, de um problema 
de Saúde Pública secular, que contribui para acarretar a sífilis na gestação e a sífilis congênita, sustentando um desafio para atingir as metas dos Objetivo de desenvolvimento Sustentável - agenda 2030, de reduzir a taxa de morbimortalidade materna e infantil.

\subsection{SíFILIS NA GESTAÇÃO}

A sífilis no período gestacional, se não tratada ou inadequadamente tratada, resulta na disseminação hematogênica do agente etiológico Treponema pallidum para o concepto chamada de transmissão vertical. O Treponema pallidum atinge o feto determinando à sífilis congênita, caracterizada por provocar manifestações congênitas, prematuridade, óbito fetal e óbito neonatal (São Paulo - Cidade, 2013), (Santos 2009 apud Miller, 2003). O estágio da sífilis na gestante e o tempo de exposição do feto ao Treponema pallidum, determinam a probabilidade da transmissão vertical, atingindo cerca de 70 -100\% nas fases primárias e secundárias da doença, pelo alto número do Treponema pallidum na circulação. Reduzindo-se para $30 \%$ nas fases terciária e fase de latência tardia. Todavia, a transmissão pode ocorrer em qualquer período gestacional ou no momento do parto no período expulsivo (Magalhães et al., 2011), (Avelleira, Bottino, 2006).

Dados da Organização Mundial da Saúde, revela que a sífilis gestacional é responsável por mais de 300 mil mortes fetais e neonatais por ano no mundo e expõe um adicional de 215 mil crianças com risco aumentado de morte por prematuridade, representando um grave problema de saúde Pública no Brasil e em muitos países (Brasil, 2016a), (Domingues 2013 apud Brasil, 2010).

A sífilis no período gestacional é uma doença de notificação compulsória em toda a rede de serviços de saúde, determinada pela Portaria Ministerial nํ 33, de 14 de julho 2005 (São Paulo- Cidade, 2013), (Tayra et al., 2007). Do período de 2005 a 2010, houve 39.789 casos de sífilis em gestantes no Brasil. De 2011 a 2016, foram notificados 129.757 casos, retratando um aumento considerável em todo o país. (São Paulo- Cidade, 2014), (Brasil, 2016a). Dados relatados pelas Coordenadorias Regionais de Saúde (CRS) do município de São Paulo, demonstraram grande aumento das taxa de detecção (TD) da sífilis em gestantes (casos por 1000 nascidos vivos). A exemplo da CRS da Zona Norte, da Prefeitura Regional (Vila 
Maria/Vila Guilherme), que apresentou um total de 337 casos notificados, contabilizados do ano de 2007 à 2013. No ano de 2007 a CRS Norte, apresentou um total de 10 casos notificados com TD de 2,2 avançando para 98 casos notificados no ano de 2013, com TD de 20,7 (São Paulo - Cidade, 2014), (Brasil, 2016a). Estes dados, demonstram os avanços da investigação e diagnóstico da sífilis na gestação, expandindo a possibilidade de realizar o tratamento adequado durante as consultas de pré-natal, contribuindo para prevenção da sífilis congênita (Brasil, 2016a).

A sífilis congênita é um agravo de notificação compulsória desde 1986, determinada pela Portaria 542, de 22 de dezembro 1986 (Brasil 2005), (São Paulo Cidade, 2013), (São Paulo -Cidade, 2014). A sífilis Congênita é considerada um problema de saúde Pública e a Organização Mundial da Saúde determina como meta de eliminação desse agravo, um coeficiente de incidência inferior a 0,5 caso por 1000 nascidos vivos ou (1 caso para 2.000 nascidos vivos) (São Paulo -Cidade, 2013), (São Paulo -Cidade, 2014), (Magalhães et al., 2011).

A redução dos casos de Sífilis Congênita é considerado um indicador de saúde dos municípios, existindo um consenso com o Ministério da Saúde e a Secretaria Estadual de Saúde, enfatizando a importância da qualidade da assistência prestada às gestantes nas consultas do pré-natal, parto e puerpério (São Paulo-Cidade, 2014). No ano de 2007, o Ministério da Saúde, lança o Plano operacional para Redução da Transmissão vertical do HIV e da Sífilis no Brasil, medidas estratégias que fortalece o cuidado às gestantes na prevenção da sífilis congênita. Apesar das políticas públicas adotadas no Brasil visando à prevenção da sífilis congênita, nos últimos 10 anos, houve um progressivo aumento na taxa de incidência de sífilis congênita: no ano de 2006, a taxa era de 2,0 casos/mil nascidos vivos/NV; no ano 2015 a taxa de incidência subiu para 6,5 casos por mil nascidos vivos. O Estado de São Paulo apresentou taxa de 5,9 casos/mil nascidos vivos (São Paulo-Cidade, 2013), (Brasil 2016a). Retratando os dados por município, a taxa de incidência da sífilis congênita no município de São Paulo, apresentou valores sempre acima de 2,0 casos por 1000 nascidos vivos. A partir de 2010, ultrapassou 3,0 casos por 1000 nascidos vivos; em 2012 alcançou 4,2 casos por 1000 nascidos vivos. Discriminando os casos por Coordenadorias Regionais de Saúde (CRS) do município de São Paulo, no ano 2012 a CRS Norte, apresentou o maior percentual $(35,3 \%)$ de casos de sífilis congênita do município, assim com maior Coeficiente de Incidência (7,5 casos /1000 NV) e a Supervisão Técnica de Saúde Vila Maria/ Vila 
Guilherme apresentou 225 casos contabilizados de 1988 a 2003 e 312 casos de 2004 a junho 2013 (São Paulo-Cidade, 2013), (São Paulo-Cidade, 2014), (Brasil, 2016a).

$\mathrm{Na}$ perspectiva de reverter estes dados, no ano de 2016, o Ministério da Saúde lança a Agenda de Ações Estratégicas para Redução da Sífilis Congênita no Brasil, novas medidas estratégicas que abordam diversos eixos metodológicos intensificando as ações educativas em saúde, o diagnóstico precoce e o tratamento oportuno e adequado às gestantes e parcerias sexuais com sífilis no pré-natal, objetivando a redução da morbimortalidade associada à transmissão vertical da doença (Brasil, 2016 b). Para evitar ou interromper a transmissão vertical da sífilis, faz-se necessário desempenhar de maneira eficaz as medidas estratégicas estabelecidas pelas políticas públicas direcionadas ao cuidado integral à saúde materna infantil.

\subsection{POLÍTICAS DE ATENÇÃO À GESTAÇÃO}

\subsubsection{POLITICAS PÚBLICAS DE ASSISTÊNCIA AO PRÉ NATAL}

A Atenção Básica, representa a porta de acesso da população aos serviços de promoção da saúde, prevenção e tratamento de agravos. No entanto, as Unidades Básicas de Saúde tornam-se referência para o atendimento às mulheres no período pré-natal, peri e pós-natal (Brasil 2000). O acompanhamento obstétrico, puerperal e neonatal na atenção básica, deve ser realizado por uma equipe multiprofissional, com ênfase na participação do profissional médico e de enfermagem (São Paulo - Estado, 2010). De acordo com o Decreto no 94.406 de 08 de junho de 1987, que regulamenta a Lei do Exercício Profissional de Enfermagem no 7.498 de 25 de junho de 1986, o pré-natal de baixo risco pode ser acompanhado integralmente pelo enfermeiro (Brasil, 1987), (São Paulo - Estado, 2010). A atenção obstétrica e neonatal ofertada pelos profissionais de saúde, deve contemplar práticas atualizadas com embasamento nos referenciais teórico-científicos, para melhoria da qualidade da assistência, com objetivo de reduzir a morbimortalidade materno-infantil (Brasil, 2005c). 
No ano de 2000, o Ministério da Saúde lançou, o "Manual Técnico de Assistência ao Pré natal", com a finalidade de referenciar as organizações da rede assistencial e os profissionais da saúde, com normas técnicas para uma assistência de qualidade, sem complicações e com prevenção das afecções perinatais (Brasil 2000). Avançando com as publicações para melhoria da assistência ao Pré Natal, no ano de 2006, o Ministério da Saúde lançou o "Manual Técnico - Pré Natal e Puerpério, atenção qualificada e humanizada - Série Direitos Sexuais e Direito reprodutivos" (Brasil, 2005c). No ano de 2010, a Secretaria de Estado da Saúde de São Paulo, lançou o "Manual Técnico - Pré Natal e Puerpério - Atenção à gestante e à puérpera no SUS-SP" (São Paulo - Estado, 2010). No ano de 2012, o Ministério da Saúde, lançou o "Caderno de atenção Básica, nº 32 - Atenção ao pré-natal de baixo risco, série A - Normas e Manuais Técnicos" (Brasil, 2012). Neste mesmo período, a Secretaria Municipal de Saúde de São Paulo, Lança o Manual Técnico: saúde da mulher nas Unidades Básicas de Saúde, este manual, dispõe sobre o modelo do Prontuário Obstétrico, para o acompanhamento das gestantes (São Paulo - Cidade, 2012).

Os manuais técnicos representam uma ferramenta de grande valia para a dimensão prática dos profissionais de saúde e as atualizações publicadas consolidam medidas para melhoria do processo do cuidar na atenção Obstétrica e neonatal (Brasil, 2012). Entre as normas estabelecidas nos manuais técnicos, destacam-se: a necessidade de Identificação precoce de todas as gestantes na comunidade, de maneira a iniciar o acompanhamento do pré-natal no primeiro trimestre gestacional, visando intervenções preventivas ou terapêuticas em tempo oportuno, assegurando o bem estar materno e neonatal (Brasil, 2000), (Brasil, 2005c.) (Brasil, 2010); (São Paulo - Estado, 2010). Os manuais estabelecem o cumprimento de no mínimo, seis consultas de pré-natal, sendo, preferencialmente, uma no primeiro trimestre, duas no segundo trimestre e três no terceiro trimestre da gestação (Brasil, 2005c.), (São Paulo - Estado, 2010). (Brasil, 2010). As consultas devem ser mensais até a 28ำ semana gestacional, passando para quinzenais entre a $28^{\circ}$ e $36^{\circ}$ semanas e semanais entre $37^{\circ}$ e $41^{\circ}$ semanas, não havendo alta do pré natal (Brasil, 2012). As normas técnicas estabelecem a necessidade de visita domiciliar para as gestantes faltosas e para todas as puerperas na primeira semana após o parto, devendo a mulher ter ao menos um retorno puerperal ao serviço de saúde, entre o sétimo e o décimo dia, considerando que parte das ocorrências de 
morbimortalidade materna e neonatal, acontecem na primeira semana após o parto. A consulta médica puerperal deve ser realizada em até 42 dias (Brasil, 2012), (São Paulo - Estado, 2010). Outra normativa diz respeito ao cumprimento da imunização em gestantes e puerperas (vacina adsorvida difteria e tétano, Hepatite $B$, Influenza, sarampo, caxumba, rubéola, vacina adsorvida diferia, tétano e pertussis acelularDtpa) (São Paulo- Estado 2017), (Brasil, 2000), (Brasil, 2005c). Os manuais estabelecem também, a necessidade da realização de exames conforme segue:

\footnotetext{
Grupo Sanguíneo e fator Rh, Dosagem de Hemoglobina/Hematócrito, na primeira consulta;

Glicemia de jejum, um exame na primeira consulta e outro próximo à $30^{\mathrm{a}}$ semana de gestação; Teste de tolerância com sobrecarga oral de $75 \mathrm{~g}$ de glicose anidra.

Teste de Coombs indireto;

Sorologia para sífilis (VDRL), um exame na primeira consulta e outro entre $28^{\text {a }}$ e $30^{a}$ semanas de gestação; no caso de positividade, repetir o exame mensalmente para controle da cura após tratamento.

Testagem anti-HIV, com um exame na primeira consulta;

Exame de Urina tipo 1, Urocultura com antibiograma (um exame na primeira consulta e outro próximo à $30^{a}$ semana de gestação);

Exame parasitológico de fezes

Sorologia para hepatite B (HBsAg), com um exame, de preferência, próximo à $30^{\text {a }}$ semana de gestação;

Sorologia para toxoplasmose (IgM), na primeira consulta (se disponível).

Colpocitologia oncótica, se a mulher não a tiver realizado nos últimos três anos ou se houver indicação;

Ultrassonografia obstétrica, realizada precocemente na gestação (Brasil, 2000), (Brasil, 2005c), (São Paulo - Estado, 2010), (Brasil, 2012).
}

$\mathrm{Na}$ identificação de qualquer alteração dos valores de referência para os exames elencados e/ou na identificação de fatores de risco para a gravidez atual, os equipamentos de saúde, deverão prover o tratamento adequado, conforme protocolos do Ministério da Saúde (Brasil, 2000).

A assistência adequada ao pré-natal, deve atender toda população-alvo da área de abrangência da unidade de saúde, assegurando a continuidade do cuidado à saúde materna e perinatal em redes de atenção à saúde - RAS, garantindo a assistência em todos os níveis de complexidade, com um sistema de referência e contra- referência eficiente (Brasil 2000). Para eficiência na comunicação entre os equipamentos de saúde e os profissionais da unidade, é necessário o preenchimento adequado dos instrumentos de registro sistematizados, para a gestação, parto e puerpério (Brasil 2000).

Outra ferramenta que contribui para o prática assistencial de forma organizada e estruturada é o SISPRENATAL, um sistema de informação 
disponibilizado pelo DATASUS, que permite o lançamento de cada atendimento prestado às gestantes, sendo de uso obrigatório nas unidade de saúde, permitindo a avaliação da assistência ao pré natal e puerpério, resultando em indicadores de processo, indicadores de resultados e indicadores de impacto por localidade e período (Brasil 2005c).

Os Indicadores de processo correspondem ao cumprimento das normativas descritas nos manuais técnicos de assistencia ao pré-natal e puerpério, as informações registradas são descritas em porcentagem, com base nas gestantes cadastradas, possibilitando uma maior compreensão da assistência prestada (Brasil 2005c).

Os Indicadores de resultado, correspondem ao percentual de recém-nascidos com diagnóstico de sífilis congênita, em relação ao total de recém-nascidos vivos do município e o percentual de recém-nascidos com tétano neonatal, em relação ao total de recém-nascidos vivos do município (Brasil 2005c).

Os indicadores de impacto, correspondem ao " Coeficiente de incidência de sífilis congênita e de tétano neonatal no município, comparado com o do ano anterior; Razão de mortalidade materna no município, comparada com a do ano anterior; Coeficiente de mortalidade neonatal precoce e tardia no município, comparado com o do ano anterior; e Coeficiente de mortalidade neonatal total no município, comparado com o do ano anterior " (Brasil 2005c).

\subsubsection{PROGRAMA DE HUMANIZAÇÃO NO PRÉ NATAL E NASCIMENTO}

Instituído pelo Ministério Público, através da portaria 569 / GM / 01/06/2000, o Programa de Humanização no Pré Natal e Nascimento (PHPN), visa assegurar melhoria do acesso à cobertura e da qualidade no acompanhamento à assistência obstétrica e Neonatal, na perspectiva dos direitos de cidadania (Neto ETS et al., 2008), (Brasil 2002). A implantação do PHPN, resulta da política de enfrentamento do PAISM 1983, por uma assistência humanizada em todas as fases do ciclo de vida das mulheres (Andreucci CB et.al. 2011).

O Programa de Humanização no Pré Natal e Nascimento, vem reforçar a necessidade de medidas favoráveis ao cuidado específico às gestantes, ao recém nascido e à puérpera, fomentando a melhoria nos investimentos financeiros, 
viabilizando os procedimentos necessários e provendo capacitações aos profissionais que atuam diretamente nesse cuidado, objetivando reduzir as taxas de morbimortalidade materna, peri e neonatal registradas no país (Neto ETS et.al., 2008), (Brasil 2002), (Serruya SJ, et al., 2004), (Magalhães et al., 2011), O Programa de Humanização no Pré Natal e nascimento, compreende entre outros, dois aspectos fundamentais:

\begin{abstract}
"O Primeiro, refere-se à convicção de ser dever das Unidades de Saúde, receber às gestantes, neonatos e seus familiares com atendimento humanizado, digno, seguro e de qualidade, ou seja, os profissionais de saúde devem prover atitudes ética e solidária; as Instituições de saúde devem criar ambientes acolhedores e dispor de condutas hospitalares que finalizem com o tradicional isolamento às mulheres" (Serruya SJ, et.al. 2004) p.1282, (Brasil 2002) p.05.

Outro aspecto fundamental refere-se à necessidade da adoção de condutas benéficas ao acompanhamento do parto e do nascimento, evitando práticas intervencionistas desnecessárias que possam acarretar maiores riscos à mulher e ao recém-nascido"(Serruya SJ, et.al. 2004) p.1282, (Brasil 2002) p.05.
\end{abstract}

Visando alcançar o principal objetivo de reduzir as altas taxas de morbimortalidade materna e perinatal, o PHPN, estabelece algumas atividades e procedimentos necessários para garantir a assistência Obstétrica e Neonatal com qualidade, referências norteadoras aos indicadores de qualidade da assistência prestada no pré-natal, parto e puerpério (Andreucci CB et al., 2011), (Brasil 2002), (Serruya SJ, et.al., 2004), entre outros:

1. "A gestante deverá realizar a primeira consulta de pré-natal até o $4^{\circ}$ mês de gestação.

2. Realização de no mínimo seis consultas de acompanhamento de pré- natal, sendo preferencialmente, uma no primeiro trimestre, duas no segundo trimestre e três no terceiro trimestre gestacional.

3. Realização de uma consulta no puerpério até quarenta e dois dias após o nascimento.

4. Oferta de Testagem anti-HIV, com um exame na primeira consulta, nos municípios com população acima de cinquenta mil habitantes.

5. Aplicação de vacina contra o tétano dose imunizante, segunda dose do esquema recomendado ou dose de reforço em mulheres já imunizadas.

6. Realização de atividades educativas.

7. Classificação de risco gestacional a ser realizada na primeira consulta e nas consultas subsequentes.

8. Garantir às gestantes classificadas como de risco, atendimento ou acesso à unidade de referência para atendimento ambulatorial e/ou hospitalar à gestação de alto risco".

Acrescido às atividade e procedimentos destacados, o PHPN Institui três componentes com objetivos específicos para a melhoria da Assistência Obstétrica e 
Neonatal, elementos estruturantes e fortalecedores do trabalho em rede, entre o Ministério da Saúde e as Secretarias de Saúde dos Estados, Municípios e Distrito Federal (Brasil 2002), (Serruya SJ, et.al. 2004).

Componente I - Incentivos à Assistência Pré Natal. Visa estimular Estados e Municípios a realizarem o acompanhamento obstétrico adequado, conforme critérios estabelecidos pela PHPN, incentivados por recursos financeiros de $R \$ 10,00$ por cadastramento da gestante no PHPN e $R \$ 40,00$ por efetivação da conclusão do pré natal, conforme procedimentos determinados no PHPN, valores repassados pelo Ministério da Saúde (Brasil 2002), (Serruya SJ, et.al. 2004).

Compete aos Estados e Municípios efetuar o cadastramento e registrar todos os atendimentos às gestantes, através do Sisprenatal - software desenvolvido pelo DATASUS para o acompanhamento adequado das gestantes inseridas no PHPN e disponibilizado aos municípios para adesão ao programa. O sistema consolida a totalidade dos dados cadastrados e mensalmente gera um Boletim de Produção Ambulatorial - BPA, repassando os dados ao Sistema de Informação Ambulatorial do SUS (SIA/SUS), permitindo qualificar a atenção prestada às gestante durante a consulta do pré natal e puerpério, analisando (cadastro efetivado até o $04^{\circ}$ mês de gestação, número de consultas realizadas, total de exames executados, imunização efetuada, dados do parto e puerpério em tempo hábil) (Andreucci CB et.al. 2011), (Brasil 2002), (Serruya SJ, et.al. 2004).

Componente II - Organização, Regulação e Investimentos na Assistência Obstétrica e Neonatal. Contempla medidas estruturais operacionais de organização da Central de Regulação e sistemas móveis de atendimentos pré e inter hospitalares para assistência obstétrica e neonatal. Ocorre repasse de financiamento aos hospitais públicos e filantrópicos integrantes do Sistema Único de Saúde; os valores são repassados pelas Secretarias Estaduais de Saúde, desde que as instituições envolvidas na assistência obstétrica e neonatal, atendam aos critérios previamente estabelecidos (Brasil 2002).

Componente III - Nova Sistemática de Pagamento à Assistência ao parto. Objetiva melhorias do recurso financeiro para a assistência ao parto nos hospitais integrantes do Sistema de Informação Hospitalares /SUS. Para este fim, eleva-se o valor renumerado dos procedimentos da tabela relativa ao parto nos hospitais que prestam assistência às gestantes do PHPN, com cumprimento do pré-natal completo, segundo os critérios estipulados (Brasil 2002). 
O PHPN, instrumentalizou o cuidado à saúde da mulher no pré natal, parto e puerpério, garantindo acesso às práticas de saúde baseadas em evidências científicas, permitindo a consolidação dos dados quantitativos e qualitativos, gerando indicadores assistenciais, fundamentais para direcionar ações programáticas e estratégicas para melhoria no cuidado à saúde materno-infantil (Andreucci CB et.al. 2011), (Serruya SJ, et.al. 2004).

\subsubsection{REDE CEGONHA}

A Rede Cegonha - RC, é uma estratégia do Ministério da Saúde no âmbito do Sistema Único de Saúde - SUS, instituída pela Portaria no 1.459 de 24 de Junho 2011. Consiste numa rede de cuidados que visa assegurar o acesso, o acolhimento e a resolutividade na assistência às mulheres no período gestacional, perigestacional e às crianças com até dois anos de idade, além de ampliar diagnóstico e tratamento das Infecções Sexualmente Transmissíveis - IST, com financiamento de testes rápidos de sífilis e HIV pelo Ministério da Saúde (Brasil, 2011), (Brasil, 2015). A Portaria ํํ 77 do MS de 12/01/2012, também dispõe sobre a realização de testes rápidos de sífilis no âmbito da atenção ao pré-natal para gestantes e suas parcerias sexuais, ampliando o acesso aos diagnósticos (Brasil, 2015).

A Rede Cegonha está inserida na ideologia de cuidados da Rede de Atenção à Saúde (RAS), que visa promover integração dos serviços de saúde para proporcionar atenção integral aos usuários. Entretanto, a RC desenvolve suas ações com vinculação das gestantes reguladas às unidades de referências ao parto e ao transporte seguro, além de realizar suas práticas baseadas em evidências, alcançando melhoria dos indicadores de morbimortalidade materno infantil (Cavalcanti PCS, et.al. 2013).

A RC é organizada por quatro componentes estruturais delineados pelas práticas assistenciais e recursos financeiros para o cuidado materno-infantil: Componente I - Pré Natal, Componente II - Parto e Nascimento, Componente III Puerpério e atenção integral à saúde da criança e Componente IV - Sistema logístico (transporte sanitário e regulação) (Brasil, 2011). 

pesquisa).

a) Realização de pré-natal na Unidade Básica de Saúde (UBS) com captação precoce da gestante (até a $12^{\underline{a}}$ semana de gestação) e com mais de 7 consultas no pré-natal;

b) Acolhimento às intercorrências na gestação com avaliação e classificação de risco e vulnerabilidade;

c) Acesso ao pré-natal de alto de risco em tempo oportuno;

d) Realização dos exames de pré-natal e acesso aos resultados em tempo oportuno;

e) Vinculação da gestante desde o pré-natal ao local em que será realizado o parto;

f) Qualificação do sistema e da gestão da informação;

g) Implementação de estratégias de programas educativos relacionados à saúde sexual e à saúde reprodutiva;

H) Prevenção e tratamento das IST/HIV/Aids e Hepatites; e

I) Apoio às gestantes nos deslocamentos para as consultas de pré-natal e para o local em que será realizado o parto, os quais serão regulamentados em ato normativo específico.(Brasil, 2011).

O financiamento ao componente I - Pré-Natal, contempla o repasse do valor de $R \$ 10,00$ (dez reais) ao município, mediante a quantidade de gestantes cadastradas no sistema de Informação - Sisprenatal à disposição do município para adesão à Rede cegonha. Neste componente, estão previstos novos exames financiados pelo Ministério da Saúde:

Teste rápido de gravidez; Teste rápido de sífilis; Teste rápido de HIV; Cultura de bactérias para identificação (urina); Acréscimo de mais um exame de hematócrito, hemoglobina; Ampliação do ultrassom obstétrico para $100 \%$ das gestantes; Proteinúria (teste rápido); Teste indireto de antiglobulina humana (TIA) para gestantes que apresentarem $\mathrm{RH}$ negativo. Exames adicionais para gestantes de alto-risco: Contagem de plaquetas, Dosagem de proteínas (urina 24 horas), Dosagens de uréia, creatinina e ácido úrico, Eletrocardiograma, Ultrassom obstétrico com Doppler e Cardiotocografia ante-parto (Brasil, 2011).

\section{Componente II - Parto e Nascimento (Principais características associadas à} pesquisa em pauta).

Compreende-se por garantir a suficiência de leitos obstétricos e neonatais (Unidade Terapia Intensiva - UTI, Unidade Cuidado Intermediário - UCI e Canguru) conforme as necessidades regionais; Aplicação de boas práticas de atenção ao parto e ao nascimento, baseadas em evidências científicas; Implementação de equipes horizontais no cuidado, nos serviços de atenção obstétrica e neonatal; e Implementação de Colegiado Gestor nas maternidades e outros dispositivos de co-gestão tratados na Política Nacional de Humanização (Brasil, 2011). 
O financiamento ao componente parto e nascimento, visa prover construção, ampliação e reforma das Casas de Parto Normal, Casas de Gestantes, Bebês e Puérperas, Qualificação dos leitos de (UTI adulto e neonatal e UCI neonatal). Estes recursos devem ser repassados aos serviços, como incentivo, conforme o cumprimento das metas (Brasil, 2011).

Componente III - Puerpério e Atenção Integral à Saúde da Criança. (Principais características associadas à pesquisa em pauta).

Compreende a necessidade de acompanhamento da puérpura e da criança na primeira semana após o parto e nascimento; Realização de busca ativa às crianças vulneráveis; Prevenção e tratamento das IST/HIV/Aids e Hepatites virais. Orientação e oferta de insumos contraceptivos; Implantação de estratégias e programas educativos relacionados à saúde sexual e reprodutiva (Brasil, 2011).

Componente IV - Sistema Logístico - Transporte e Regulação: (Principais características associadas à pesquisa em pauta).

Compreende estratégias de cuidados em situações de urgência, provendo acesso ao transporte seguro para as gestantes, puérperas e ao recém nascidos de alto risco, através do Sistema de Atendimento Móvel de Urgência - SAMU Cegonha devidamente equipadas para atender tais públicos; Implantação do modelo "Vaga Sempre", elaboração e implantação do plano de vinculação da gestante ao local de ocorrência do parto; e Implantação da regulação de leitos obstétricos e neonatais (urgências e regulação ambulatorial) (Brasil, 2011).

A Rede Cegonha, delineia em seu instrumento, os meios de operacionalização (financiamentos, contratualização e metas quantiqualitativas) para organização dos processos da rede de atenção à saúde materno infantil, a ser implantado e fortalecido pela União, Estado, Distrito Federal e Municípios, acrescido da realização de fóruns da Rede Cegonha construindo espaço de participação popular, compondo um novo modelo de atenção materno infantil (Brasil, 2011). 


\subsection{TRATAMENTO DA SÍFILIS}

\subsubsection{TRATAMENTO SÍFILIS}

O médico bacteriologista Inglês Alexander Fleming, no ano de 1928, fez a descoberta da penicilina, alcançando o tratamento eficaz contra o Treponema pallidum. A penicilina age interferindo na síntese da parede celular do T. pallidum e mostra-se eficaz em todas as fases da doença sífilis. A penicilina foi produzida e comercializada em grandes quantidades a partir do ano de 1943 (Magalhães et al., 2011), (Souza, 1996).

Conforme a portaria oㅡ 3161, de 27/12/2011, a aplicação da Penicilina G Benzatina, deverá ser realizada em todas as unidades básicas de saúde (Brasil, 2015). O Sistema do Cofen/ Conselho regionais de Enfermagem, reafirmam na Nota Técnica do Cofen 03/2017, que a Penicilina Benzatina, pode ser administrada no âmbito da Unidade Básica de saúde, por profissionais de Enfermagem (Auxiliar de Enfermagem, Técnico de Enfermagem e Enfermeiro), mediante a prescrição médica ou do enfermeiro. Esclarece que os Enfermeiros podem prescrever a Penicilina Benzatina conforme protocolos estabelecidos pelos Ministério da Saúde, Secretarias Estaduais, Secretarias Municipais, Distrito Federal, ou em rotina aprovada pela Instituição de Saúde. A Nota Técnica, afirma também, que a ausência do profissional médico na Unidade Básica de Saúde, não determina motivo para não aplicação da Penicilina Benzatina por profissionais de Enfermagem (COFEN, 2018).

A penicilina benzatina é reconhecida como um medicamento essencial para controle da transmissão vertical da sífilis (Brasil 2016). Apesar da sua importância, o Brasil identificou desde 2014 a falta da Penicilina Benzatina no âmbito Nacional. A Nota Técnica 02/2015 da Secretaria Municipal da Saúde, esclarece que os produtores no Brasil, apresentavam dificuldade para obtenção da matéria prima deste medicamento (São Paulo- cidade 2015). A Nota Informativa Conjunta no 109/105/ vem enfatizar a prioridade do uso da Penicilina G Benzatina ao tratamento da sífilis gestacional na prevenção da sífilis congênita e dá outras alternativas para os demais tratamentos da sífilis, uma decisão compreendida em articulação com à Agencia Nacional da Vigilância Sanitária (Anvisa), Conselho Nacional de Secretários 
de Saúde (CONASS), Conselho Nacional de Secretários Municipais de Saúde (CONASEMS), Organização Pan-Americana da Saúde (OPAS/OMS), empresas produtoras Nacionais e Sistema Único de Saúde (Brasil 2015a).

Para os demais casos de sífilis em homens ou mulheres não gestantes, a estratégia de tratamento contempla o uso da doxiciclina 100mg, via oral 12/12 horas por 15 dias para sífilis recente (até um ano duração da doença) e 30 dias, para sífilis tardia (mais de um ano da duração da doença. Outra medicação de escolha referese a Ceftriaxona $1 \mathrm{~g} \mathrm{EV} \mathrm{ou} \mathrm{IM} 1$ vez ao dia por 08 a 10 dias (São Paulo- cidade 2014a), (São Paulo- cidade 2015), (Brasil 2015a).

Observando o aumento do número de casos de sífilis, a Nota Informativa no 02 /2018 vem revogar a Nota Informativa nำ109/105 e dá providências de ampliar o uso da Penicilina Benzatina para o tratamento da sífilis adquirida e parcerias, atendendo a todos os casos de sífilis. O Ministério da Saúde (MS) assume a responsabilidade pela aquisição e distribuição deste medicamento aos estados e Distrito Federal, que deverão armazená-los e distribuí-los aos municípios (Brasil 2018).

A investigação da sífilis na primeira consulta pré-natal, permite o diagnóstico precoce da doença e iniciar o tratamento o quanto antes e a repetição do exame investigatório de sífilis entre a $28^{\underline{a}}$ e $30^{\underline{a}}$ semana gestacional, permite que 0 tratamento seja instituído e finalizado até 30 dias antes do parto, período mínimo para que o recém-nascido seja considerado tratado intraútero (Brasil, 2010), (Tayra, 2007). As gestantes tratadas, devem realizar mensalmente o seguimento sorológico quantitativo para controle da cura. Caso não identifique resposta ao tratamento realizado e/ou haja aumento de duas diluições em relação ao último título VDRL, as gestantes, deverão ser tratadas novamente, para prevenir a transmissão vertical e reduzir a incidência da Sífilis Congênita, decorrente da ausência ou do tratamento inadequado (Magalhães et al., 2011), (Santos, 2009), (São Paulo - Estado, 2010), (São Paulo- Cidade, 2014), (Tayra, 2007).

Considera-se tratamento inadequado das gestantes com sífilis;

[tratamento inadequado: tratamento com qualquer medicamento que não seja penicilina; tratamento com penicilina realizada nos últimos 30 dias anterior ao parto; tratamento incompleto conforme diretrizes de tratamento vigente; tratamento não adequado para a fase clínica da doença; ou por ausência de comprovação documental do tratamento; ou se não constar queda dos títulos após tratamento; elevação de títulos em sorologia não 
treponêmica (VDRL ou RPR); Brasil (2006), Brasil (2015), Santos (2009) apud Miller (2003).

\subsubsection{TRATAMENTO CONFORME A FASE DA DOENÇA SÍFILIS}

A Penicilina G Benzatina, apresenta-se em 1 ampola de 1200.000Ul aplicada via Intramuscular (IM) em cada glúteo (Brasil, 2015).

Uma série de aplicação corresponde ao total 2.400.000Ul; Duas séries de aplicações correspondem ao total $4.800 .000 \mathrm{Ul}$; Três séries de aplicações correspondem ao total 7.200.000UI (Brasil, 2015).

\footnotetext{
$\checkmark$ Tratamento da sífilis primária :

Penicilina G. Benzatina - Dose Única. Uma série de aplicação: Total de 2.400.000UI - Via Intramuscular (São Paulo - Estado, 2010), (Brasil, 2015).

$\checkmark$ Tratamento da sífilis secundária - latente precoce. (menos 1 ano de evolução)

Penicilina G. Benzatina - Duas séries de aplicação com total de 4.800.000UI, Intramuscular - Intervalo de uma semana entre as séries (São Paulo - Estado, 2010), (Brasil, 2015).

$\checkmark$ Tratamento da sífilis terciária - latente tardia .

Penicilina G. Benzatina - Três séries de aplicação com total de 7.200.000UI, Intramuscular - Intervalo de uma semana entre as séries (São Paulo - Estado, 2010), (Brasil, 2015).
}

\subsubsection{TRATAMENTO DA SÍFILIS EM GESTANTE ALÉRGICA À PENICILINA}

Gestante com histórico comprovado de alergia grave a Penicilina por meio anamnese e teste de sensibilidade, deverão ser encaminhadas para serviço de referência para serem dessensibilizadas, procedimento a ser realizado no ambiente hospitalar (São Paulo - Estado, 2010), (Brasil, 2015). Para as gestantes comprovadamente alérgica à penicilina e com impossibilidade de dessensibilização, poderão ser tratadas com Ceftriaxona $1 \mathrm{~g}$ EV ou IM 1 vez ao dia por 08 a 10 dias. Contudo, o recém-nascido será considerado com sífilis Congênita devendo ser tratado segundo o diagnóstico (São Paulo - Estado, 2015). 


\subsubsection{TRATAMENTO DO PARCEIRO SEXUAL}

Todos os parceiros sexuais expostos nos últimos 90 dias precedentes ao diagnóstico de sífilis primária, secundária ou latente precoce da gestante, com ou sem resultado reagente das provas sorológica, deverão ser tratado presumivelmente (Brasil, 2015). Os parceiros sexuais expostos há mais de 90 dias com as mesmas circunstâncias deverão ser tratados mesmos na ausência do resultado dos testes sorológicos. Parceiros sexuais antigos de pacientes com sífilis latente, devem ser avaliados clinica e sorologicamente e tratados conforme os achados diagnóstico (Brasil, 2015).

Por tudo aqui colocado, levando-se em consideração a magnitude da sífilis gestacional em nosso meio, que poderá aumentar a possibilidade da ocorrência de sífilis congênita e considerando a importância do Pré Natal qualificado como importante indicador da assistência à gestante e prevenção da sífilis, tornou-se necessário desenvolver a pesquisa em pauta. 


\section{Objetivos}




\section{OBJETIVOS}

\subsection{OBJETIVO GERAL}

Analisar a atenção prestada no pré-natal às gestantes de uma Unidade Básica de Saúde, pertencente à Coordenadoria Regional de Saúde - Norte, pelos Profissionais de Saúde, no que se refere à sífilis gestacional.

\subsection{OBJETIVOS ESPECÍFICOS}

1. Identificar perfil sócio demográfico das gestantes com sífilis.

2. Analisar a assistência prestada pelos profissionais de saúde às gestantes com sífilis.

3. Analisar a adesão do parceiro ao tratamento da sífilis.

4. Propor medidas de melhorias para assistencia às gestantes com sífilis. 
3. Metodologia 


\section{METODOLOGIA}

\subsection{TIPO DE ESTUDO}

Trata-se de um estudo descritivo, de corte transversal, com abordagem quantitativa, que buscou informações no banco de dados Institucional, dos registros de sífilis gestacional, dos atendimentos às gestantes que submeteram -se ao prénatal na UBS Vila Izolina Mazzei, do Distrito de Saúde Vila Guilherme, nos anos de 2015 e 2016.

\subsection{LOCAL DO ESTUDO}

O estudo ocorreu, na Unidade Básica de Saúde - UBS Vila Izolina Mazzei, uma Unidade tradicional, situada no Distrito de Saúde da Vila Guilherme, da Zona Norte do Município de São Paulo, uma Unidade de Administração Pública, vinculada à Organização Social de Saúde - OSS - Associação Paulista para o Desenvolvimento da Medicina - SPDM, que segue os princípios do SUS e integra as redes de cuidados e os sistemas de regulação municipal, legitimada por meio de um contrato de gestão com o Distrito de Saúde Vila Maria e Vila Guilherme - VMVG, da Coordenadoria Regional de Saúde Norte.

A Unidade Básica de Saúde Vila Izolina Mazzei é composta por 106 profissionais, conforme dados do Cadastro Nacional de Estabelecimentos de Saúde - CNES, estes profissionais constituem uma equipe multiprofissional preparada para atender a população local e regional, por demanda espontânea e referenciada. A composição desta equipe contempla profissionais médicos clínicos e especialistas (Homeopata, Pediatras, Geriatra, Pneumologistas, Radiologistas, Neurologista, Ginecologistas / Obstetras); Profissionais de Enfermagem (Enfermeiras, Auxiliares de Enfermagem); Profissional Farmacêutico e Auxiliares de Farmácia; Profissionais Cirurgiões Dentistas e Agentes de Saúde Bucal; Profissionais Técnicos em Radiologia e Imaginologia; Profissional Psicóloga, Assistentes Sociais, Nutricionista; Profissional Técnico em Métodos Eletrográficos em Encefalografia; Profissionais 
Cuidadores de Idosos, Profissionais Administrativos, Auxiliares de escritório e Profissionais de Hotelaria.

A UBS Vila Izolina Mazzei é estruturada pelos serviços: Programa Acompanhante de Idosos (PAI), imunização, nebulização, exames laboratoriais, curativos, farmácia, odontologia, diagnóstico por Imagem (RX e USG), eletrocardiografia, eletroencefalografia, central de esterilização de materiais, serviços administrativos, hotelaria e serviço de prontuários de pacientes -SPP.

\subsection{CARACTERIZAÇÃO DA ZONA NORTE NO MUNICÍPIO DE SÃO PAULO}

A Coordenadoria Regional de Saúde - Norte contempla os Distritos de Saúde Vila Maria / Vila Guilherme (Figura 1,2), abrange a área de 26,40 quilômetros quadrados, com uma população estimada no ano 2010 de 297.713 habitantes e densidade demográfica total de 11,277 habitantes por quilometro quadrado. 0 Distrito Administrativo da Vila Guilherme, área de localização da UBS Vila Izolina Mazzei, contempla uma área de 6,90 quilômetros quadrados, com população em 2010 de 54.331 habitantes, 17.750 domicílios com 3,06 pessoas para cada domicílio (São Paulo-Cidade 2010a), (São Paulo -cidade 2010b).

A Coordenadoria de Saúde da Região Norte, do Distrito de Saúde da Vila Maria e Vila Guilherme (VMVG), contempla 10 Unidades Básicas de Saúde, 3 Unidades Básicas de Saúde Integradas e outros estabelecimentos de saúde descritos no quadro 1, responsáveis por atender a população local e regional, por demanda espontânea e referenciada. 
Figura 1- Mapa das Regiões, Subprefeituras e Distritos - Município de São Paulo2014.

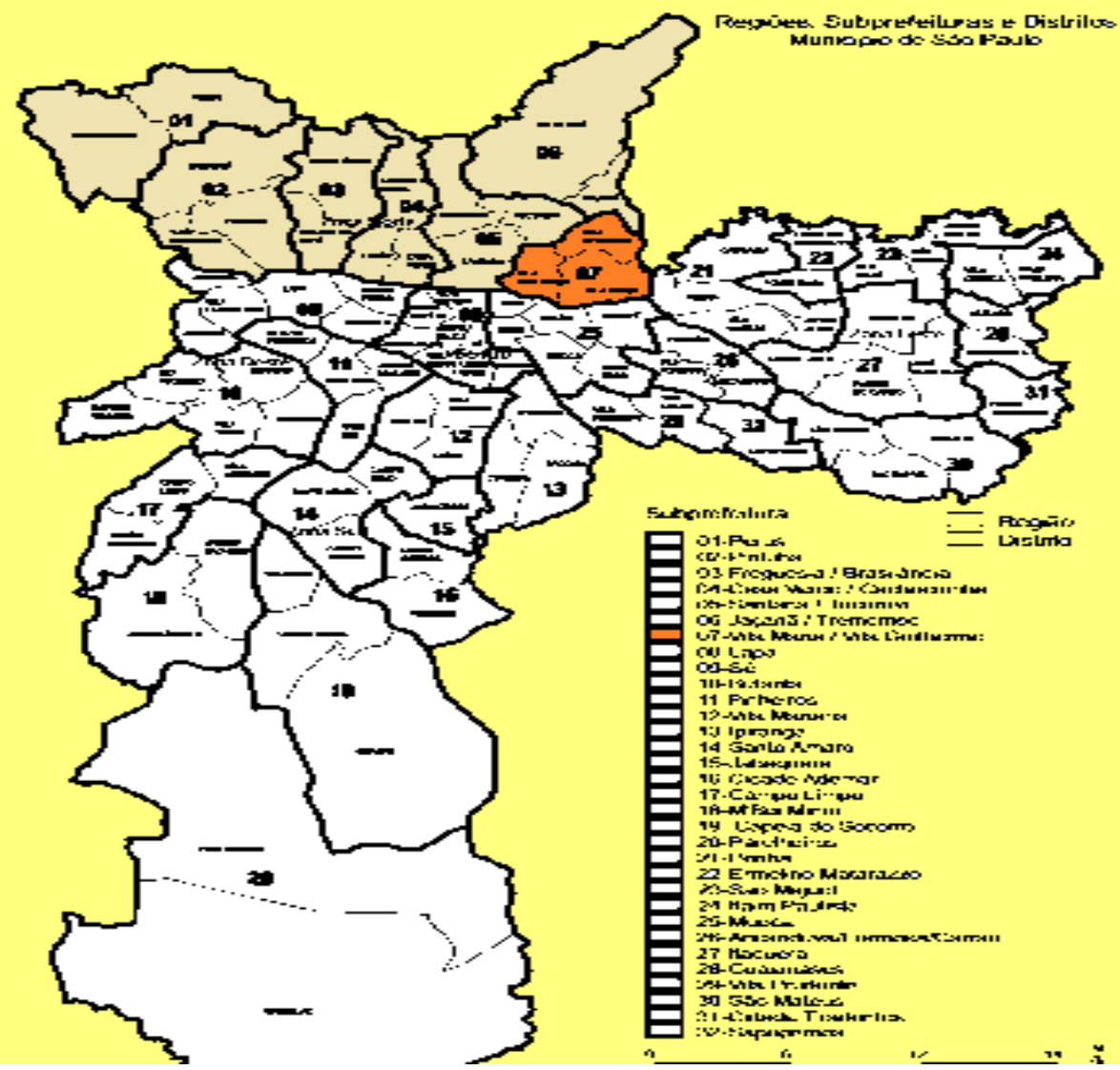

Fonte:http://infocidade.prefeitura.sp.gov.br/mapas/3_regioes_subprefeituras_e_distritos_2014_10338. pdf

Figura 2 - Mapa Zona Norte; Subprefeituras e Distritos - Município de São Paulo2014.

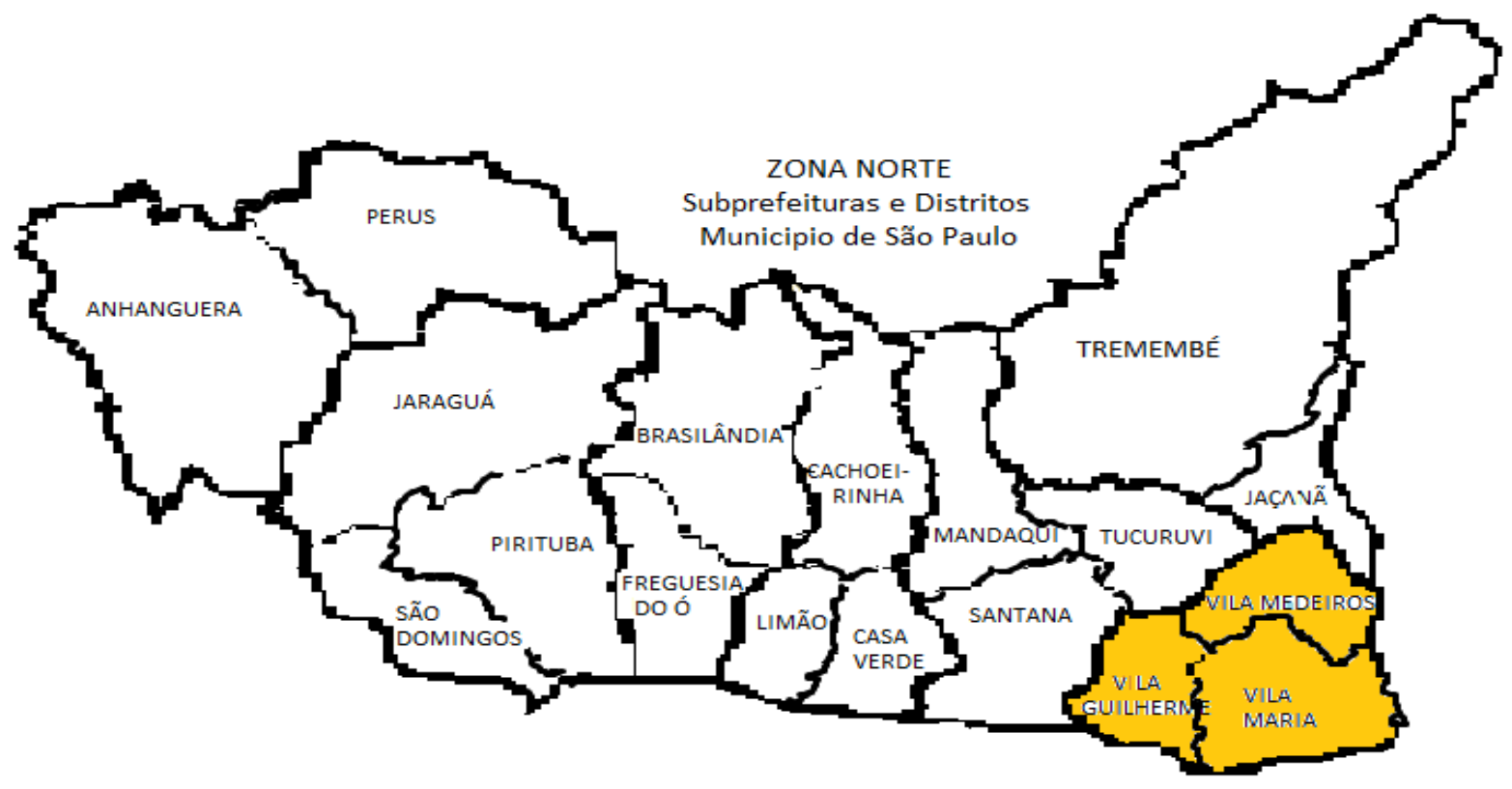

Fonte:http://infocidade.prefeitura.sp.gov.br/mapas/3_regioes_subprefeituras_e_distritos_2014_10338. pdf 
Quadro 1 - Estabelecimentos de Saúde, Subprefeitura Vila Maria / Vila Guilherme. São Paulo 2017.

\begin{tabular}{|c|c|c|}
\hline Rede de Atenção à saúde & Quantidade & Serviço de Saúde \\
\hline Atenção Primária & 10 & $\begin{array}{l}\text { Unidades Básicas de Saúde - UBS / } \\
\text { Duas unidades ESF }\end{array}$ \\
\hline \multirow{4}{*}{$\begin{array}{l}\text { Atenção Primária e } \\
\text { Secundária }\end{array}$} & 3 & $\begin{array}{c}\text { AMA / UBS Integrada. } \\
\text { (Assistência Médica Ambulatorial e Unidades } \\
\text { Básicas de Saúde Integradas) }\end{array}$ \\
\hline & 2 & $\begin{array}{c}\text { Serviço de Atenção Domiciliar - SAD } \\
\text { Programa Melhor em Casa }\end{array}$ \\
\hline & 1 & NASF- Núcleo de Apoio à Saúde da Família \\
\hline & 1 & $\begin{array}{l}\text { Unidade de Referência Saúde do Idoso - } \\
\text { URSI }\end{array}$ \\
\hline \multirow{3}{*}{$\begin{array}{c}\text { Rede de Atenção } \\
\text { Especializada Ambulatorial }\end{array}$} & 1 & Hora Certa - Hospital Dia \\
\hline & 1 & Hora Certa - Hospitalar \\
\hline & 1 & $\begin{array}{l}\text { Assistência Médica Ambulatorial de } \\
\text { Especialidade - AMA E }\end{array}$ \\
\hline \multirow{2}{*}{$\begin{array}{l}\text { Atenção às Urgências e } \\
\text { Emergências }\end{array}$} & 1 & Pronto Socorro Municipal - PSM \\
\hline & 1 & Hospital Municipal \\
\hline \multirow[t]{2}{*}{ Atenção à Saúde Mental } & 1 & $\begin{array}{c}\text { CAPS I -II - Centro de Atenção Psicossocial } \\
\text { Infanto-juvenil }\end{array}$ \\
\hline & 1 & $\begin{array}{l}\text { CECCO - Centro de Convivência e } \\
\text { Cooperativa }\end{array}$ \\
\hline Atenção à Saúde Bucal & 1 & $\begin{array}{l}\text { CEO - Clínica de Especialidades } \\
\text { Odontológicas }\end{array}$ \\
\hline Atenção à Reabilitação & 1 & $\begin{array}{c}\text { CER III - Centro Especializado em } \\
\text { Reabilitação III } \\
\text { Núcleos Integrados de Reabilitação (NIR), de } \\
\text { Saúde Auditiva (NISA) e do Programa de } \\
\text { Acompanhante da Pessoa com Deficiência } \\
\text { (APD) }\end{array}$ \\
\hline \multirow[t]{2}{*}{ Atenção Secundária } & 1 & Unidade de Apoio Diagnóstico e Terapia \\
\hline & 1 & Supervisão de Vigilância em Saúde - SUVIS \\
\hline
\end{tabular}

Fonte:http://www.prefeitura.sp.gov.br/cidade/secretarias/upload/saude/arquivos/organizacao/TabelaE stabServSUBPREF.pdf

http://www.prefeitura.sp.gov.br/cidade/secretarias/upload/saude/ANEXOVDESCRICAOTECNICAVILA MARIAVILAGUILHERME.pdf 


\subsection{POPULAÇÃO DO ESTUDO}

A população do estudo contemplou gestantes com diagnóstico de Sífilis, que realizaram o pré-natal nos anos de 2015 e 2016, na UBS Vila Izolina Mazzei, no município de São Paulo.

\subsection{ASPECTOS ÉTICOS}

Respeitando os pressupostos da Resolução 466/2012, para efetivação da pesquisa, fez-se necessário, a obtenção da carta de anuência do Coordenador de Saúde da Região Norte (anexo I), seguida da carta de aprovação do Comitê de Ética em Pesquisa (CEP) da Escola de Enfermagem da USP, concedida em 19/06/2017, sob numeração do Certificado de Apresentação para Apreciação Ética - CAAE: 67782417.3.0000.5392 (anexo II) e da aprovação do CEP da Secretaria Municipal da Saúde de São Paulo, em 01/08/2017, sob a numeração CAAE: 67782417.3.3001.0086 (anexo III). O CEP da SMS-SP não autorizou a solicitação de dispensa do TCLE, embora tratando-se de dados secundários, assim, a pesquisadora elaborou o TCLE a ser apresentado às gestantes, para obtenção da anuência e prosseguimento com a pesquisa (Apêndice A).

\subsection{COLETA DE DADOS}

Posteriormente à aprovação dos CEPs, foi realizada a análise do banco de dados Institucional, para identificação das gestantes com diagnóstico de sífilis gestacional, que realizaram o pré-natal nos anos de 2015 e 2016 na UBS Vila Izolina Mazzei. Foram selecionadas todas as gestantes identificadas neste período, independente da idade, raça ou local de residência. Essas gestantes foram contatadas previamente por telefone, e foi agendado um horário de atendimento na unidade de saúde para maiores esclarecimentos sobre a pesquisa que seria desenvolvida e para obter autorização por meio da ciência ao Termo de Consentimento Livre e Esclarecido - TCLE, se assim concordassem. No caso de impossibilidade de contato telefônico com as gestantes, a pesquisadora dirigiu-se 
até as residências das mesmas para realizar o contato, vivenciando dificuldades nesta etapa, considerando a distância e barreiras de acesso às residências das gestantes envolvidas no banco de dados, havendo necessidade de retorno repetidas vezes, por não encontrá-las na residência e em alguns casos, não residindo mais no endereço de cadastro, sendo necessário obter informações com moradores do local, sobre o endereço atual da gestante e seguir com a busca, para a obtenção da anuência, com assinatura do TCLE.

A coleta dos dados foi realizada através da utilização de um instrumento elaborado especificamente para a pesquisa em pauta, viabilizando a captação de informação sobre a assistência prestada às gestantes com sífilis durante a consulta de pré-natal, com base nas Portarias do Ministério da Saúde sobre a Consulta de Pré Natal, focando no diagnóstico, tratamento e cura da sífilis na gestação (Apêndice B).

As informações foram obtidas através do acesso aos bancos de dados, nos Sistemas de Informação da Secretaria Municipal de Saúde, da Cidade de São Paulo, pelo Programa Mãe Paulistana / SISPrenatal, desenvolvido pelo DATASUS; acrescido das informações do Sistema de Informação de Agravo de Notificação de Sífilis em Gestantes, no ano de 2015 e 2016, obtidas junto ao setor de Vigilância Epidemiológica da Secretaria Municipal de Saúde, da Coordenadoria Regional de Saúde Norte e do Sistema de controle das coleta de exames sorológicos, da Secretaria Municipal de Saúde - (MATRIXNET).

A coleta buscou, obter dados referentes à caracterização da gestante com diagnóstico de sífilis (etnia, idade, escolaridade, atividade ocupacional, composição do convívio familiar e antecedentes obstétricos), números de consultas de pré natal realizadas, idade gestacional no início do pré-natal, período gestacional no diagnóstico da sífilis gestacional, classificação clínica da doença, esquema de tratamento realizado à gestante, segundo a classificação clínica da doença, esquema de tratamento prescrito e efetivamente realizado junto à parceria e continuidade no controle da titulação sorológica, conforme as Portarias de Cuidado Pré Natal. 


\subsection{DESCRIÇÃO DOS DADOS INVESTIGADOS}

1. Características sociodemográficas (Idade, etnias, escolaridade em anos de estudo, etnia versus escolaridade, atividade ocupacional e Composição do convívio familiar). A variável etnia, será apresentada conforme as cinco categorias descritas pelo Instituto Brasileiro de Geografia e Estatística - IBGE, a saber: branca, parda, preta, amarela e indígena (IBGE 2018).

2. Antecedentes Obstétricos (número de gestação, aborto, paridade).

3. Assistência pré-natal (Início do pré-natal, consultas, exames sorologias para sífilis, tratamento da sífilis).

4. Tratamento da parceria.

\subsection{PROCESSAMENTO E ANÁLISE DOS DADOS}

Os dados estatísticos, foram consolidados em planilhas do Sistema Operacional da Microsoft Windows 7 Professional, com Office Excel® 2007. Os dados analisados foram representados em gráficos e tabelas para sua organização e a análise das variáveis do estudo foram descritas em frequências absoluta e relativa. 
4. Resultados 


\section{RESULTADOS}

\subsection{CONTEXTO DO ESTUDO}

A Unidade Básica de Saúde Vila Izolina Mazzei, apresentou no sistema Sisprenatal - Mãe Paulistana, o cadastro de 181 gestantes que iniciaram o pré natal no ano de 2015, destas, 146, iniciaram em período menor à 120 dias de gestação e 35 , posteriormente à 120 dias de gestação. No que se refere à faixa etária, 26 gestantes apresentaram idade de 15 a 19 anos, 81 com idade de 20 a 29 anos e 74 , de 30 a 49 anos. A característica étnica autodeclarada, contemplou 101 gestantes brancas, 10 pretas, 04 amarelas, 48 pardas, 01 indígena e 17 não declaradas.

Considerando as gestantes que iniciaram o pré-natal em 2015, acima descritas, mais as que já se encontravam em acompanhamento, soma-se um total de 313 gestantes, registrando 1.740 consultas de pré-natal no ano de 2015. Há registro de 143 consultas de puerpério, sendo 122 consultas realizadas em período menor 42 dias após o parto e 21 consultas ocorreram posteriormente a 42 dias do parto. Consta registro de 55 casos de interrupção ao pré-natal, destes, 16 casos de abortamento, 16 abandonos, 11 casos por mudança de município, 01 caso de óbito, 02 casos optaram por continuidade no convênio, 02 casos desvinculado por cadastro duplo e 07 casos cadastrados desvinculados por outros motivos não especificados (ver tabela 01)

No ano de 2016, a Unidade Básica de Saúde Vila Izolina Mazzei, registrou no Sistema Sisprenatal - Mãe Paulistana, o cadastro de 175 gestantes que iniciaram o pré-natal naquele ano. Destas, 150 gestantes em período menor a 120 dias de gestação e 25 posteriormente a 120 dias de gestação. A faixa etária contemplou 26 gestantes com idade de 15 a 19 anos, 97 de 20 a 29 anos e 52 de 30 a 49 anos. A característica étnica autodeclarada, contemplou: 100 gestantes brancas, 07 pretas, 02 amarela, 42 pardas e 24 não declaradas.

Considerando as gestantes que iniciaram o pré-natal em 2016, acima descritas, mais as que já se encontravam em acompanhamento, soma-se um total de 356 gestantes, registrando 1.879 consultas de pré-natal no ano. Ocorreram 150 consultas de puerpério, sendo 123 consultas realizadas em período menor a 42 dias 
após o parto e 27 consultas posteriormente a 42 dias após o parto. Foram registrados 82 casos de interrupção ao pré-natal, destes 26 abortos, 16 abandonos, 12 casos por mudança de município, 08 casos optaram por dar continuidade no convênio, 06 casos desvinculados por cadastro duplo e 14 casos desvinculados por outros motivos não especificados (ver tabela 01 ).

Tabela 1 - Caracterização das Gestantes; Pré natal e puerpério realizados nos anos 2015 e 2016 na Unidade Básica de Saúde Vila Izolina Mazzei. São Paulo, 2018.

\begin{tabular}{|c|c|c|c|c|}
\hline \multirow[b]{2}{*}{ CARACTERIZAÇÃO } & \multicolumn{2}{|c|}{2015} & \multicolumn{2}{|c|}{2016} \\
\hline & $\mathbf{N}$ & $\%$ & $\mathbf{N}$ & $\%$ \\
\hline $\begin{array}{l}\text { GESTANTES ACOLHIDAS } \\
\text { Período }<120 \text { dias } \\
\text { Período }>120 \text { dias } \\
\text { Total }\end{array}$ & $\begin{array}{c}146 \\
35 \\
181\end{array}$ & $\begin{array}{c}81 \\
19 \\
100\end{array}$ & $\begin{array}{c}150 \\
25 \\
175\end{array}$ & $\begin{array}{c}86 \\
14 \\
100\end{array}$ \\
\hline \multicolumn{5}{|l|}{ FAIXA ETÁRIA } \\
\hline $\begin{array}{l}15 \text { a } 19 \text { Anos } \\
20 \text { a } 29 \text { Anos } \\
30 \text { a } 49 \text { Anos } \\
\text { Total }\end{array}$ & $\begin{array}{c}26 \\
81 \\
74 \\
181\end{array}$ & $\begin{array}{c}15 \\
45 \\
40 \\
100\end{array}$ & $\begin{array}{c}26 \\
97 \\
52 \\
175\end{array}$ & $\begin{array}{c}15 \\
55 \\
30 \\
100\end{array}$ \\
\hline \multicolumn{5}{|l|}{ ETNIA } \\
\hline $\begin{array}{l}\text { Branca } \\
\text { Parda } \\
\text { Preta } \\
\text { Indígena } \\
\text { Amarela } \\
\text { Não informado }\end{array}$ & $\begin{array}{c}101 \\
48 \\
10 \\
01 \\
04 \\
17\end{array}$ & $\begin{array}{r}56 \\
27 \\
5,5 \\
0,5 \\
2 \\
9\end{array}$ & $\begin{array}{c}100 \\
42 \\
07 \\
- \\
02 \\
24\end{array}$ & $\begin{array}{c}57 \\
24 \\
4 \\
- \\
01 \\
14\end{array}$ \\
\hline Total & 181 & 100 & 175 & 100 \\
\hline $\begin{array}{l}\text { CONSULTAS DE PUERPÉ } \\
\text { Até } 42 \text { dias } \\
>42 \text { dias } \\
\text { Total }\end{array}$ & $\begin{array}{c}122 \\
21 \\
143\end{array}$ & $\begin{array}{c}85 \\
15 \\
100\end{array}$ & $\begin{array}{l}123 \\
27 \\
150\end{array}$ & $\begin{array}{c}82 \\
18 \\
100\end{array}$ \\
\hline \multicolumn{5}{|c|}{ INTERRUPÇÃO PRÉ NATAL } \\
\hline $\begin{array}{l}\text { Aborto } \\
\text { Abandono } \\
\text { Mudança de município } \\
\text { Óbito } \\
\text { Convênio } \\
\text { Cadastro duplo } \\
\text { Outros motivos } \\
\text { Total }\end{array}$ & $\begin{array}{l}16 \\
16 \\
11 \\
01 \\
02 \\
02 \\
07 \\
55\end{array}$ & $\begin{array}{c}29 \\
29 \\
20 \\
1,8 \\
3,6 \\
3,6 \\
13 \\
100\end{array}$ & $\begin{array}{c}26 \\
16 \\
12 \\
- \\
08 \\
06 \\
14 \\
82\end{array}$ & $\begin{array}{c}32 \\
19 \\
15 \\
- \\
10 \\
7 \\
17 \\
100\end{array}$ \\
\hline
\end{tabular}




\subsection{CARACTERIZAÇÃO - UNIVERSO DO ESTUDO}

A Unidade Básica de Saúde Vila Izolina Mazzei, apresentou um total de 356 gestantes cadastradas no sistema Sisprenatal - Mãe Paulistana, que iniciaram o pré-natal nos anos de 2015 e 2016. Destas, identificaram-se 14 gestantes com diagnósticos de sífilis, sendo 07 gestantes em 2015 e 07 gestantes em 2016.

Essas 14 gestantes apresentaram as seguintes variáveis sócio demográficas: Com relação à faixa etária, todas elas tinham idades que variavam de 15 a 33 anos, contemplando três gestantes com idade entre 15 a 19 anos, (21,43\%), 10 gestantes com idade entre 20 à 29 anos, (71,43\%) e uma gestante com idade entre 30 a 39 anos, $(7,14 \%)$.

Com relação à classificação Étnica: 06 gestantes brancas (43\%), 06 gestantes pardas (43\%) e 2 gestantes não declaradas (14\%).

Com relação ao nível de escolaridade em anos de estudo: seis gestantes com escolaridade entre 4 a 7 anos estudo (43\%), sete gestantes entre 8 a 11 anos de estudos (50\%) e uma gestante com 12 anos ou mais de estudo (7\%).

Com relação à situação de convívio familiar: três gestantes convivem com companheiro com laços conjugais e sem filhos (21,42\%), duas convivem com companheiro com filhos e/ou outros familiares (14,29\%), uma convive com companheiro e filho $(7,14 \%)$, seis convivem com familiares sem companheiro $(42,86 \%)$ e duas não informaram convívio (14,29\%).

Com relação ao desenvolvimento de atividades remuneradas ou não: 09 gestantes não realizavam atividade remunerada no período gestacional $(64,0 \%)$ e cinco desenvolviam atividade remunerada durante o período de gestação $(36,0 \%)$. (ver tabela 02)

A correlação da variável étnica com o nível de escolaridade em anos de estudo foi: entre as seis gestantes autodeclaradas brancas, duas apresentaram de 4 a 7 anos de estudos; três de 08 a 11 anos de estudo e uma gestante apresentou 12 anos ou mais de estudo. Entre as seis gestantes autodeclaradas pardas, três apresentaram de 4 a 7 anos de estudos; três tinham de 08 a 11 anos de estudo e entre as duas gestantes com etnias não declaradas, uma tinha de 4 a 7 anos de estudo e a outra de 08 a 11 anos de estudo (ver gráfico 01 ). 
Tabela 2 - Caracterização das gestantes com diagnóstico de sífilis, que iniciaram o pré-natal nos anos 2015 e 2016 na Unidade Básica de Saúde Vila Izolina Mazzei. São Paulo-2018.

VARIÁVEIS SOCIODEMOGRAFICA

\section{FAIXA ETÁRIA}

$<20$ Anos

20 a 29 Anos

30 a 40 Anos n $\%$

\begin{tabular}{c|r}
\hline 03 & 21,43 \\
10 & 71,43 \\
1 & 7,14
\end{tabular}

\section{ETNIA}

Parda

06

43

Branca

06

Não Informado

02

43

14

\section{ESCOLARIDADE (em anos)}

12 Anos ou mais

08 a 11 Anos

04 A 07 Anos
01

07

06

Gestantes convivem com companheiro com

\section{SITUAÇÃO FAMILIAR}

laços conjugais sem filho

Gestantes convivem com companheiro com filhos e/ou outros familiares

Gestante convive com companheiro e filho

Gestante convive com familiares sem companheiro.

Gestante não informaram convívio

\section{REALIZA ATIVIDADE REMUNERADA}


Gráfico 1 - Caracterização das gestantes com sífilis na Unidade Vila Izolina Mazzei, Correlação entre a Etnia e o Nível de Escolaridade em anos de estudo. São Paulo2018

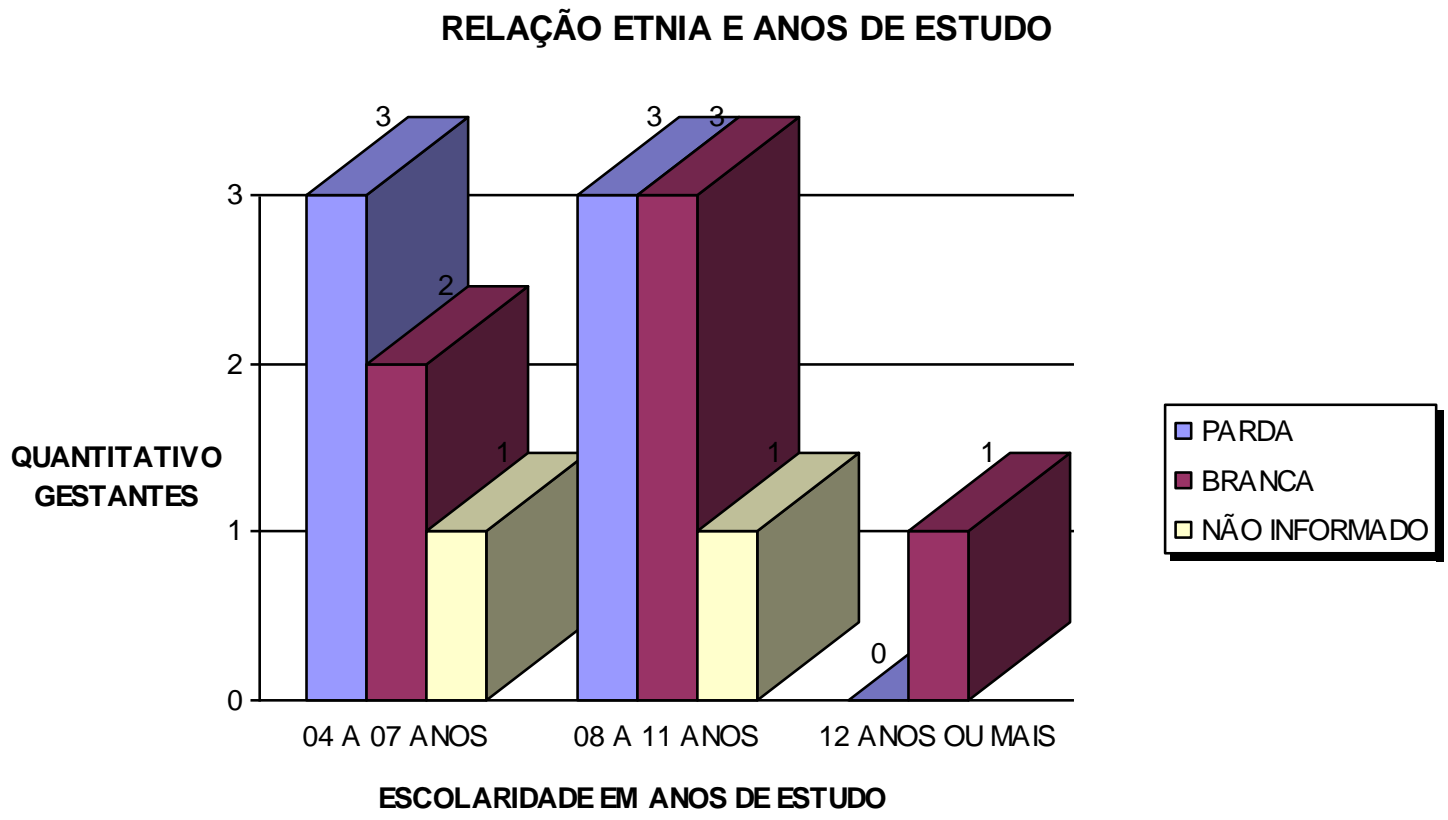

No que diz respeito à variável Antecedentes Obstétricos, constatou-se gestantes em situação de primigesta à sextigesta. Destas, 09 eram primigestas (64\%), uma secundigesta (7\%) e quatro multigestas (29\%) Quanto ao número de filhos, 09 eram nulíparas (64\%), uma primípara (7\%) e 4 eram multíparas (29\%), entre estas gestantes há histórico de 2 abortos. (ver tabela 03). 
Tabela 3 - Antecedentes obstétricos das gestantes com diagnóstico de sífilis da UBS Izolina Mazzei, que iniciaram pré-natal no ano 2015 e 2016. São Paulo- 2018.

\begin{tabular}{llc}
\hline Variáveis Antecedentes Obstétricos & $\mathbf{n}$ & $\%$ \\
\hline NÚMERO GESTAÇÃO & & 64 \\
Primigesta & 09 & 7 \\
Secundigesta & 01 & 29 \\
Multigesta & 04 & \\
NÚMERO PARIDADE & & 64 \\
Nulípara & 09 & 07 \\
Primípara & 01 & 29 \\
Multípara & 04 & \\
NÚMERO FILHOS & & 64 \\
Sem filhos & 09 & 14 \\
Até 2 filhos & 02 & 22 \\
$>$ dois filhos & 03 & \\
HISTÓRICO DE ABORTO & & 93 \\
Sem histórico de aborto & 13 & 07 \\
Até 02 abortos & 01 & \\
\hline
\end{tabular}

No que se refere à variável Assistência ao Pré Natal, a relação das gestantes que iniciaram o pré natal no primeiro trimestre gestacional, considerando a Data da Última Menstruação - DUM, até a data de atendimento na UBS, totalizou 12 gestantes, com início do pré natal no primeiro trimestre gestacional (86\%) e duas iniciaram o pré natal no segundo trimestre gestacional (14\%). (ver Gráfico 2 ). 
Gráfico 2 - Distribuição das gestantes, de acordo com a semana gestacional, no início do pré-natal na UBS Izolina Mazzei nos anos de 2015 e 2016. São Paulo 2018

IDADE GESTACIONAL NO INICIO PRÉ NATAL

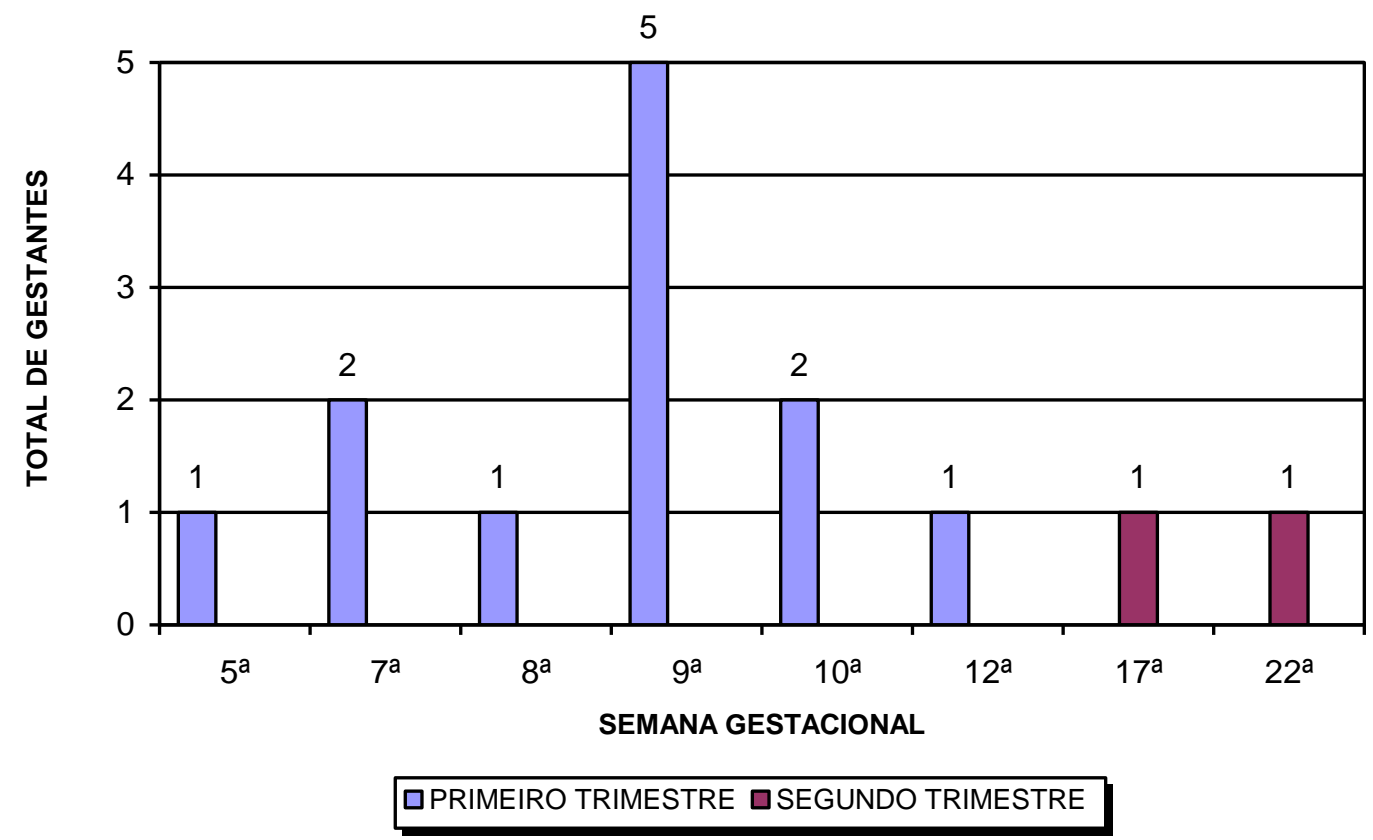

As 12 gestantes que iniciaram o pré-natal no primeiro trimestre gestacional, realizaram de 02 a 13 consultas de pré-natal. Referente à gestante que realizou 02 consultas de pré-natal, consta a informação no sistema da Prefeitura SP -Mãe Paulistana, que esta foi presa aos quatro meses de gestação, após início do prénatal, impossibilitando a continuidade das consultas de pré-natal pela Unidade Básica de Saúde. Quanto às duas gestantes que iniciaram pré-natal no segundo trimestre gestacional, realizaram um total de 03 e 09 consultas de pré-natal. (Ver Gráfico 3). 
Gráfico 3 - Número de consultas de pré-natal, em gestantes com sífilis, realizadas na UBS Vila Izolina Mazzei. São Paulo-2018.

TOTAL DE CONSULTA DE PRÉ NATAL

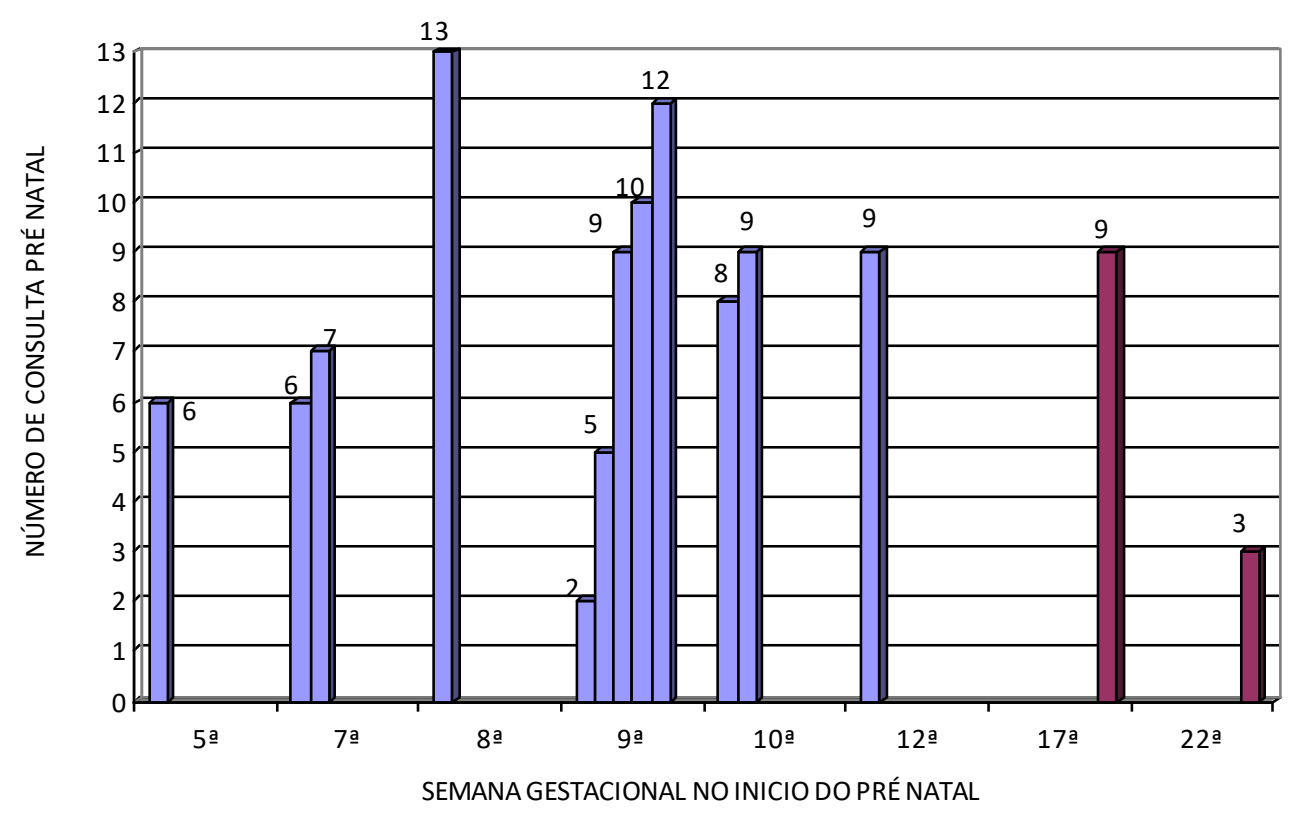

A realização do primeiro exame de sorologia para pesquisa de sífilis na gestação, foi realizado por 08 gestantes ainda no primeiro trimestre gestacional (57\%) e 06 gestantes realizaram no segundo trimestre de gestação (43\%). Dentre as 08 gestantes que realizaram a sorologia de sífilis no primeiro trimestre gestacional, 07 obtiveram o diagnóstico na primeira investigação realizada e uma obteve o diagnóstico na segunda investigação com 22 semanas de gestação (2a trimestre gestacional). Das 06 gestantes que realizaram o primeiro exame de sorologia para sífilis no segundo trimestre gestacional, cinco obtiveram o diagnóstico nesta primeira investigação e uma obteve o diagnóstico na realização de um novo exame, já no terceiro trimestre, na trigésima semana gestacional (Ver Gráfico 4). Quanto à classificação clínica da doença, não foi possível identificar o estágio da mesma, por não constar dados nos arquivos pesquisados. 
Gráfico 4 - Idade Gestacional na primeira investigação da sífilis, relacionada à ldade gestacional no diagnóstico da sífilis. São Paulo - 2018.

IDADE GESTACIONAL NA INVESTIGAÇÃO E NO DIAGNÓSTICO DA SÍFILIS
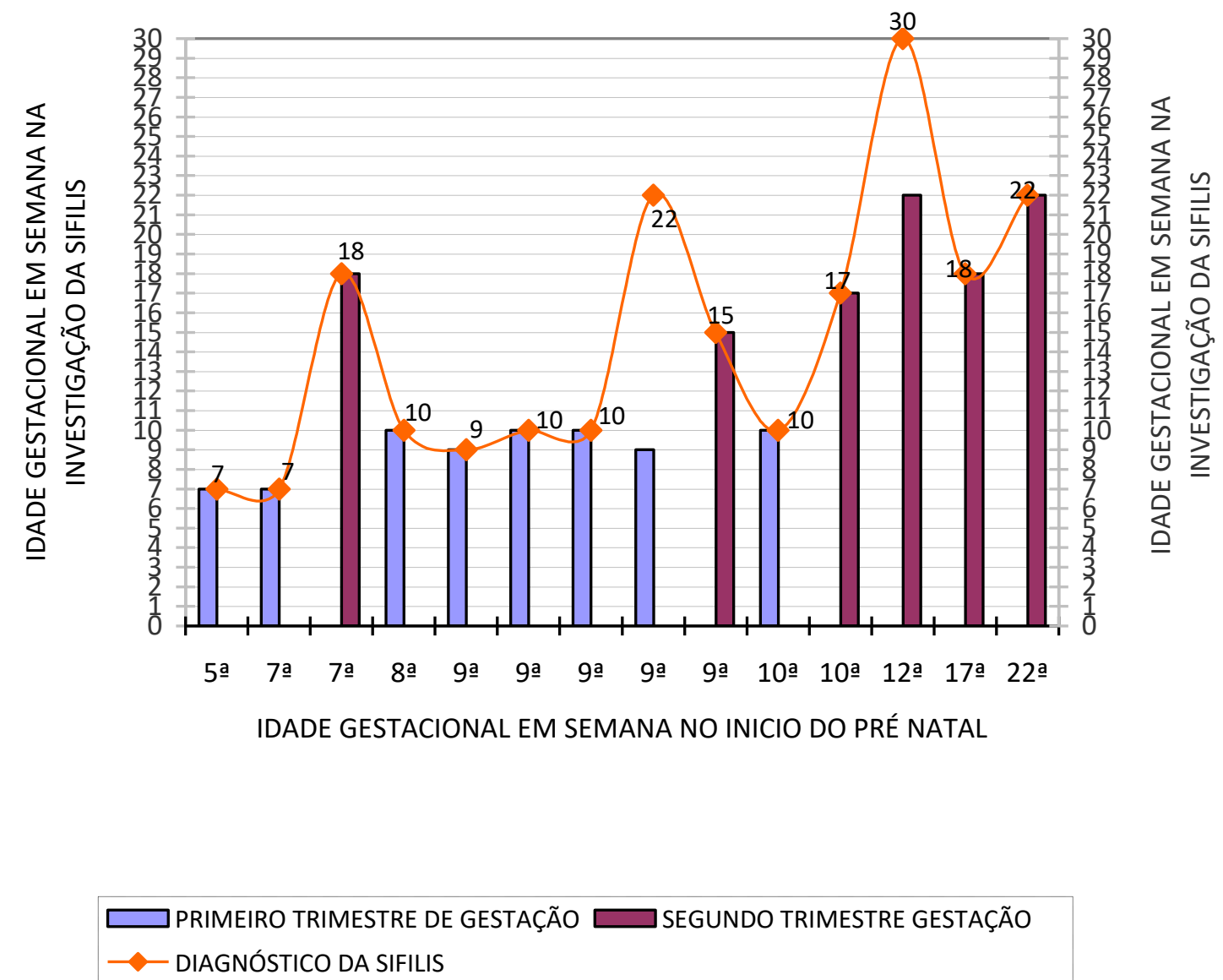

Com relação à repetição do exame sorológico para controle da titulação, duas gestantes não realizaram novos exames sorológicos, um dos casos, refere-se à gestante que foi presa no período gestacional, conforme informação no sistema da Prefeitura SP- Mãe Paulistana, impossibilitando a continuidade dos exames. As demais gestantes realizaram a segunda investigação dentro de um período de 30 a 150 dias (ver gráfico 5). 
Gráfico 5 - Período em dias entre o diagnóstico da sífilis e o exame de controle da titulação e cura. Gestantes com sífilis acompanhadas na UBS Vila Izolina Mazzei. São Paulo - 2018.

PERIODO EM DIAS ENTRE O DIAGNÓSTICO DA SíFILIS E O CONTROLE DA TITULAÇÃO

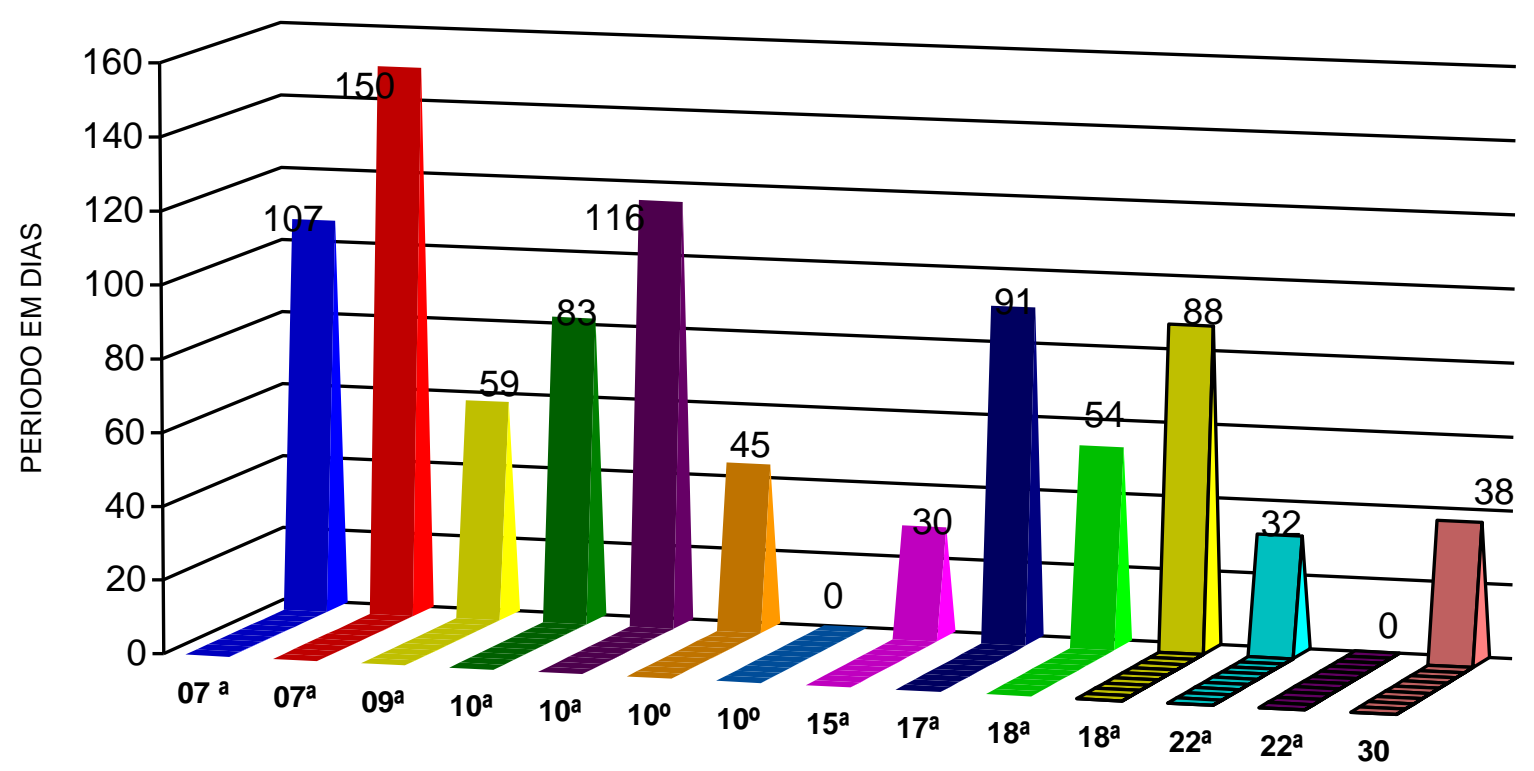

IDADE GESTACIONAL EM SEMANA NO DIAGNÓSTICO DA SÍFILIS

O quantitativo de exames sorológicos posteriores ao diagnóstico, mostrou que $57 \%$ das gestantes realizaram 2 exames posteriores ao diagnóstico da sífilis, 7\% realizou 3 exames, 22\% realizaram um exame e 14\% não repetiram o exame. (Ver Gráfico 06). Constatou-se uma mediana de dois exames investigativos por gestante, para controle da titulação sorológico para sífilis. 
Gráfico 6 - Número de exames sorológicos posteriores ao diagnóstico da sífilis para controle da doença. São Paulo - 2018.

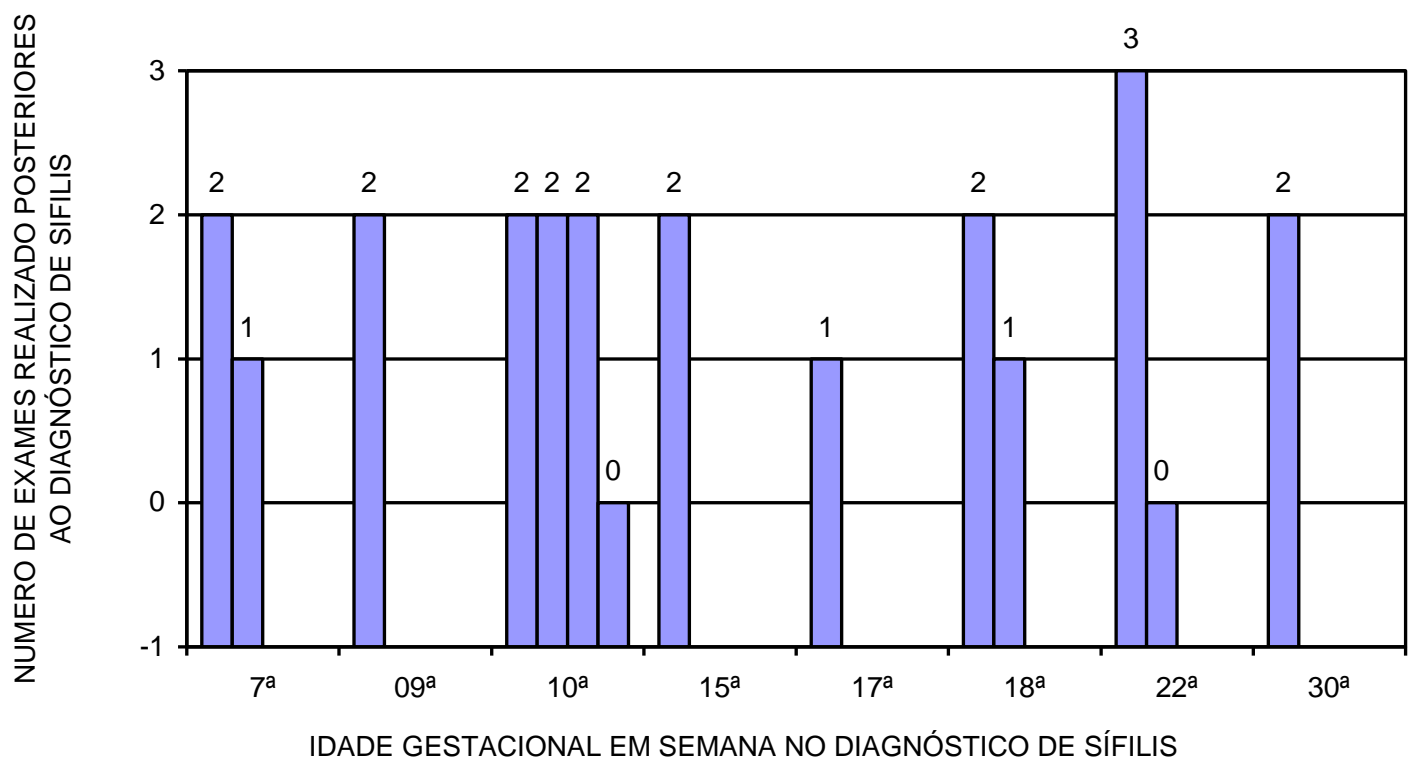

Em relação ao tratamento realizado, 13 gestantes realizaram o tratamento com esquema de 7200.000 UI de Penicilina G Benzatina (93\%) e uma realizou o tratamento com esquema de 4800.000 UI de Penicilina G Benzatina (7\%), não completando o tratamento prescrito de $7200.000 \mathrm{UI}$.

No que se refere ao tratamento dos parceiros das 14 gestantes com sífilis, somente um parceiro realizou o tratamento com esquema de 7200. $000 \mathrm{UI}$ de Penicilina G Benzatina (7\%), os demais (93\%) não realizaram o tratamento.

O espaço de tempo em dias decorridos, entre o diagnóstico da sífilis na gestação, até o início do tratamento das gestantes, foi de 06 a 97 dias para o inicio do tratamento (Ver Gráfico 7 e 8). 
Gráfico 7 - Período da semana gestacional no exame diagnóstico da sífilis e no início do tratamento da sífilis das gestantes acompanhas na UBS Vila Izolina Mazzei. São Paulo - 2018.

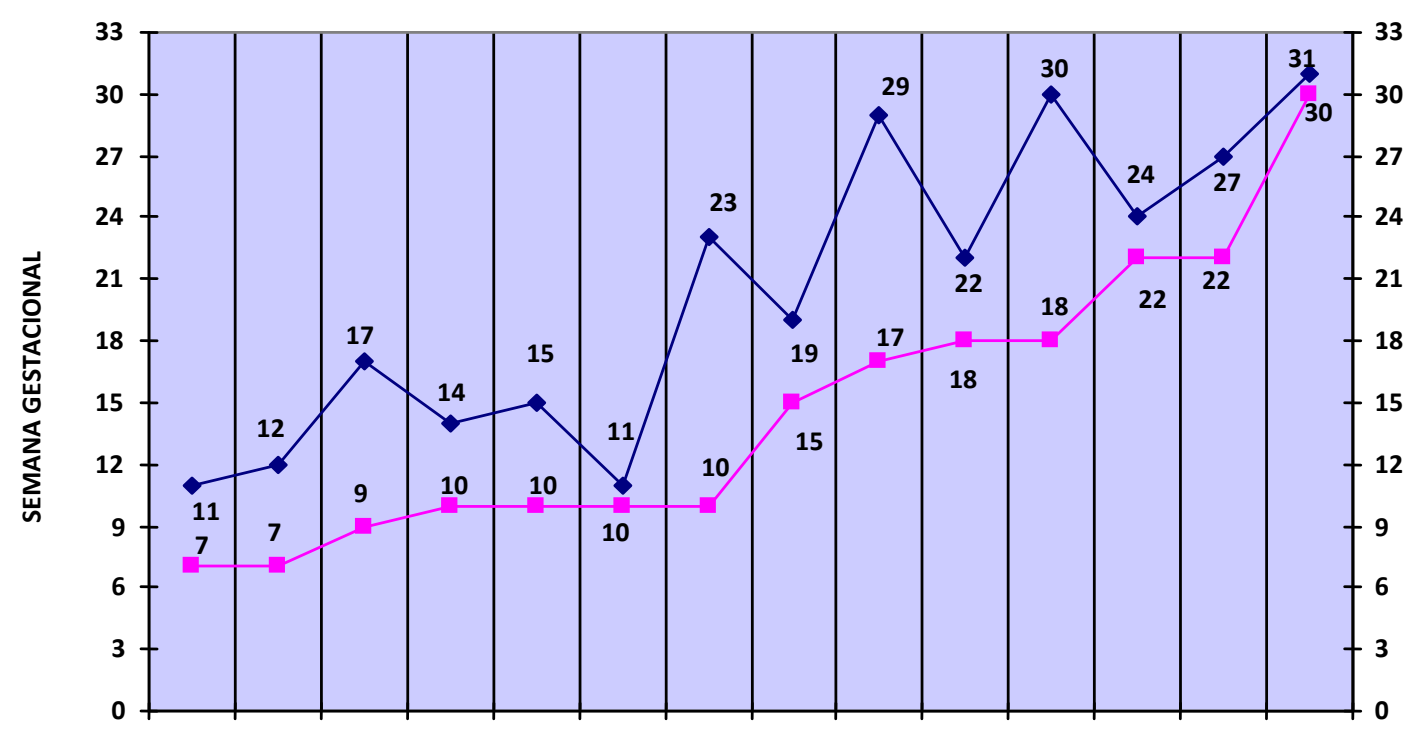

Gráfico 8 - Período em dias entre o diagnóstico e tratamento da sífilis, em gestantes acompanhas na UBS Vila Izolina Mazzei. São Paulo - 2018.

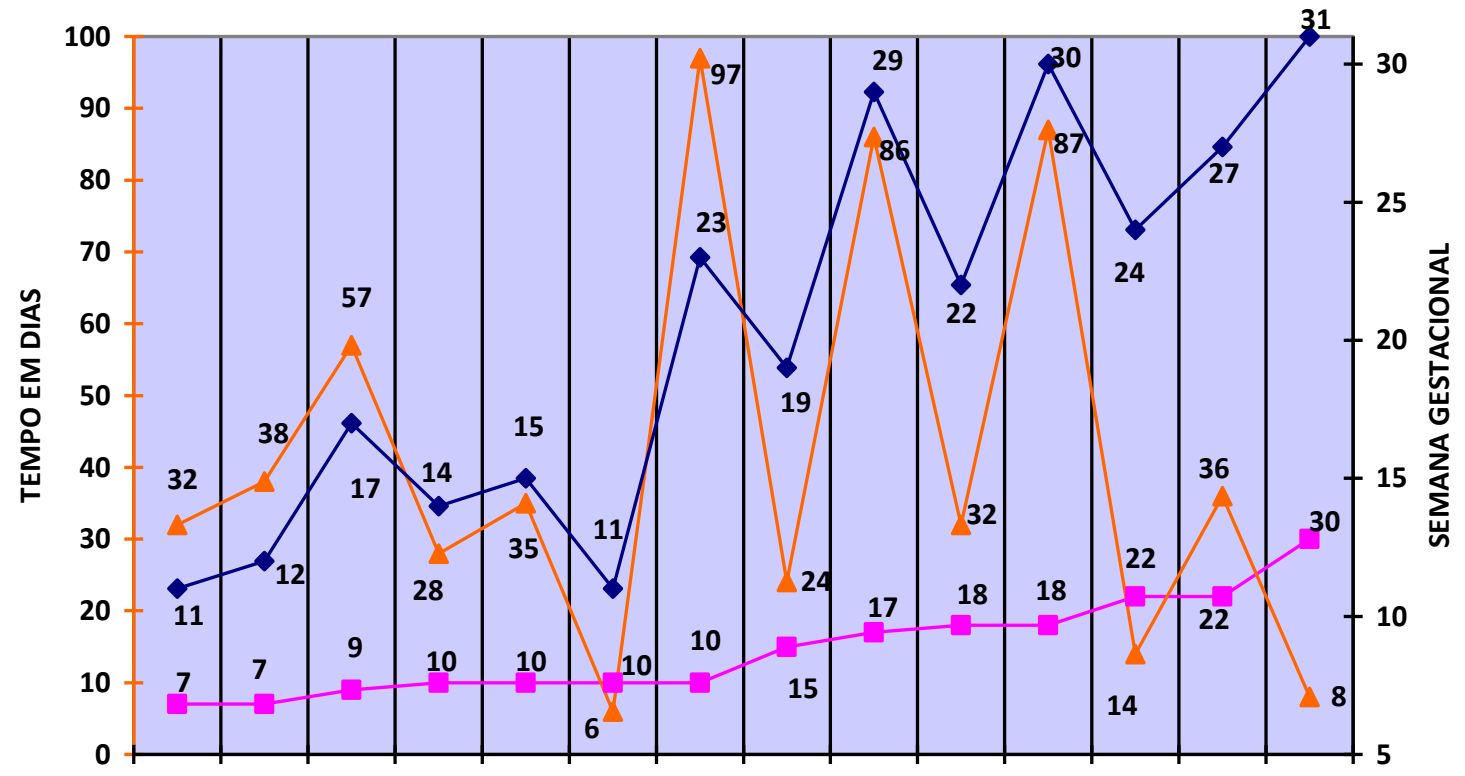


A finalização do tratamento contemplou um período de 33 a 196 dias anteriores ao parto, contudo, estes dados referem-se às oito gestantes que realizaram a consulta de puerpério, especificando a data correta do parto, destas, 07 gestantes realizaram a consulta de puerpério no período de até 42 dias. A presente pesquisa, constatou que seis gestantes não realizaram a consulta de puerpério, impossibilitando identificar possíveis ocorrências de manifestações congênitas, entre elas a gestante que foi presa no período de gestação, conforme informação disponibilizada no sistema da Prefeitura SP - Mãe Paulistana. Outra gestante, apresentou manifestação de sífilis congênita, por natimorto com 36 a semana gestacional, 24 dias após o término do tratamento com Penicilina G Benzatina. (Ver tabela 4).

No que diz respeito ao tratamento adequado ou inadequado da sífilis gestacional, apenas uma gestante foi adequadamente tratada, tendo recebido 7200.000 Ul de Penicilina G Benzatina, concomitantemente ao tratamento do parceiro e o tratamento de ambos foi finalizado 165 dias antes do parto. As demais gestantes foram consideradas inadequadamente tratadas, por não haver registro do tratamento do parceiro (Ver tabela 4). 
Tabela 4 - Puerpério e tratamento das gestantes com diagnóstico de sífilis e suas parcerias. UBS Vila Izolina Mazzei 2015 e 2016. São Paulo - 2018

\begin{tabular}{lll}
\hline \multicolumn{1}{c}{ Variáveis } & $\mathbf{N}$ & $\%$ \\
\hline GESTANTES COM CONSULTA PUERPÉRIO & & 57 \\
Realizado & 08 & 43 \\
Não realizado & 06 & $\%$
\end{tabular}

\section{PERIODO DA CONSULTA PUERPÉRIO}

Até 42 dias após parto

\section{TRATAMENTO GESTANTES COM PENICILINA G}

\section{BENZATINA}

Realizado conforme prescrição

Não realizado conforme prescrição

\section{TRATAMENTO DE PARCEIROS - PENICILINA G}

\section{BENZATINA}

Realizado conforme prescrição

\section{TRATAMENTOS INADEQUADOS *}

Gestante não tratada adequadamente

Parceria não tratada

Gestantes tratamento finalizado $>30$ dias do parto

08

\section{7}

\footnotetext{
* Os sujeitos da pesquisa apresentaram mais de um motivo de inadequação do tratamento
} 


\section{Discussão}




\section{DISCUSSÃO}

\subsection{CARACTERIZAÇÃO - UNIVERSO DO ESTUDO}

Em relação ao perfil sociodemográfico do universo de estudo, classificando as gestantes por faixa etária, $21,43 \%$ tinham idade de 15 a 19 anos; $71,43 \%$ de 20 a 29 anos e 7,14\% de 30 a 39 anos. Observa-se que a maior proporção ocorreu nas gestantes com faixa etária de 20 a 29 anos, um dado esperado, considerando que $50 \%$ do total de gestantes acolhidas na UBS, apresentavam a mesma faixa etária, ou seja, entre 20 a 29 anos. Condição semelhante foi encontrada no estudo de Soares LG et al. (2017), com $75 \%$ das gestantes com faixa etária predominante entre 20 a 34 anos. Segundo dados do Boletim Epidemiológico de Sífilis de 2017, Brasil (2017), a predominância da ocorrência de sífilis em gestantes nesta faixa etária, sustenta uma série histórica no Brasil desde 2005 até 2017.

A proporção de gestantes com sífilis de 15 a 19 anos, superior àquela observada em gestantes de 30 a 39 anos, surpreende, considerando que na UBS Vila Izolina Mazzei, há mais gestantes na faixa etária de 30 a 39 anos. Dados registrados no país, mostram que a proporção de gestantes com sífilis com faixa etária de 15 a 19 anos, vem se mantendo superior às de 30 anos, desde 2011 à 2017 (Brasil, 2017).

Quanto à classificação étnica das gestantes com sífilis, os resultados da pesquisa mostraram que $43 \%$ delas se autodeclararam brancas, outras $43 \%$ se autodeclararam pardas e 14\% não declaradas. Observa-se igualdade proporcionais nos resultados entre brancas e pardas. Contudo, ao analisar o quantitativo das gestantes que iniciaram o pré - natal na UBS, nos anos de 2015 e 2016, constatouse uma porcentagem de $56 \%$ de gestantes brancas, diferente daquela constatada nas gestantes com sífilis.

Leal et al. (2017) em estudo que avaliou categorias étnicas em puérperas, obteve dados similares aos aqui encontrados, identificando numa população de 13.318 mulheres, 6.659 pardas e 6.659 brancas. Contrariamente aos resultados encontrados na pesquisa em pauta, os dados dos indicadores de sífilis nos municípios brasileiros, Brasil (2016c), revelam que as gestantes pardas predominam 
nas notificações apresentadas desde 2005 a 2015. Ainda nesse estudo dos indicadores de sífilis nos municípios brasileiros, no que se refere às gestantes com etnias não declaradas, informa que em 2015 a junho 2016, houve uma proporção de $18 \%$ de gestantes nessa condição no Brasil. Em relação às gestantes pretas, amarelas e indígenas, essas representaram apenas $8 \%$ das gestantes que iniciaram o pré-natal na UBS em 2015 e 2016, sem ocorrência de sífilis. Contudo, os indicadores de sífilis nos municípios brasileiros, Brasil (2016c), evidenciam um aumento 13 vezes maior do número de gestantes pretas com sífilis notificadas no ano de 2006 a 2015. Neste mesmo período, identificou-se, um aumento três vezes maior nas gestantes amarelas e um aumento duas vezes maior, nas gestantes autodeclaradas indígenas. Segundo Leal et al.(2005) e Araújo et al. (2011 apud Adorno et al. 2004, p. 122), a autodeclaração da cor da pele é subjetiva e há risco de provocar "fluidez" dos dados, na medida em que as pessoas de cor preta tenderiam a se autodeclarar pardas, a depender da inserção social das mesmas.

Referente ao nível de escolaridade em anos de estudo das gestantes com sífilis, 43\% delas apresentaram escolaridade entre 4 a 7 anos estudo, 50\% com 8 a 11 anos de estudos e 7\% com 12 anos ou mais de estudo. A pesquisa evidencia que a maior proporção ocorreu entre as gestantes com nível médio de estudo, contradizendo o que diz a literatura. Cunha et al. (2015), no estudo de sífilis em parturientes, identificou uma redução da prevalência da sífilis, à medida que aumenta o nível de escolaridade. Dados dos indicadores de sífilis nos municípios brasileiros, Brasil (2016c), evidenciaram que a maior proporção 43,5\% das gestantes no período de 2007 a 2015, apresentavam de 4 a 7 anos de estudos. Fortalecendo essa evidência, estudos de Maciel et al.( 2017) e Moreira et al. (2017) demonstraram que a maior proporção da doença ocorre em mulheres com baixo grau de escolaridade. Teixeira et al. (2010) corrobora, que a baixa escolaridade pode representar um agravante para saúde.

No estudo em pauta constatou-se que as gestantes autodeclaradas brancas, foram as que apresentaram maior nível de escolaridade, de 08 a 11 anos de estudo. Estudo de Leal et al. (2005), identificou que puérperas pardas e pretas apresentam menor grau de escolaridade e destaca ainda que mulheres pretas e pardas vivenciam desvantagens que ultrapassam os indicadores socioeconômicos e se estendem à assistência ao concepto. 
No que diz respeito à atividade remunerada no período gestacional, 64,0\% das gestantes não realizavam atividade remunerada e 36,0\% delas desenvolviam atividade remunerada durante o período de gestação. Resultados similares foram descritos no município de Porto Velho, onde Moreira et al. (2017), identificaram que $79,80 \%$ das mulheres com sífilis na gestação não exerciam atividade remunerada. Estudo de Soares LG et al. (2017), realizado no município de Guarapuava-Paraná, constatou que $75 \%$ das gestantes com sífilis ocupava-se com afazeres do lar. 0 estudo de Campos et al. (2010), constatou que a sífilis ocorreu majoritariamente nas gestantes com renda familiar menor que um salário mínimo. Resultados semelhantes foram descritos no estudo de Magalhães et al. (2013), em que a baixa renda pôde ser associada à maior prevalência da doença.

Teixeira et al. (2010) constataram que a renda familiar representa um indicador de saúde, demonstrando que as populações mais vulneráveis, necessitam da intervenção das políticas públicas de saúde e educação, para diminuição das desigualdades sociais.

No que se refere à situação de convívio familiar, a estudo identificou que $43 \%$ das gestantes convivem com companheiro, outras $43 \%$ convivem com familiares sem companheiro e $14 \%$ das gestantes não informaram convívio. Esse achado de igualdade proporcional, difere dos encontrados na literatura. Os resultados obtidos por Lafetá et al. (2016) e Magalhães et al. (2013), onde 53,8\% e 56,0\% das gestantes respectivamente, não residiam com parceiro. Em contrapartida, Soares LG et al. (2017) e Campos et al. (2010) demonstraram em seus estudos, que a maior proporção das mulheres $80 \%$ e $67 \%$ respectivamente, declararam conviver com os parceiros (casadas ou em união estável). O estudo de Rezende e Souza, (2012), evidência que a falta de um companheiro na vida das gestantes, afeta expressivamente suas condições emocionais, contribuindo negativamente nas suas qualidades de vida, quando comparadas com as gestantes casadas.

Com relação à variável antecedentes obstétricos, a pesquisa em pauta constatou que 64\% das gestantes eram primigesta e nulíparas, 07\% era secundigesta e primípara e $29 \%$ eram multigestas e multíparas. Quanto ao número de filhos, 64\% não tinham filhos, 14\% tinham até 2 filhos e 22\% tinham mais que dois filhos. No que se refere ao histórico de abortamento, 93\%, sem aborto e 07\% com até dois abortos. Esses achados diferem dos encontrados por Nonato SM et al. (2015), identificando em seu estudo $(77,8 \%)$ das gestantes com sífilis, tinha história 
de gestações anteriores, $72,2 \%$ contavam um ou mais filhos vivos - média de dois filhos por gestante e 31,7\% referiam resultados adversos (aborto ou natimorto) de gestações anteriores.

Com relação à variável Assistência ao Pré Natal, 86\% das gestantes iniciaram o pré-natal no primeiro trimestre gestacional e 14\% no segundo trimestre. Neste contexto, Campos et al. (2010), Lafetá et al. (2016) e Magalhães et al.(2013), também identificaram em seus estudos, que 46,8\%, 48,4\% e 50,7\% das gestantes,respectivamente, iniciaram o pré natal no primeiro trimestre gestacional. Conforme as normas estabelecidas nos Manuais Técnicos do Ministério da Saúde e Secretaria da Saúde, que destacam a importância do início precoce do pré-natal, preferencialmente antes do primeiro trimestre gestacional, visando intervenções preventivas ou terapêuticas em tempo oportuno, assegurando o bem estar materno e neonatal. Brasil (2000), Brasil (2005c.), Brasil (2010) e São Paulo - Estado, (2010).

O presente estudo, identificou que a maior proporção $79 \%$ das gestantes, realizaram seis ou mais consultas e $21 \%$ realizaram número inferior a seis consultas. O PHPN, estabelece a realização de no mínimo seis consultas de acompanhamento ao pré-natal, durante a gravidez, (Andreucci CB et.al. 2011), (Brasil 2002). Campos et al.(2010), Lafetá et al. (2016) e Magalhães et al. (2013), em seus estudos corroboram, atingindo maior proporção das gestantes 41,4\%, 43\% e 49,3\% respectivamente, com seis ou mais consultas. Por sua vez, Soares LG et al. (2017), revelaram que $62,5 \%$ das gestantes, realizaram mais de sete consultas de pré-natal. $\mathrm{Na}$ Rede Cegonha são preconizadas no mínimo 07 consultas de pré-natal, estabelecidas pelo Ministério da Saúde ampliando as políticas de melhoria da assistência às mulheres no período materno e perigestacional (Brasil, 2011).

Outra Normativa dos Manuais Técnicos de Saúde e do PHPN, determina a realização do exame de sorologia para sífilis (VDRL) na primeira consulta e outro na trigésima semana de gestação (Brasil, 2000), (Brasil, 2005c), (São Paulo - Estado, 2010), (Brasil, 2012).

Os resultados obtidos nesse estudo demonstraram que a realização do primeiro exame de sorologia para pesquisa de sífilis na gestação, foi realizado por $57 \%$ das gestantes, ainda no primeiro trimestre gestacional e $43 \%$ no segundo trimestre da gestação. O estudo de Silva Neto, (2017), identificou que 62,0\% das gestantes, realizaram o exame sorologia para sífilis ainda no primeiro trimestre 
gestacional, demonstrando expansão da atenção às gestantes, nos estabelecimentos de saúde, nesse critério diagnóstico estabelecido.

No presente estudo, $50 \%$ das gestantes foram diagnosticadas no primeiro trimestre gestacional, $43 \%$ no segundo trimestre e $7 \%$ no terceiro trimestre. Achados similares no estudo de Silva Neto, (2017), 57,0\% das gestantes, foi diagnosticada no primeiro trimestre de gestação, possibilitando intervenções em tempo hábil, quando necessárias.

$\mathrm{Na}$ pesquisa em pauta, a repetição do exame de sorologia para sífilis, para o controle da cura da doença, foi realizada por $86 \%$ das gestantes, com período de 30 a 150 dias após o primeiro exame e 14\% não realizaram novo exame após diagnóstico da sífilis. Difere dos resultados obtidos por Pedrosa LDCO, (2015), em que apenas $45,7 \%$ das mulheres com VRDL positivo na gestação repetiram o exame após o tratamento. Conforme protocolos vigentes nos Manuais Técnicos de Saúde e no PHPN, a repetição do exame de sorologia, no caso de soro positividade para sífilis, deve ser realizado mensalmente para controle da cura após o tratamento (Brasil, 2000), (Brasil, 2005c), (São Paulo - Estado, 2010), (Brasil, 2012).

O presente estudo mostrou que a maior proporção, 64\% das gestantes, realizaram 2 ou mais exames posteriormente ao diagnóstico da sífilis, $22 \%$ realizaram 1 exame e 14\% não o repetiram. No estudo de Soares LG et al. (2017), somente $45 \%$ das gestantes realizaram de dois ou mais exames. Campos et al. (2010) não identificou em seu estudo, a realização do segundo exame de sorologia para sífilis nas gestantes estudadas. É oportuno relembrar que a política de saúde materno-infantil no Brasil determina que na identificação de qualquer alteração dos parâmetros normais no pré-natal, exigirá a continuidade do cuidado, conforme normas registradas nos protocolos do Ministério da Saúde (Brasil, 2000), Brasil, (2005c).

Com relação ao trabalho em pauta, o tratamento da sífilis com esquema de 7.200.000 UI de Penicilina G Benzatina, conforme protocolo clínico, foi realizado por 93\% das gestantes e 7\% recebeu apenas parcialmente, 4.800.000 UI de Penicilina G Benzatina. Estes achados difere do estudo de Lins CDM, (2014), em que a maior proporção $(48,48 \%)$ das gestantes com diagnóstico de sífilis, não realizaram o tratamento e somente $(39,39 \%)$ realizaram o tratamento com penicilina benzatina. 
A penicilina benzatina foi reconhecida pela 69a Assembléia Mundial da Saúde, no primeiro semestre de 2016, como um medicamento essencial para o controle da transmissão vertical de sífilis (Brasil ,2016).

O presente estudo não identificou a fase clínica da doença, esta informação não constava nos arquivos pesquisados. Campos et al. (2010) exibe os mesmos achados.

No que se refere ao estudo ora descrito, somente $7 \%$ dos parceiros realizou 0 tratamento com esquema de 7.200.000 UI de Penicilina G Benzatina, os demais 93\% não realizaram. De acordo com a publicação da Revista de saúde Pública, (2008), do total de $56 \%$ das gestantes com diagnóstico de sífilis, somente $13,3 \%$ dos parceiros foram tratados. Contribuindo para reinfecção da gestante tratada ampliando a possibilidade da sífilis congênita. Esses dados diferem dos protocolos para o cuidado da sífilis, os quais estabelecem que todos os parceiros sexuais da gestante, expostos nos últimos 90 dias precedentes ao diagnóstico de sífilis primária, secundária ou latente precoce, com ou sem resultado reagente das provas sorológicas, deverão ser tratados presumivelmente (Brasil, 2015). Parceiros sexuais pregressos, com mais de 90 dias, de pacientes com sífilis latente, devem ser avaliados clínica e sorologicamente e tratados conforme os achados diagnósticos. Em última análise, havendo desconhecimento do status sorológico para sífilis da parceria sexual, esta deverá ser tratada ( Brasil 2015).

Ainda no que diz respeito ao presente estudo, 57\% das gestantes, completaram o tratamento até 30 dias antes do parto, outras $36 \%$ não realizaram a consulta de puerpério, impossibilitando o conhecimento sobre o desfecho da gestação e 7\% apresentou um natimorto como manifestação congênita da doença, este fato ocorreu 24 dias posteriormente ao tratamento com Penicilina G Benzatina e 47 dias anteriores à data provável do parto (DPP). Os achados de Campos et al. (2010) difere deste estudo, apresentando maior proporção 37,9\% das gestantes que finalizaram o tratamento em período menor que 30 dias antes do parto. Magalhães et al. (2013) apresentou a ocorrência de 03 caso de aborto.

Estudos recomendam que o tratamento da sífilis seja iniciado antes do quinto mês de gestação e finalizado até 30 dias antes do parto. Devendo ser realizado controle mensal da titulação da doença até o parto e caso não se identifique resposta ao tratamento realizado e/ou haja aumento de duas titulações em relação ao último título do VDRL, as gestantes, deverão ser tratadas novamente, para 
prevenir a transmissão vertical e reduzir a incidência da sífilis congênita, decorrente da ausência ou do tratamento inadequado (Magalhães et.al., 2011), (Santos, 2009), (São Paulo- Cidade, 2014), (Tayra, 2007). (São Paulo - Estado, 2010).

Nesse trabalho, apenas uma gestante foi considerada adequadamente tratada, por ter realizado o tratamento com Penicilina G Benzatina, na dosagem correta, concomitante com o parceiro, conforme protocolos vigentes. As demais (13) gestantes foram consideradas inadequadamente tratadas, por não haver registros do tratamento do parceiro (2006), Brasil (2015), Santos (2009) apud Miller (2003). 


\section{Considerações Finais}




\section{CONSIDERAÇÕES FINAIS}

Na perspectiva de realizar um diagnóstico situacional da atenção às gestantes em relação à sífilis, em uma Unidade Básica de Saúde do município de São Paulo, foi analisado as etapas de acompanhamento do pré-natal, puerpério e os processos de diagnóstico, tratamento e cura da sífilis, em consonância com os protocolos implantados pelo Ministério da Saúde. Esses protocolos, fazem parte da Política Pública Brasileira para o controle, prevenção e tratamento da sífilis gestacional em território nacional, assegurando os cuidados necessários, para a redução da morbimortalidade materna, neonatal e infantil por esse agravo.

O estudo, apresentou dados relevantes em resposta aos objetivos propostos. No que diz respeito aos fatores associados à sífilis na gestação, os resultados evidenciam que a sífilis atinge em maior proporção, gestantes com idade entre 20 a 29 anos, dados similares aos resultados encontrados na literatura.

Quanto à classificação étnica das gestantes com sífilis, os resultados da presente pesquisa apresentaram número igual entre brancas e pardas, não havendo ocorrência de sífilis nas gestantes negras, amarelas ou indígenas, diferentemente dos achados em alguns estudos, em que há um predomínio das gestantes pardas e um aumento de casos entre as gestantes negras, amarelas e indígenas.

No que se refere ao nível de escolaridade, houve maior ocorrência da doença entre as gestantes de 08 a 11 anos de estudo, diferentemente de outros estudos, em que o maior número de casos ocorreu entre as gestantes com menor nível de escolaridade de 4 a 7 anos de estudo. Contudo, os estudos corroboram que 0 alto nível de estudo (12 anos ou mais de estudo), distância a possibilidade de ocorrência da sífilis.

No que diz respeito entre a correlação etnia e escolaridade, a pesquisa revelou que as gestantes autodeclaradas brancas apresentam maior nível de escolaridade em anos de estudo, comparadas às pardas, dados confirmados com a literatura analisada.

Com relação à atividade remunerada no período gestacional, o estudo evidenciou que a maioria das gestantes não realizavam nenhuma atividade, este 
achado vem ao encontro dos resultados obtidos em diversas pesquisas, em que a baixa renda está associada à maior ocorrência da sífilis na gestação.

No que se refere à situação de convívio familiar, as gestantes que residem com companheiro e as gestantes que residem sem companheiro apresentaram a mesma proporção. A literatura não corrobora esses achados anteriormente citados, talvez, essa realidade pode estar começando a mudar.

Pertinente ao antecedente obstétrico, o estudo constatou, que a maior proporção das gestantes eram primigestas e/ou nulíparas, diferentemente da literatura analisada.

No que se refere ao segundo objetivo específico da pesquisa em pauta, que era o de analisar a assistência dos profissionais de saúde às gestantes com sífilis, o estudo constatou que as ações dos profissionais pré-natalistas, apresentaram descontinuidade na atenção às gestantes com diagnóstico de sífilis, conforme os protocolos vigentes do Ministério da Saúde. O estudo identifica que os profissionais apresentaram efetividade na captação precoce de $86 \%$ das gestantes, iniciando o pré natal ainda no primeiro trimestre de gestação. Cumpriram com a realização de seis ou mais consultas, para $79 \%$ das gestantes com sífilis, conforme recomendação do Programa de Humanização do Pré Natal e Nascimento. No entanto, não apresentaram uma continuidade na qualidade da assistência às gestantes com sífilis, considerando que apenas $57 \%$ das gestantes realizaram a consulta de puerpério e destas, $12,5 \%$ realizaram essa consulta posteriormente aos 42 dias preconizados pelo PHPN, Ministério da Saúde. Em decorrência da descontinuidade na assistência, 36\% das gestantes não realizaram consulta de puerpério, impossibilitando o conhecimento da equipe sobre a ocorrência de possíveis manifestações congênitas (aborto, prematuridade, óbito fetal, natimorto).

Outra situação constatada, refere-se à realização do exame de sorologia da sífilis no primeiro trimestre de gestação, que contemplou (57\%) das gestantes, embora $86 \%$ das gestantes haviam iniciado o pré-natal no primeiro trimestre, ampliando a possibilidade de intervenção em tempo oportuno, no caso de positividade do exame. A repetição do exame sorológico, posteriormente ao diagnóstico da sífilis, atingiu uma mediana de 02 exames por gestantes, apesar de $50 \%$ das gestantes terem obtido o diagnóstico da sífilis ainda no primeiro trimestre de gestação, o número de sorologias oferecidas poderia ter sido maior, ampliando a possibilidade de um melhor controle da titulação sorológica e cura. Entretanto 
observa-se que, o "Prontuário Obstétrico - Acompanhamento do pré natal", que encontra-se no Manual Técnico: saúde da mulher nas Unidades Básicas de Saúde (São Paulo - Cidade, 2012), da maneira como se apresenta, sem espaços adequados para o registro do controle sorológico mensal da titulação de sífilis, tornase um dificultador para o registro correto dos efetivos monitoramentos mensais do controle de cura da doença.

Em virtude dessa constatação, o presente estudo apresenta como proposta de melhoria para o monitoramento e controle da cura da sífilis, a criação de um Instrumento de "Monitoramento da gestante com sífilis", a ser anexado ao prontuário da gestante que apresentar sorologia positiva para a doença (Apêndice C). Este instrumento vem atender ao quarto objetivo da pesquisa em pauta.

A efetivação do tratamento da doença com Penicilina G Benzatina, alcançou 93\% das gestantes, situação que difere dos 93\% de parceiros não tratados, evidenciando a falta de adesão dos parceiros aos tratamentos.

Com relação ao terceiro objetivo específico, a consolidação dos dados permite inferir a existência de uma descontinuidade da atenção às gestantes com o diagnóstico de sífilis e seus parceiros, refletindo diretamente nos indicadores de vigilância epidemiológica.

O resultados do presente estudo, permitiu algumas reflexões pertinentes: a sífilis não atinge apenas um perfil específico da população, afeta diversos grupos, remodelando constantemente o perfil epidemiológico, requerendo intensas ações de promoção e prevenção à população em geral. O estudo permite avaliar que apesar das medidas estratégicas estabelecidas pelas políticas públicas Municipais, Estaduais e Federais, recomendando as praticas terapêuticas, ainda ocorre lacunas no processo assistencial ao pré-natal das gestantes com sífilis, sendo recomendado aprimoramento dos profissionais, para ofertar uma assistência de melhor qualidade, refletindo nos melhores resultados nas ações de promoção da saúde, na captação precoce das gestantes para inicio do pré natal, elaborar medidas estratégicas contribuintes para adesão das gestantes ao acompanhamento do pré natal e puerpério, fortalecer a busca ativa do parceiro para efetivação e contribuição ao tratamento adequado da doença e intensificar as ações de vigilância das Sífilis, prevenindo riscos para gestante e concepto; A proposta do novo Instrumento de controle da cura da sífilis (Apêndice $C$ ) contribuirá com melhorias aos processos de monitoramento vigilância da sífilis, favorecendo a redução da morbimortalidade 
materna, neonatal e infantil, contribuindo para obtenção das metas do desenvolvimento sustentável do milênio- agenda 2030. 
7.Conclusão 


\section{CONCLUSÃO}

A partir dos resultados obtidos com a presente pesquisa, identificou-se que existem hoje no Brasil Políticas Públicas voltadas para a promoção, prevenção e assistência à sífilis na gestação. Embora os protocolos assistenciais para o pré natal sejam claros e especifiquem os caminhos para a assistência, ainda verifica-se níveis alarmantes de sífilis na gestação e sífilis congênita no país.

O estudo demonstrou lacunas na assistência ao pré-natal das gestantes com sífilis, tendo como baliza os protocolos do Ministério da Saúde.

Justifica-se a necessidade de intensificar as ações de educação permanente junto aos profissionais pré-natalistas, para que possam aderir veementemente aos protocolos que buscam a qualificação da atenção às gestantes com sífilis.

Pesquisas como a presente, devem ser conduzidas, para adensar 0 conhecimento sobre esse tema, contribuindo para a redução da morbimortalidade materna, infantil e neonatal por sífilis. 


\section{Referências}




\section{REFERÊNCIAS}

Andreucci CB, Cecatti JG. Desempenho de indicadores de processo do Programa de Humanização do Pré-natal e Nascimento no Brasil: uma revisão sistemática. Cad. Saúde Pública, Rio de Janeiro, jun, 2011. 27(6):1053-1064. [Internet] 2018 Citado [05 janeiro 2018]. Disponível em: http://repositorio.unicamp.br/handle/REPOSIP/36318

Araújo EC, Costa KSG, Silva RS, Azevedo VNG, Lima FAS. Importância do pré-natal na prevenção da sífilis congênita. Revista Paraense de Medicina V.20 (1) Pará; janeiro-março 2006. Citado em: [2018 Abril 27]. Disponível em: http://scielo.iec.gov.br/pdf/rpm/v20n1/v20n1a08.pdf

Araújo CL, Silva RX. Monitoramento das desigualdades raciais em saúde no Brasil. In: Popolo FD, Cunha EMGP, Ribotta B, Azevedo M. Pueblos indígenas y afrodescendientes en América Latina: dinámicas poblacionales diversas y desafíos comunes. 1a. Edición. Río de Janeiro, Brasil 2011. ALAP Editor. Serie Investigaciones $\mathrm{N}^{\circ}$ 12. p. 151-176.

Avelleira JCR, Bottino G. Sífilis: Diagnóstico, tratamento e controle. Brasil, An Bras Dermatol. 2006. v81 (2):111-26.

Àvila MMM. Origem e evolução do Programa de Agentes Comunitários de Saúde no Ceará. Fortaleza, RBPS. Abr/Jun. 2011. 24(2): 159-168.

Brasil. Decreto № 094.406 de 08 de junho de 1987. Regulamenta a Lei no 7.498 de 25 junho de 1986, que dispõe sobre o exercício profissional da enfermagem, e dá outras providências. Brasília, 1987. [internet] 2018. Citado [08 de Março 2018]. Disponível em: http://www.planalto.gov.br/ccivil_03/leis//7498.htm

Brasil. Ministério da Saúde. Secretaria de Políticas de Saúde - SPS. Assistência ao Pré Natal. Manual Técnico. Brasília 2000. 66 p.

Brasil. Ministério da Saúde. Secretaria Executiva. Programa Humanização do Parto Humanização no Pré Natal e Nascimento. Brasília 2002. 28 p.

Brasil. Ministério da saúde. Secretaria de Atenção à Saúde, Departamento de Ações Programáticas Estratégicas. Política Nacional de Atenção Integral à Saúde da Mulher - Princípios e Diretrizes. Série c. Projetos, programas e relatórios. Brasília DF: Ministério da Saúde, 2004. 82 p.: il.

Brasil. Ministério da Saúde. Secretaria de atenção à Saúde Departamento de ações Programáticas Estratégicas. Pacto Nacional pela Redução da Mortalidade Materna e Neonatal. 2004a. Brasília. 
Brasil. Ministério da Saúde; Secretaria de Vigilância em Saúde, Programa Nacional de DST e AIDS. Diretrizes para o controle da Sífilis Congênita. Brasília: 2005. Coleção DST. Aids - 52p. (Série Manuais n. 62).

Brasil. Ministério da Saúde. Secretaria de Atenção à Saúde, Departamento de Ações Programáticas Estratégicas - Àrea Técnica de Saúde da Mulher. Direitos sexuais e direitos reprodutivos: uma prioridade do governo. Brasília: Ministério da Saúde, 2005b. p. 24.

Brasil. Ministério da Saúde. Secretaria de Atenção à Saúde. Departamento de Ações Programáticas Estratégicas. Área Técnica de Saúde da Mulher. Pré-natal e Puerpério: atenção qualificada e humanizada - Manual Técnico. Brasília, 2005c. 158 p. (Série A. Normas e Manuais Técnicos), (Série Direitos Sexuais e Direitos Reprodutivos - Caderno no 5).

Brasil. Ministério da Saúde. Secretaria Executiva. Diretrizes operacionais dos Pactos pela vida, em defesa do SUS e de Gestão. 2006. Brasília (1). 76 p. (Série A. Normas e Manuais Técnicos).

Brasil. Ministério da Saúde. Secretaria de Vigilância em Saúde. Programa Nacional de DST/AIDS. Manual de Controle das doenças sexualmente transmissíveis DST. 4ํㅡㄴ ed. Brasília. 2006a. p 31-46 - (Série Manuais ํㅡ 68).

Brasil. Ministério da Saúde - Secretaria de Vigilância em Saúde. Secretaria de Assistência à Saúde. Plano Operacional; Redução da Transmissão Vertical do HIV e da Sífilis. In. Brasil. Ministério da Saúde. Plano Operacional 2007. Brasília; 2007. [Internet] 2017 Citado: [20 Janeiro 2017]. Disponível em: http://bvsms.saude.gov.br/bvs/publicacoes/plano_operacional_WEB.pdf.

Brasil. Ministério da Saúde. Secretaria de Atenção à Saúde. Departamento de Atenção Básica. - Cadernos de Atenção Básica, saúde sexual e reprodutiva n26. Brasília : Ministério da Saúde, 2010. 300 p.

Brasil. Ministério da Saúde. Portaria GM n. 1459 de 24 de Junho de 2011. Institui no âmbito do Sistema de Saúde - SUS - a Rede Cegonha, uma rede de cuidados humanizados à saúde materno-infantil. Ministério da Saúde. Rede Cegonha. Brasilia, 2011. [Internet] 2018. Citado [23 janeiro 2018]. Disponível em: http://bvsms.saude.gov.br/bvs/saudelegis/gm/2011/prt1459_24_06_2011.html

Brasil. Ministério da Saúde. Secretaria de Atenção à Saúde. Departamento de Atenção Básica. Atenção ao pré-natal de baixo risco. Brasília, 2012. 318 p.: il. (Série A. Normas e Manuais Técnicos) (Cadernos de Atenção Básica, n 32 )

Brasil. Ministério da Saúde. Secretaria de Atenção à Saúde. Departamento de Atenção Básica - Política Nacional de Atenção Básica. Brasília: 2012a. 110 p. : il. (Série E. Legislação em Saúde) 
Brasil. Ministério do Planejamento, Orçamento e Gestão. Secretaria de Planejamento e Investimentos Estratégicos. Objetivos de Desenvolvimento do Milênio: Relatório Nacional de Acompanhamento. Brasília, 2014. 208 p. : il. [citado 2018 março 28]. Disponível em: http://www.ipea.gov.br/portal/images/stories/PDFs/140523_relatorioodm.pdf

Brasil. Ministério da Saúde. Secretaria de Vigilância em Saúde. Departamento de DST / Aids e Hepatites Virais. Boletim Epidemiológico - Sífilis. Ano IV. № 1. Brasil 2015. [Internet] 2017. Citado [12 dezembro 2016]. Disponível em: http://www.aids.gov.br/publicacao/2015/boletim-epidemiologico-de-sifilis-2015.

Brasil. Ministério da Saúde. Secretaria de Vigilância em Saúde. Departamento de Vigilância, Prevenção e Controle das Doenças Sexualmente Transmissíveis, Aids e Hepatites Virais. Manual Técnico para Diagnóstico da Sífilis. Brasília, 2016. [Internet 2018]. Citado: [ 2018 Abril 21]. Disponível em: http://www.aids.gov.br/ptbr/pub/2016/manual-tecnico-para-diagnostico-da-sifilis

Brasil. Ministério da Saúde. Secretaria de Vigilância em Saúde. Boletim Epidemiológico Sífilis. Ano V. N 35. vol.47. Brasil: 2016a. [Internet] 2016. Citado: [11 dezembro 2016]. Disponível em: http://www.aids.gov.br/pt-br/pub/2016/boletimepidemiologico-de-sifilis-2016

Brasil. Ministério da Saúde. Secretaria de Vigilância em Saúde. Departamento de Vigilância. Prevenção e Controle das DST, Aids e Hepatites Virais. Combate a Sífilis Congênita: Agenda de ações estratégicas para redução da sífilis congênita no Brasil. Brasília: 2016b. [Internet] 2017. Acesso: [21 de Janeiro 2017]. Disponível em: http://www.aids.gov.br/sites/default/files/anexos/publicacao/2016/59215/agenda_de_ acoes_estrategicas_pdf_14626.pdf .

Brasil. Ministério da Saúde. Secretaria de Vigilância Saúde. Departamento de DST/Aids e Hepatites Virais. Indicadores e dados básicos da sífilis nos municípios brasileiros. Brasil 2016c. [internet] 2017. Citado : [2018 marco 19]. Disponível em: http://indicadoressifilis.aids.gov.br/

Brasil. Ministério da Saúde. Secretaria de Vigilância em Saúde. Departamento de Vigilância, Prevenção e Controle das IST, do HIV/Aids e das Hepatites Virais. Boletim Epidemiológico - Sífilis Volume $48 \mathrm{~N}^{\circ} 36$. Brasil 2017. [Internet] 2018. Citado [17 de Março 2018]. Disponível em: http://portalarquivos.saude.gov.br/images/pdf/2017/novembro/13/BE-2017-038Boletim-Sifilis-11-2017-publicacao-.pdf

Cadastro Nacional de Estabelecimento de Saúde. [Internet] São Paulo; Citado: [10 de Março 2018]. Disponível em: http://cnes.datasus.gov.br/pages/estabelecimentos/ficha/profissionaisativos/3550302788993 
Carlo WA, Travers CP. Maternal and neonatal mortality: time to act. J Pediatr. Rio J. 2016; 92:543-5. [Citado 2018 março 28]. Disponível em: http://www.scielo.br/pdf/jped/v92n6/pt_0021-7557-jped-92-06-0567.pdf

Casarin ST, Siqueira HCH. Planejamento Familiar e os Direitos Reprodutivos: A Produção Científica da Enfermagem. [S.I.]: Rev Enferm Ufpe On Line. Jan./Mar 2010; 4(1):348-56. [internet] 2016 - [Citado 2016 Novembro 19]; Disponível em: http://www.revista.ufpe.br/revistaenfermagem/index.php/revista/issue/view/28

Campos ALA, Araújo MAL, Melo SP, Gonçalves MLC. Epidemiologia da sífilis gestacional em Fortaleza, Ceará, Brasil: um agravo sem controle. Cad. Saúde Pública, Rio de Janeiro, set, 2010. 26(9):1747-1755. Citado [2018 março 19]. disponível em: http://www.scielo.br/pdf/csp/v26n9/08.pdf

Cavalcanti PCS, Junior GDG, Vasconcelos ALR, Guerrero AVP. Um modelo lógico da Rede Cegonha. Physis Revista de Saúde Coletiva. Rio de Janeiro, 2013. 23 [ 4 ]: 1297-1316.

Coelho EAC, Lucena MFG, Silva ATM. O Planejamento Familiar no Brasil no Contexto das Políticas Públicas de Saúde: Determinantes Históricos. São Paulo Rev.Esc.Enf.USP . mar. 2000. v. 34, n. 1, p. 37-44 - [internet] 2016 - Citado 2016 Novembro 19]; Disponível em: http://www.scielo.br/scielo.php?script=sci_arttext\&pid=S0080-62342000000100005

Corrêa S, Alves JED, Jannuzzi PM. Direitos e saúde sexual e reprodutiva: marco teórico-conceitual e sistema de indicadores. In: Indicadores municipais de saúde sexual e reprodutiva / Suzana Cavenaghi (Organizadora). - Brasília : UNFPA, 2006. 282p. [internet] 2016 - [Citado 2016 Novembro 13]; Disponível em: http://www.unfpa.org.br/novo/index.php/biblioteca/publicacoes/populacao/51 indicadores-municipais-de-saude-sexual-e-reprodutiva

Cunha ARC, Merchan-Hamann E. Sífilis em parturientes no Brasil: prevalência e fatores associados, 2010 a 2011. Rev Panam Salud Publica. Brasil 2015. 38(6):479_ 86. Citado [2018 março 13]. Disponível em: https://www.scielosp.org/pdf/rpsp/2015.v38n6/479-486/pt

Domingues RMSM, Laura LM, Saraceni V, Leal MC. Manejo da sífilis na gestação: conhecimentos, práticas e atitudes dos profissionais pré-natalistas da rede SUS do município do Rio de Janeiro. Ciência \& Saúde Coletiva. Assoc. Brasileira de PósGraduação em Saúde Coletiva Rio de Janeiro. Brasil: 2013. vol. 18, n. 5. pp. 1341 1351. [Internet] 2016. Citado: [2016 Dezembro 03]. Disponível em: http://www.redalyc.org/articulo.oa?id=63026340011.

Figueiredo R, Filho JMC, Kalckmann S. Planejamento Familiar e Reprodutivo na Atenção Básica do Município de São Paulo: direito constitucional respeitado?. São Paulo: Boletim do Instituto de Saúde (BIS); Dezembro - 2014: Volume 15 - no 2 : 1809-7529. [internet] 2016. [citado 2016 Novembro 21]; Disponível em: 
http://www.saude.sp.gov.br/resources/instituto-desaude/homepage/bis/pdfs/bisvol15-n2.pdf

Ferreira RV, Costa MR, Melo DCS. Planejamento Familiar: Gênero e Significados. (Porto Alegre), Textos \& Contextos; jul./dez. 2014. v. 13, n. 2, p. 387 - 397. [internet] 2016 - [Citado 2016 Novembro 13]; Disponível em: http://revistaseletronicas.pucrs.br/ojs/index.php/fass/article/viewFile/17277/12520

Instituto Brasileiro de Geografia e Estatística - IBGE [Internet]. Brasil; 1937 -2018 [Citado 2018 março 22]. Disponível em: https://www.ibge.gov.br/

Lafetá KRG, Junior HM, Silveira MF, Paranaíba LMR. Sífilis materna e congênita, subnotificação e difícil controle. Rev. Bras. Epidemiol - Montes Claros (MG), Brasil.Jan - Mar 2016; 19(1): 63-74.

Lansky S, Friche AAL, Silva AAM et, al. Pesquisa Nascer no Brasil: perfil da mortalidade neonatal e avaliação da assistência à gestante e ao recém-nascido. Cad. Saúde Pública. 2014. Rio de Janeiro, 30 Sup:S192-S207.

Leal MC; Gama SGN; Cunha CB. Desigualdades raciais, sociodemográficas e na assistência ao pré-natal e ao parto, 1999-2001.Brasil 2005. Rev. Saúde Publica 2005; 39 (1):100-7. [internet] 2017. Citado: [ 16 de Março 2018]. Disponível em: http://www.saude.sp.gov.br/resources/ses/perfil/profissional-da-saude/grupo-tecnicode-acoes-estrategicas-gtae/saude-da-populacao-negra/documentostecnicos/assistencia_ao_parto.pdf

Leal MC, Gama SGN, Pereira APE, Pacheco VE, Carmo CN, Santos RV. A cor da dor: iniquidades raciais na atenção pré-natal e ao parto no Brasil. Cad. Saúde Pública . Rio Janeiro. 2017; 33 Sup 1. [Internet]. Citado 22 de Março 2018]. Disponível em: http://www.scielo.br/pdf/csp/v33s1/1678-4464-csp-33-s1e00078816.pdf

Lins CDM. Epidemiologia da sífilis gestacional e congênita, no extremo setentrional da amazônia. [Dissertação] Universidade Federal de Roraima. Boa Vista RR, 2014. [Citado em 2018 Abril 27]. Disponível em: http://www.bdtd.ufrr.br/tde_busca/arquivo.php?codArquivo=214

Magalhães DMS, Kawaguchi IAL, Dias A, Calderon IMP. A sífilis na gestação e sua influência na morbimortalidade materno-infantil. Brasil: 2011. Com. Ciên. Saúde. 22 Sup. 1:S43-S54. [Internet] 2017. Citado: [20 de Janeiro 2017]. Disponível em: http://www.escs.edu.br/pesquisa/revista/2011Vol22_6sifilis.pdf.

Magalhães DMS, Kawaguchi IAL, Dias A, Calderon IMP. Sífilis materna e congênita: ainda um desafio. Cad. Saúde Pública, Rio de Janeiro. jun, 2013. 29(6):1109-1120. Citado [2018 março 19]. Disponível em: http://www.scielo.br/pdf/csp/v29n6/a08v29n6.pdf 
Marconi MA, Lakatos EM. Fundamentos de Metodologia Científica. 5ํ. ed. São Paulo. Atlas SA. 2003.

Martinelli KG, Santos Neto ET, Gama SG, Oliveira AE. Adequação do processo da assistência pré-natal segundo os critérios do Programa de Humanização do Prénatal e Nascimento (PHPN) e Rede Cegonha. Rev Bras Ginecol Obstet. 2014; 36(2):56-64.[Internet] 2018. Citado: [ 07 de Janeiro 2018]. Disponível em: http://www.scielo.br/pdf/rbgo/v36n2/0100-7203-rbgo-36-02-00056.pdf

Maciel RB, Barros IC, Ugrinovich LA, Simini PU, Oliveira CF. Perfil epidemiológico dos casos de sífilis na cidade de Americana - SP de 2005 a 2015. Rev. Epidemiol. Control. Infec. Santa Cruz do Sul, 2017. 7(3):161-168.

Moreira KFA, Oliveira DM, Alencar LN, Cavalcante DFB, Pinheiro AS, Orfãos NH. Perfil dos casos notificados de sífilis congênita. Rev. Cogitare Enferm. Porto Velho, RO, Brasil 2017. (22)2: e48949.

Neto ETS, Alves KCG, Zorzal M, Lima RCD. Políticas de Saúde Materna no Brasil: os nexos com indicadores de saúde materno-infantil. São Paulo. Saúde Soc. 2008, v.17, n.2, p.107-119. [internet] 2017. Citado:[ 19 de Novembro 2017]. Disponível em: http://www.scielo.br/scielo.php?script=sci_arttext\&pid=S0104-12902008000200011

Nonato SM, Souto AP, Guimarães MMDC. Sífilis na gestação em Belo Horizonte. Epidemiol. Serv. Saúde, Brasília, 24(4):681-694, Brasil - Minas Gerais out-dez 2015. Citado em [2018 de abril 27]. Disponível em: http://www.scielo.br/pdf/ress/v24n4/2237-9622-ress-24-04-00681.pdf

United Nations. Departamento de Assuntos Econômicos e Sociais do Secretariado das Nações Unidas. Relatório sobre os Objetivos de Desenvolvimento Do Milênio 2015. New York, 2015. [Citado 2018 Março 28]. Disponível em: Https://www.unric.org/pt/images/stories/2015/pdf/mdg2015_pt.pdf

Organização das Nações Unidas no Brasil - ONU. Objetivo e Desenvolvimento Sustentável. Transformando Nosso Mundo: A Agenda 2030 para o Desenvolvimento Sustentável. setembro/2015. [Internet] 2016 - [Citado 2016 Novembro 14]; Disponível em: https://nacoesunidas.org/pos2015/agenda2030/

Objetivos de Desenvolvimento do Milênio Brasil. [Internet]. Brasil; 2000-2015. [Citado 2018 março 27]. Disponível em: http://www.odmbrasil.gov.br/o-brasil-e-os-odm

Patriota T. Relatório da Conferência Internacional sobre população e Desenvolvimento - Plataforma de Cairo, 1994. In: Instrumentos Internacionais de Direitos das Mulheres. Brasília: Secretaria Especial de Políticas para as Mulheres, $2006.260 p$. (Série Documentos). http://www.observatoriodegenero.gov.br/menu/publicacoes/outros-artigos-e- 
publicacoes/instrumentos-internacionais-de-direitos-dasmulheres/view?searchterm=instrumento

Pedrosa LDCO. Sífilis congênita: fatores de risco em gestantes admitidas nas maternidades de Maceió/AL e área Metropolitana e avaliação dos critérios diagnósticos adotados no Brasil. [Doutorado]. Recife, 2015. Universidade Federal de Pernambuco. Citado em: [2018 Abril 27]. Disponível em: https://repositorio.ufpe.br/bitstream/123456789/15486/1/TESE\%2009agol2015\%20\% $281 \% 29 . p d f$

Pinto VM, Tancredi MV, Alencar HDR, Carmolesi E, Holcman MM, Grecco JP, Grangeiro AL, Grecco ETO. Prevalência de Sífilis e fatores associados a população em situação de rua de São Paulo, Brasil, com utilização de Teste Rápido. Brasil: Rev Bras Epidemiol. 2014; p341-354. [Internet] 2016. Citado: [2016 dezembro 11] Disponível em: http://www.scielo.br/pdf/rbepid/v17n2/pt_1415-790X-rbepid-17-0200341.pdf.

Rezende CL, Souza JC. Qualidade de vida das gestantes de alto risco de um centro de atendimento à mulher. Psicólogo inFormação. Mato Grosso Sul. jan./dez. 2012. ano 16, n, 16. Citado em [2018 março 22]; Disponível em: http://pepsic.bvsalud.org/pdf/psicoinfo/v16n16/v16n16a03.pdf

Revista de saúde Pública , 2008. Sífilis congênita e sífilis na gestação. Rev. Saúde Pública 2008;42(4):768-72. [Citado em 2018 Abril 27]. Disponível em: https://www.scielosp.org/pdf/rsp/2008.v42n4/768-772/pt

Rodrigues NCP, Monteiro DLM, Almeida AS, Barros MBL, Pereira Neto A, O'Dwyer $\mathrm{G}$, et al. Temporal and spatial evolution of maternal and neonatal mortality rates in Brazil, 1997---2012. JPediatr. Rio Janeiro. 2016; 92:567---73. [Citado 2018 março 21]. Disponível em: http://www.scielo.br/pdf/jped/v92n6/pt_0021-7557-jped-92-060567.pdf

Santos VC, Anjos KF. Sífilis: uma realidade previsível; Sua erradicação, um desafio atual. Brasil. Revista Saúde e Pesquisa. 2009. v. 2, n. 2, p. 257-263, - ISSN 19831870. [Internet] 2016. Citado: [04 dezembro 2016] Disponível em: http://periodicos.unicesumar.edu.br/index.php/saudpesq/article/view/1027/790.

São Paulo (Cidade). Secretaria Municipal das Prefeituras Regionais do Município de São Paulo. Dados demográficos do Distrito vila Maria Vila Guilherme São Paulo. 2010a. [Internet] 2017. Citado: [ 2017 Janeiro 07]. Disponível em: http://www.prefeitura.sp.gov.br/cidade/secretarias/subprefeituras/subprefeituras/dado s_demograficos/index.php? $p=1275$

São Paulo (Cidade). Secretaria Municipal de Desenvolvimento Urbano (SMDU) de São Paulo. Dados demográficos Domicílios, População e Densidade Domiciliar Distrito vila Maria / Vila Guilherme. São Paulo: 2010b. [Internet] 2017. Citado: [2017 
Janeiro

07].

Disponível

em:

http://infocidade.prefeitura.sp.gov.br/index.php?cat=7\&titulo=Demografia.

São Paulo (Cidade). Secretaria da Saúde. Manual Técnico: Saúde da Mulher nas Unidades Básica de Saúde. Coordenação da Atenção Básica / Estratégia Saúde da Família. São Paulo: 2012. 2. ed. 70p. (Série Enfermagem). Citado [2018 março 26]. Disponível em: http://www.prefeitura.sp.gov.br/cidade/secretarias/upload/saude/arquivos/enfermage m/Enfermagem_Atencao-SaudeMulher_2013.pdf

São Paulo (Cidade). Secretaria de Municipal da Saúde de São Paulo. Coordenadoria de Controle de Doenças - Programa Municipal de DST/AIDS de São Paulo. Centro de Vigilância Epidemiológica DST/Aids. Boletim Epidemiológico de AIDS - HIV e DST do Município de São Paulo. Ano XVII no 16 - São Paulo. Junho 2013. n.16. p.76-95.

São Paulo (Cidade). Secretaria de Municipal da Saúde de São Paulo. Coordenadoria de Controle de Doenças - Programa Municipal de DST/AIDS de São Paulo. Centro de Vigilância Epidemiológica DST/Aids. Boletim Epidemiológico de AIDS - HIV e DST do Município de São Paulo. Ano XVIII. nº 17. São Paulo: Junho 2014. p. 97117.

São Paulo (Estado). Secretaria de Estado da Saúde de São Paulo. Coordenadoria de Controle de Doenças. Centro de Vigilância Epidemiológica "Alexandre Vranjac". Centro de Referencia e Treinamento em DST/Aids-SP. Programa Estadual de DST/Aids de São Paulo. Boletim Epidemiológico C.R.T - DST/Aids. CVE. Ano XXV №1. Brasil: Dez 2008. p 50-71.

São Paulo (Estado). Secretaria da Saúde. Coordenadoria de Planejamento em Saúde. Assessoria Técnica em Saúde da Mulher. Atenção à gestante e à puerpera no SUS - SP: manual técnico do pré natal e puerpério. São Paulo: SES/SP, 2010. $234 \mathrm{p}$.

São Paulo (Estado). Secretaria de Estado da Saúde de São Paulo. Coordenadoria de Controle de Doenças. Centro de Referencia e Treinamento em DST/Aids-CRTDST/AIDS-SP. Programa Estadual de DST/Aids de São Paulo: Boletim Epidemiológico C.R.T. DST/Aids. C.V.E. Ano XXX- №1 São Paulo. Junho 2013. p.75-107.

São Paulo (Estado). Secretaria de Estado da Saúde, Coordenadoria de Controle de Doenças, Programa Estadual de DST/Aids. Centro de Referencia e Treinamento em DST/Aids. Guia de bolso para o manejo Clínico da Sífilis em Gestante e Sífilis Congênita. São Paulo - Brasil: 2015. 112p.

São Paulo (Estado). Governo do Estado de São Paulo. Secretaria de Estado da Saúde de são Paulo. Calendário de Vacinação 2017. Citado em [2018 de Abril 26] Disponível em: http://portal.saude.sp.gov.br/cve-centro-de-vigilancia-epidemiologicaprof.-alexandre-vranjac/areas-de-vigilancia/imunizacao/calendario-vacinal 
Saraceni V, Guimarães MHFS, Theme Filha MM, Leal MC. Mortalidade perinatal por sífilis congênita: indicador da qualidade da atenção à mulher e à criança. Cad. Saúde Pública, Rio de Janeiro, jul-ago, 2005. 21(4):1244-1250.

Serruya SJ, Cecatti JG, Lago TG. O Programa de Humanização no Pré-natal e Nascimento do Ministério da Saúde no Brasil: resultados iniciais. Rio de Janeiro. Cad. Saúde Pública. 2004. 20(5):1281-1289. [Internet] 2017. Citado: [20 Janeiro 2017]. Disponível em: http://www.scielo.br/pdf/csp/v20n5/22.pdf .

Shetty S. Declaração e objetivos de desenvolvimento do milênio: Oportunidades para os direitos humanos. SUR; [S.I.]: Revista Internacional de Direitos Humanos. 2005. v.2. n2. [Internet] 2016 - [Citado 2016 Novembro 13]; Disponível em: http://www.scielo.br/pdf/sur/v2n2/a01v2n2.pdf

Silva Neto SE, Investigação de Sífilis Congênita no município de Itapeva (SP): fatores que podem interferir no diagnóstico e tratamento da sifilis na gestação. [Dissertação] São Paulo, 2017. Faculdade de Medicina da Universidade de São Paulo; 2017. Citado em [2018 Abril 27]. Diponível em: http://www.teses.usp.br/teses/disponiveis/5/5134/tde-28112017-151854/pt-br.php

Silva OMP, Panhoca L. A contribuição da vulnerabilidade na determinação do índice de desenvolvimento humano: estudando o estado de Santa Catarina. - Ciência \& Saúde Coletiva, 2007 - 12(5):1209-1219, [internet] 2016 - [Citado 2016 Novembro 13]. Disponível em: http://www.scielo.br/pdf/csc/v12n5/12.pdf

Soares LG, Zarpellon B, Soares LG, Baratieri T, Lentsck MH, Mazza VA. Sífilis gestacional e congênita: características maternas, neonatais e desfecho dos casos. Rev. Bras. Saúde Matern. Infant., Recife, out. / dez., 2017 . 17 (4): 791-799.

Souza JG. Impacto Social da Sífilis, alguns Aspectos históricos. Medicina Interna. [S.I.] 1996. vol. 3. n.3. 1996. [Internet] 2016. Citado: [ 04 de dezembro 2016] Disponível em:

http://repositorio.chlc.minsaude.pt/bitstream/10400.17/385/1/RSPMI\%201996\%20184.pdf.

Tayra A, Matida LH, Saraceni V, Paz LC, Ramos Jr AN. Duas décadas de vigilância epidemiológica da Sífilis Congênita no Brasil: A propósito das definições de caso. Brasil. 2007. DST. J bras Doenças Sex Transm. 2007. 19(3-4): p.111-119; ISSN: 0103-4065. [Internet] 2016. Citado: [03 de dezembro 2016]. Disponível em: http://www.dst.uff.br//revista19-3-2007/1.pdf .

Teixeira SVB, Rocha CR, Moraes DSM, Marques DM. Villar ASE. Education in health: the influence from socio-economic-cultural of pregnant woman. Rev. enferm ufpe on line. Rio de janeiro. Jan. / mar. 2010; 4(1):133-41 
Anexos 
ANEXOS

ANEXO I - Carta de anuência da Coordenadoria Regional de saúde da - Norte

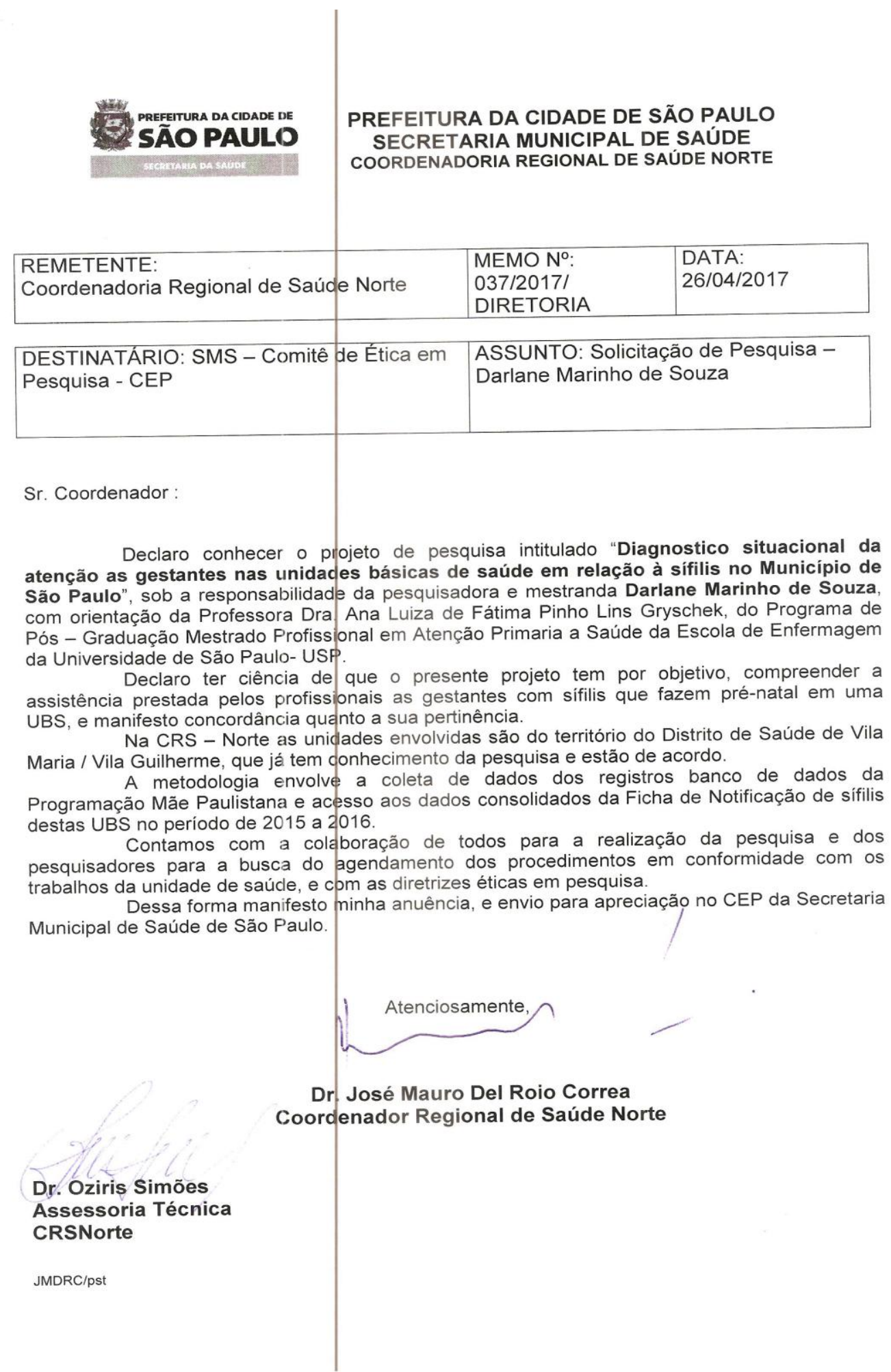


ANEXO II - Carta de aprovação do Comitê de Ética em Pesquisa (CEP) da Escola de Enfermagem da USP.

USP - ESCOLA DE
ENFERMAGEM DA
ENFERMAREM

\section{PARECER CONSUBSTANCIADO DO CEP}

\section{DADOS DO FFOUETO DE FESQUISA}

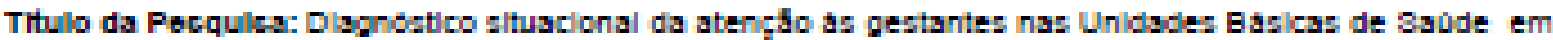
relspato a errils no Murlelplo de gio Fado.

Pacqulcador: DHFLANE MAFINHO DE SCUZA.

Area Tematha:

Vorra: 2

CAAE: 67792417.3.0001.5392

Inctitulgso Proponente: Eecola de Enfermspem da Unherzldsde de cho Faulo - Eeusp

Patroolnador Prinolpal: Financlamento Froprio

DADOS DO PAFECER

Número do Pareore: 2.125.494

Aprocinta-so do Projoto:

Trata-se de Dlasertaplo apresentada ao Programa de Pos Graduagb Mestrado Proflssional em En'ermagem na Atença Primaria em Babde no Bletema Unilo de Baude Extudo descritho de corte

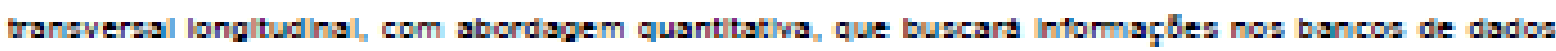
lnatbuclonsla dos reglstros de abendlmento as pestante que zubmeteram-se ao pre-natal nas UEb sob a competencla do Distrito de Gaùde Vla Marla / Vla Gullheme no ano de 2015 e 2016.

Dbjetuo da Pacqulca:

Obletivo Frimario:

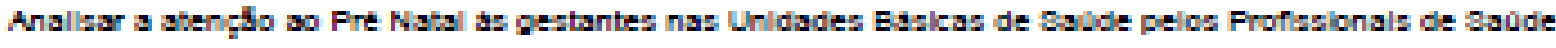
no que se relert arlla Gestadonal.

obletwo Becundaria:

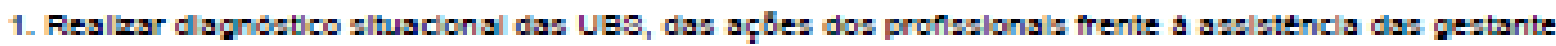
com aifls, conforme protocolo vlgente do Mnleterlo da Gaude 2. Caractertzar o percurso teraptutlco da:

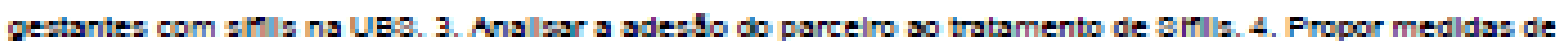

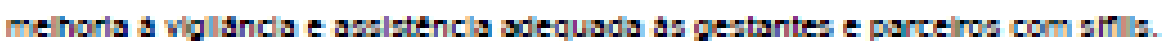

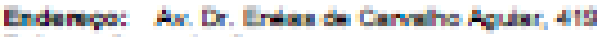

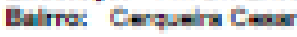

LF: Bp Munkipa BADPALt

다: $0=-1+50$

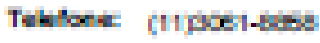

E-mall bestapto 


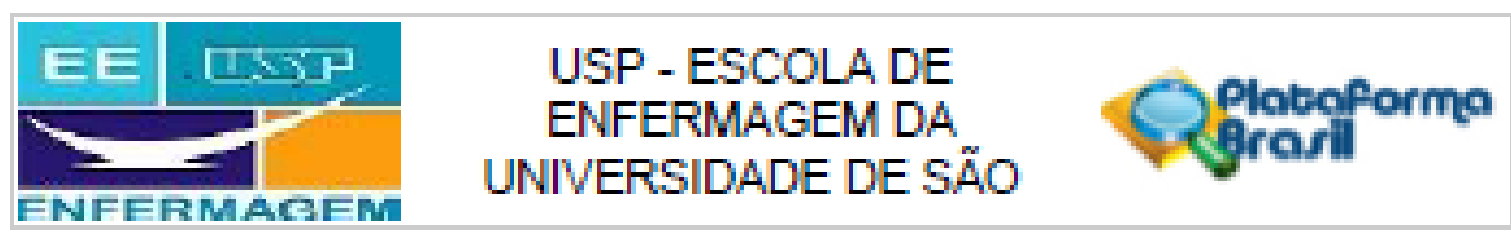

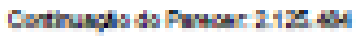

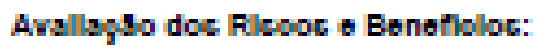

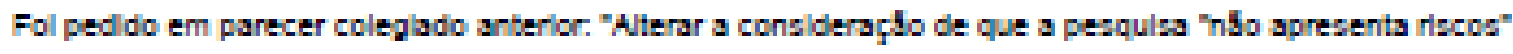
por "poselblldade de perda, extravlo ou dano da base de dadoa".

O peaquasador alterou oa rlacos descritoa na Flataforma Erasll para: " Os racos para elaboraç5o da

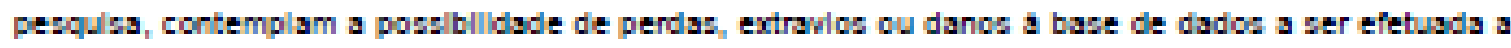

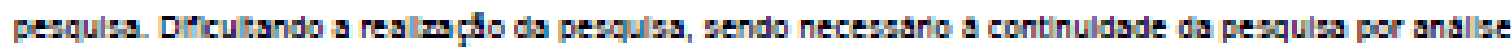
documental aca arqulyos fielcos Organlzaclonals.

Comentarloc o Conclderaplec cobre a Pocqulca:

Conclushes ou Fendenclas e Llato de Insdequaghtes do Farecer coleplado anterior

1-Aberar a conslderagho de que a pesqulsa "nSo apresenta riscoa" por "poaslblldade de perda, ertravio ou dano da base de dadod".

Oa rlacos foram modificados na Fistatorma Erasl

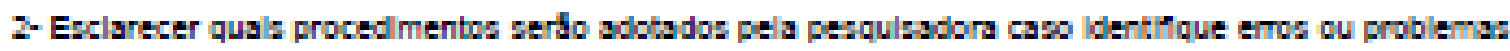
arpanlzaclonals durante a Inuestlpaghto. Aa alterap̧lies solleltadas devem ser reallzadss em todos documentos anerados a Fiataforms Brasill.

Fol acreacentada ao Frojeto Detalnado e Fiataforma Erasll a segulnte sentença: "Dlante dos rlaco de perdse, extrovlos ou dance a base de dados a ser efetusda a pesqules, a continuldade ds pesqula se dara por andilse documental aos arquhos fillog Orpanlzachonals."

Conelders;

O pesqulsobr pede a dispensa do TCLE, pols as intomsples serbo obtdas atroves da andilse doe dodos

Conduedec ou Pendobulse of Llata do Insdequsyos:

As pendenclas antes menclonsdas foram ansdas

Conelderayse Flnalc a orttarlo do CEP:

- Eate CEP' Informa a necenaldade de reglatro doa reaultadoa parcials e finala na Fiatahona Braz;

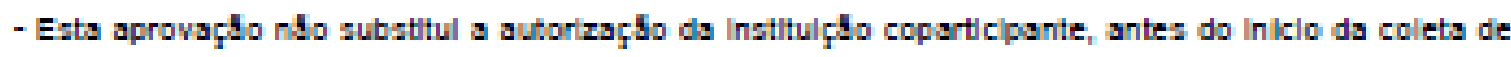
dados.

Ecte parsoer fol blaborado tucsudo noe documentoc abolwo relaolonadoc:

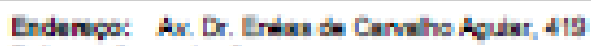

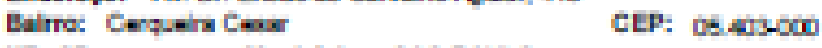

LF: Bip Mankipar Babilut

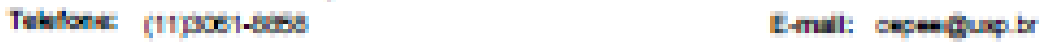




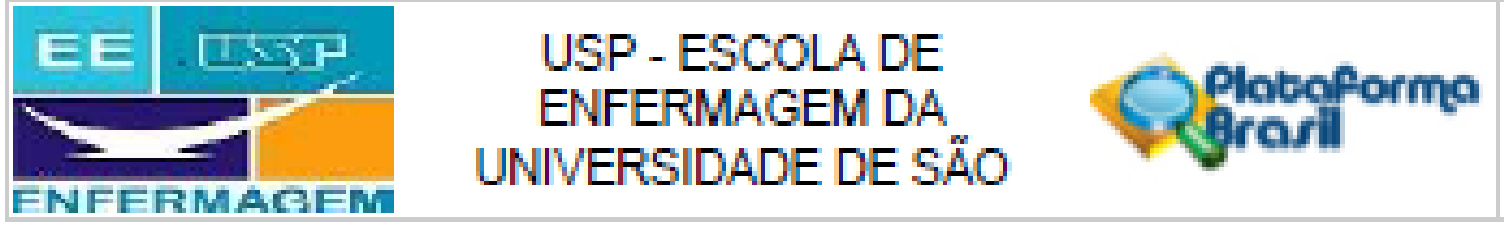

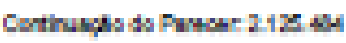

\begin{tabular}{|c|c|c|c|c|}
\hline Tipo Documento & Arquluo & Fostspen & Autor & 3toug,ta \\
\hline $\begin{array}{l}\text { Informogdes Buslas } \\
\text { do Proleto }\end{array}$ & 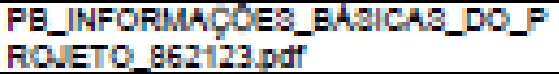 & $\begin{array}{l}28052017 \\
174393\end{array}$ & & Acelto \\
\hline $\begin{array}{l}\text { Proleto Deta hodo I } \\
\text { Brochura } \\
\text { Invertpador }\end{array}$ & modiflcadoFLATAFOAMABRASL Lot & $\begin{array}{c}27052017 \\
17: 1628\end{array}$ & $\begin{array}{l}\text { DARLANE } \\
\text { MARIHHO DE } \\
\text { OOUZA }\end{array}$ & Acelto \\
\hline 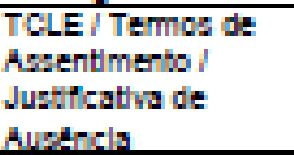 & TCLEDH PA' & $\begin{array}{c}\text { DHoERZ17 } \\
1831=24\end{array}$ & $\begin{array}{l}\text { DARLLANE } \\
\text { MARIFHO DE } \\
\text { POUZA }\end{array}$ & Acelto \\
\hline $\begin{array}{l}\text { Declaracibo de } \\
\text { Insthulphos } \\
\text { Infreatruturn }\end{array}$ & CARTADEANUENCLACRO pdf & $\begin{array}{c}0105 / 2017 \\
162858\end{array}$ & $\begin{array}{l}\text { DARLANE } \\
\text { MARIFHO DE } \\
\text { OOUZA }\end{array}$ & Acelto \\
\hline Folha de Foato & 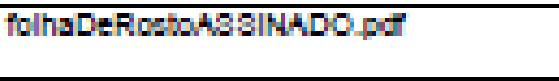 & 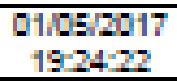 & $\begin{array}{l}\text { DARLANE } \\
\text { MAINHO DE }\end{array}$ & Acelto \\
\hline
\end{tabular}

Situsyo do Pareoer:

Aprovisto

Feocelta Apresla; bo da CONEP:

NGo

BHO PAULO, 19 de Junho de 2017

Acclnado por:

Marosilo Jock dor Santoc

(Coordenador) 
ANEXO III - Carta de aprovação do Comitê de Ética em Pesquisa (CEP) da Secretaria Municipal da Saúde de São Paulo.

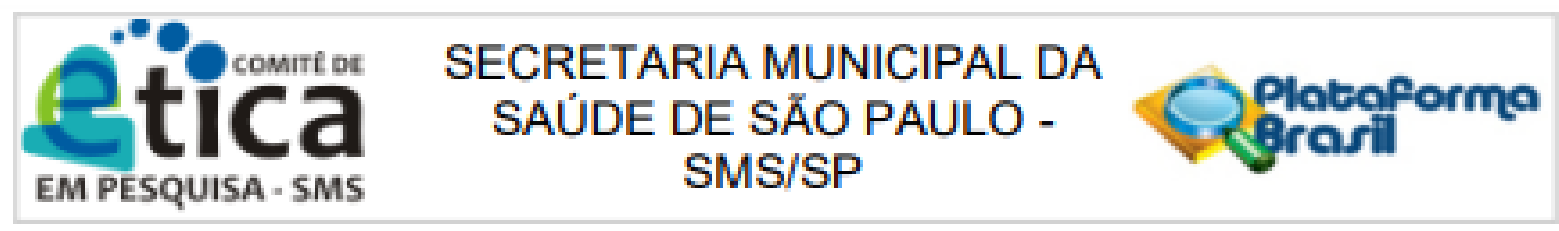

\section{PARECER CONSUBSTANCIADO DO CEP}

Elaborado pela Instituiçäo Coparticipante

\section{DADOS DO PROJETO DE PESQUISA}

Título da Pesquisa: Diagnóstico situacional da atençăo às gestantes nas Unidades Básicas de Saúde em relaçăo a sifilis no Municipio de Sao Paulo.

Pesquisador: DARLANE MARINHO DE SOUZA

Área Temática:

Versalo: 1

CAAE: 67782417.3.3001.0086

Instituiçăo Proponente: Escola de Enfermagem da Universidade de SAo Paulo - EEUSP

Patrocinador Principal: Financiamento Próprio

\section{DADOS DO PARECER}

Número do Parecer: 2.182.937

\section{Apresentaçäo do Projeto:}

Trata-se de Dissertação apresentada ao Programa de Pós Graduaçăo Mestrado Profissional em Enfermagem na Atençăo Primária em Saúde no Sistema Único de Saúde.

Estudo descritivo de corte transversal longitudinal, com abordagem quantitativa, que buscará informaçōes nos bancos de dados Institucionais dos registros de atendimento as gestante que submeteram-se ao prénatal nas UBS sob a competência do Distrito de Saúde Vila Maria / Vila Guilherme no ano de 2015 e 2016.

\section{Objetivo da Pesquisa:}

Objetivo Primárioc.

Analisar a atençăo ao Pré Natal às gestantes nas Unidades Básicas de Saúde pelos Profissionais de Saúde no que se refere sifilis Gestacional.

Objetivo Secundário:

1. Realizar diagnóstico situacional das UBS, das açbes dos profissionais frente à assistência das gestante com sifilis, conforme protocolo vigente do Ministério da Saúde.

2. Caracterizar o percurso terapeutico das gestantes com sifilis na UBS.

3. Analisar a adesão do parceiro ao tratamento de Sifilis.

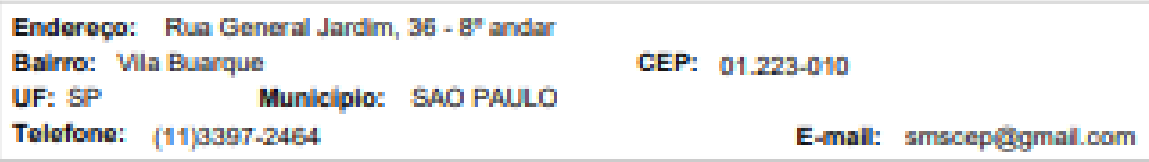




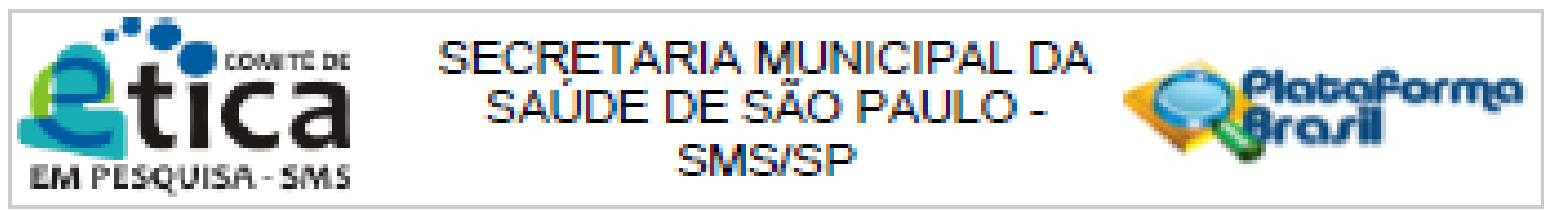

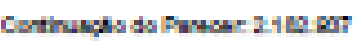

4. Fropor medidas de mehoria a wallancla e aszlesencla adsquala as pestantes e parceiros com siflls.

Aralla,9o dos Filsoos is Enefloloc:

aepundo o perqulsador:

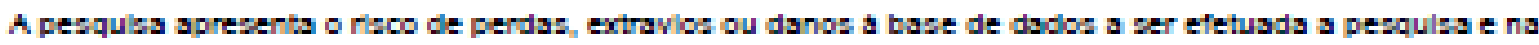
posablldsde desta ocomencla, a continulabe da pesqusa se dard por andige documental ace arquhos Halcos Crpanizacionale.

A pesqulas apresenta rlaco do profasional de esode spresentar decconforto com a particlpapho woluntaria

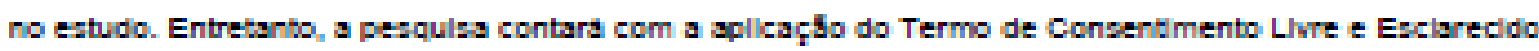

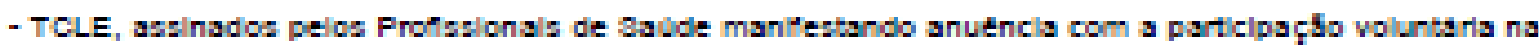
pesquilas.

Comentarloc concldarapobc cobre a Pocqulca:

A metodologla descrita neceselta redifcaples/esclareclmentos.

Conclderajoc cobro oc Ternoc de aprecentagso obrlgatorla:

A Folha de Rosto esta comekmente preenchida, foram lidentficadas Insthulpho proponente e copstidpante, autorizaplo para real lzagbo da peaqulas fol solequadamente apresentada.

TCLE, Cronoprama, orgamento dets hado e fonte financladora etho adequados.

\section{Reoomendapose:}

Inclulr campo para aselnstura do peequlgabrino TCLE.

Conducbec ou Penddnolsc o Llata do Insdequagob:

Fropto lleerado para inlesi.

Concldera,joc Flnalg a ortitirlo do CEP:

Fara Iniclo da coleta dos dados, o pesqusador deverd se apresertar na mesma Instancla que autorixou a realisplo do estudo (Coordensdorla, Gupervisto, ambigab, etci.

ae a projeto prever apllcapa de TCLE, todas as paghas do documento deverá ser rubricadas pelo pesqulador e pelo woluntarlo e a ultima paglina asalnada por ambos, conforme carta Circular no

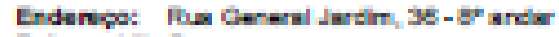
Eulre: Ho Bunqu-

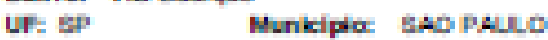

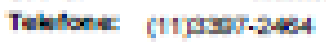

다: 01:30

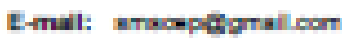




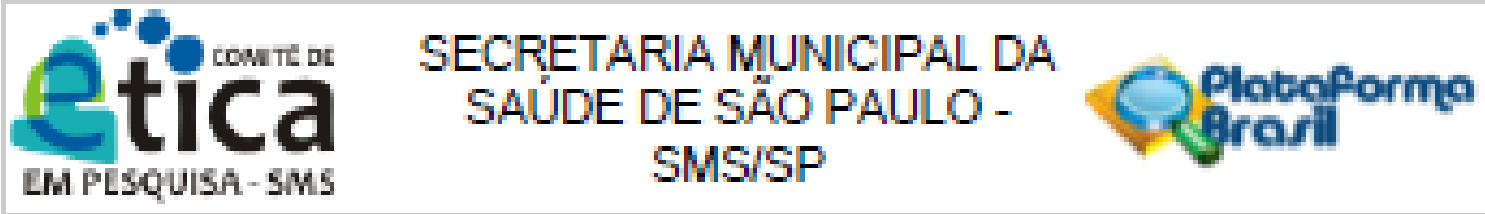

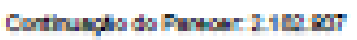

Do3zont da CONEPICNE.

Ballentsmos que o peequlsador deve desenvolver a pesqula contome del neada no protocolo aprovsdo. Evantusa modrcaptes cu emendss so protocolo devem ger spresenkds so cef de toms clara e sudinta, Identflicando a parte do proboglo a ser modifloda e zuas Justlicathas. Lembramos que etta modifogho neceseltard de aprowajo ella do CEP antes de ser limplementada.

De scordo com s Res. CN8 49812, o pegqusador deve apresentar os relsibrios parclas e fins atroves da

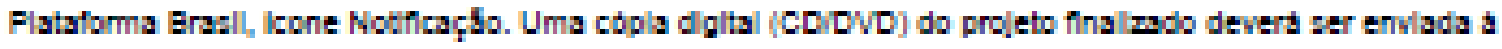
Instanda que autorizou a realizg,bo do estudo, vla comelo ou entrepue pesoalmente, lopo que o mesmo Etther concluldo.

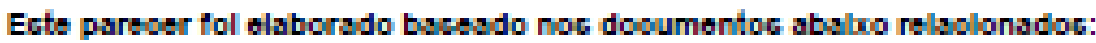

\begin{tabular}{|c|c|c|c|c|}
\hline Tlpo Documerto & Arquino & Fosispe-" & Aubr & 8Rusedo \\
\hline $\begin{array}{l}\text { Proleto Deta rodo I } \\
\text { Brochura } \\
\text { Inutertipsdor }\end{array}$ & modiflcsdoFLATAFCFUABRAS LES & $\begin{array}{c}\text { 27MEMU17 } \\
\text { 17-16-28 }\end{array}$ & $\begin{array}{l}\text { DARLANE } \\
\text { MARIFHO DE } \\
\text { BOUZA }\end{array}$ & Acesto \\
\hline $\begin{array}{l}\text { Informages Bdelcas } \\
\text { do Fnith }\end{array}$ & 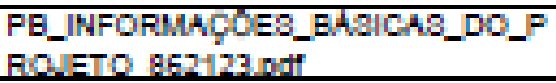 & 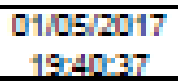 & & Acelto \\
\hline $\begin{array}{l}\text { Proleto Deta hodo i } \\
\text { Brochura } \\
\text { Invez:psdor }\end{array}$ & modificsdoFLATA=OFMABRAS LdOE & $\begin{array}{c}\text { 011252017 } \\
193222\end{array}$ & $\begin{array}{l}\text { DAFLANE } \\
\text { MARIFHO DE } \\
\text { BOUZA }\end{array}$ & Acesto \\
\hline $\begin{array}{l}\text { TCLE / Temos d: } \\
\text { Asentmento i } \\
\text { Justilicatha de } \\
\text { Ausencls }\end{array}$ & TCLEDHPH' & 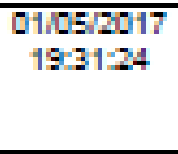 & $\begin{array}{l}\text { DAFLANE } \\
\text { MAFIFHO DE } \\
\text { BOIZA }\end{array}$ & Acelto \\
\hline $\begin{array}{l}\text { Declargpho de } \\
\text { Insthulphe } \\
\text { Infrestruturs }\end{array}$ & CARTADEANUENELACRE.pd' & 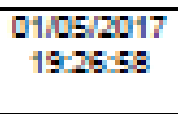 & $\begin{array}{l}\text { DAFLAWE } \\
\text { MARIFHO DE } \\
\text { BOURA }\end{array}$ & Acelto \\
\hline Folha de Fosto & 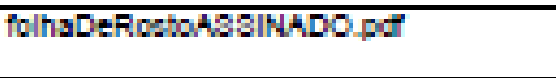 & $\begin{array}{c}\text { Dhaszo17 } \\
19 \geq 472\end{array}$ & $\begin{array}{l}\text { DARLANE } \\
\text { MAFIFHO DE }\end{array}$ & Acelto \\
\hline
\end{tabular}

artusyso do Pareos:

Aprowado

Heoscrita Apreola,bo da COHEP:

NHo

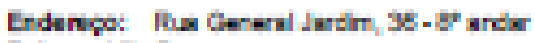
Burre: Ha Burque

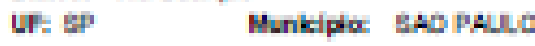

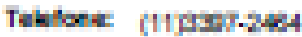

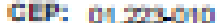

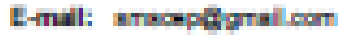




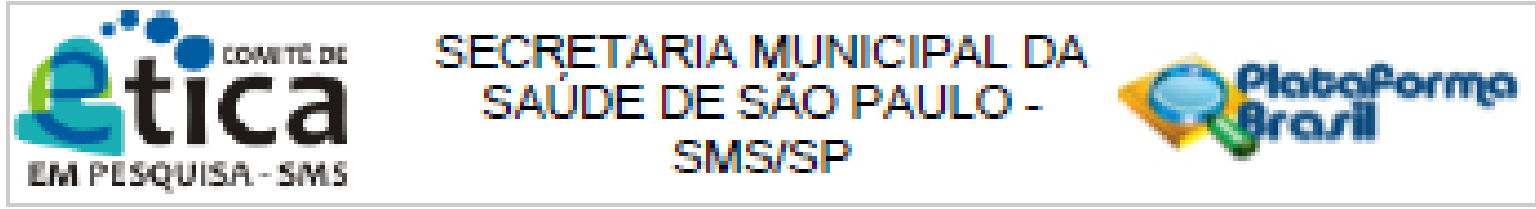

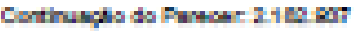

BAO FAULO, 01 de Agoto de 2017

Asclnado por:

SIMONE MONGELLI DE FAHTINI

coordenador)

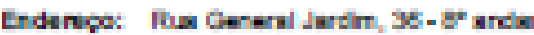
Eulre; Ha Burqu-

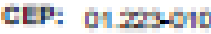

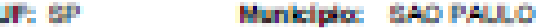

Tabsore thost-2404

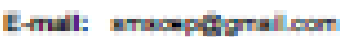




\section{Apêndices}




\section{APÊNDICES}

\section{APENDICE A - TERMO DE CONSENTIMENTO LIVRE E ESCLARECIDO - TCLE.}

Convido você a participar da pesquisa titulada "Diagnóstico situacional da atenção às gestantes em relação à Sífilis em uma Unidade Básica de Saúde no Município de São Paulo" que tem por objetivo contribuir para melhoria da qualidade da atenção pelos profissionais de saúde às gestantes com diagnóstico de sífilis na Unidade Básica de Saúde. Sua participação aprecia em consentir de forma voluntária à pesquisadora acessar as informações dos banco de dados Organizacionais informações quanto a caracterização da usuária, ao diagnóstico, tratamento e acompanhamento da sífilis em gestante durante as consultas de pré natal. Você pode se recusar a participar sem sofre quaisquer prejuízo. Você não terá despesas e não receberá compensação financeira para participar da pesquisa. Todos os gastos com a pesquisa são de inteira responsabilidade da pesquisadora e todas as dúvidas com a pesquisa devem ser sanadas pela pesquisadora. A pesquisadora compromete-se: assegurar a privacidade das voluntárias citadas nos bancos organizacionais, de modo a garantir que as informações coletadas não causarão prejuízo ao voluntário e/ou a organização, respeitando deste modo as Diretrizes Éticas da Pesquisa Envolvendo Seres Humanos, nos termos estabelecidos na Resolução CNS № 466/2012, e obedecendo as disposições legais estabelecidas na Constituição Federal Brasileira, artigo 5, incisos X e XIV e no Novo Código Civil, artigo 20.

Para dúvidas, denúncias, esclarecimentos e reclamações sobre os aspectos éticos dessa pesquisa, entrar em contato com: Comitê de Ética em Pesquisa da Escola de Enfermagem da USP, Rua Dr. Enéas de Carvalho Aguiar, 419, Cerqueira Cesar, ํㅜ andar, sala 2 CEP: 05403-000, e-mail:cepee@usp.br , tel: (11) 3061-8858 e Comitê de Ética Secretaria Municipal da Saúde, rua General Jardim, 36, 8o andar. Tel (11) 33972464. email: smscep@gmail.com . Contatos da Pesquisadora: Darlane Marinho de Souza Tel: (11) 967614457 - e-mail: darlane.m@gmail.com

Após ter sido devidamente esclarecido, concordo em participar voluntariamente da pesquisa.

São Paulo, 2017

Nome completo: DN:

Assinatura:

Assinatura do Pesquisador: 


\section{APÊNDICE B - INSTRUMENTO PARA COLETA DOS DADOS}

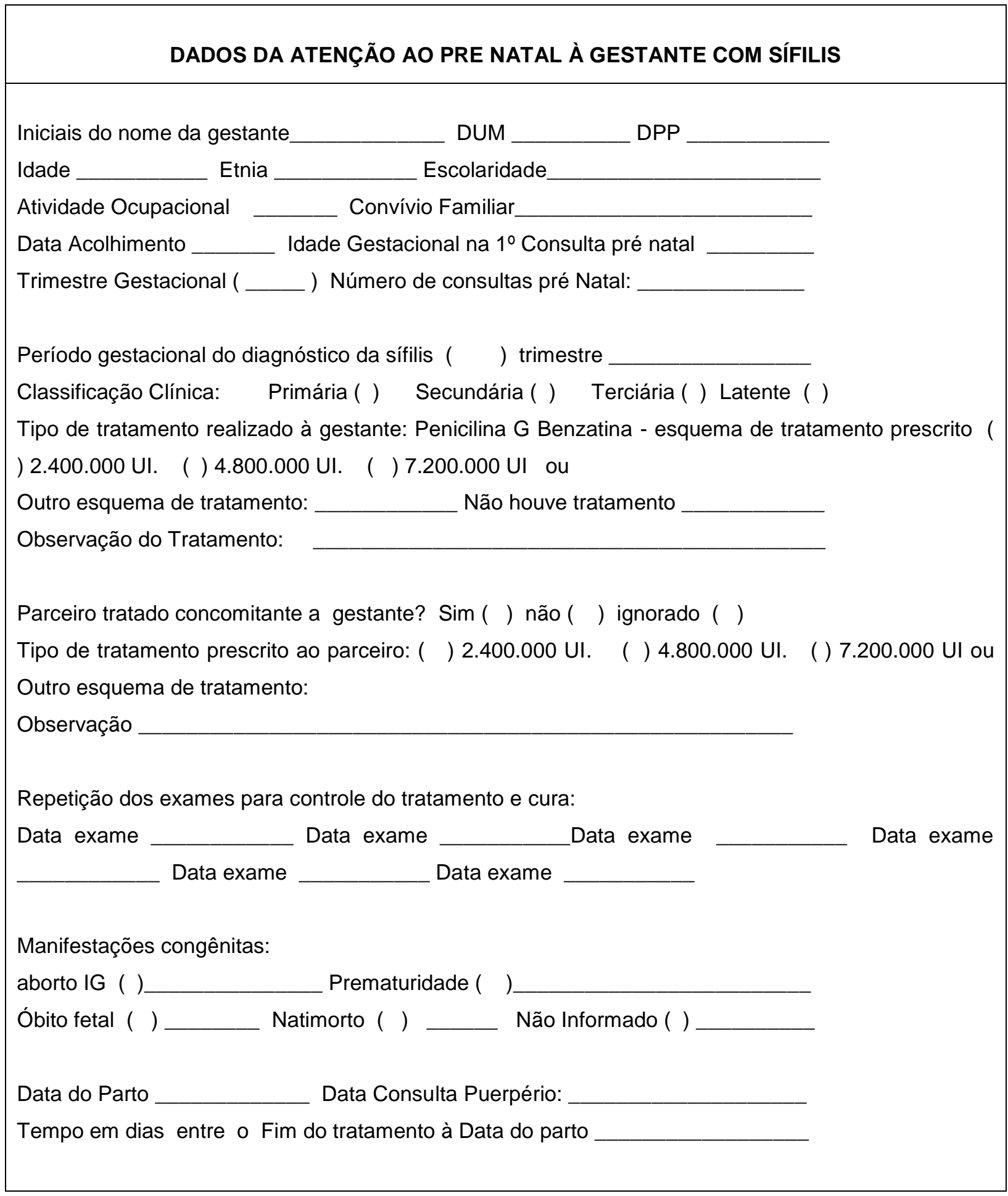




\section{APÊNDICE C - INSTRUMENTO A SER ANEXADO AO PRONTUÁRIO DE ACOMPANHAMENTO DA GESTANTE COM DIAGNÓSTICO PARA SÍFILIS *}

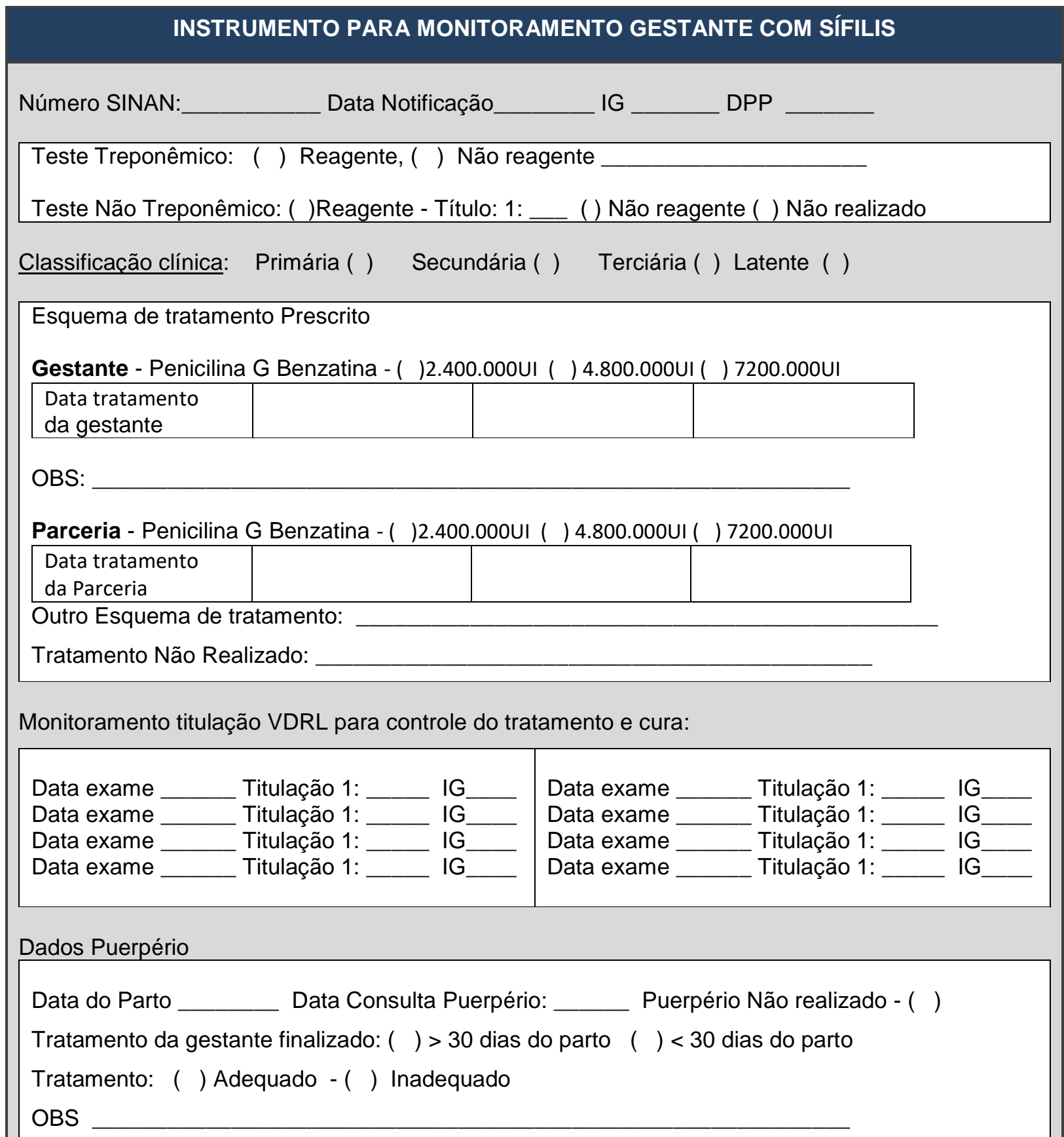

Manifestações congênitas:
( ) aborto IG
( ) Óbito fetal - IG
( ) Natimorto
( ) Não Informado
( ) Prematuridade IG

* Adaptado do Formulário - Monitoramento da Sífilis Gestante e Congênita -Rede Assistencial Supervisão Técnica da Saúde Vila Maria/ Vila Guilherme - OSS/SPDM - ASSOCIAÇÃO PAULISTA PARA o DESENVOLVIMENTO DA MEDICINA 2017. 